\author{
Universidade de São Paulo \\ Escola de Engenharia de São Carlos \\ Departamento de Engenharia Elétrica
}

Job Nicolau Travaini

\title{
Descritores de Textura Local para Reconhecimento Biométrico da Íris Humana.
}



Job Nicolau Travaini

\section{Descritores de Textura Local para Reconhecimento Biométrico da Íris Humana.}

Dissertação apresentada à Escola de Engenharia de São Carlos da Universidade de São Paulo para a obtenção do título de Mestre em Ciências, Programa de engenharia Elétrica.

Área de Concentração: Processamento de sinais e instrumentação Orientador: Prof. Dr. Adilson Gonzaga

Trata-se da versão corrigida da dissertação. A versão original se encontra disponível na EESC/USP que aloja o Programa de Pós-Graduação de Engenharia Elétrica

$$
\text { USP - São Carlos/SP }
$$


AUTORIZO A REPRODUÇÃO TOTAL OU PARCIAL DESTE TRABALHO, POR QUALQUER MEIO CONVENCIONAL OU ELETROONICO, PARA FINS DE ESTUDO E PESQUISA, DESDE QUE CITADA A FONTE.

N779d

Nicolau Travaini, Job

Descritores de Textura Local para Reconhecimento Biométrico da Íris Humana / Job Nicolau Travaini; orientador Adilson Gonzaga. São Carlos, 2015.

Dissertação (Mestrado) - Programa de Pós-Graduação em Engenharia Elétrica e Área de Concentração em Processamento de Sinais e Instrumentação -- Escola de Engenharia de São Carlos da Universidade de São Paulo, 2015.

1. Biometria, 2. LFP. 3. Íris, 4. Classificação de Padrões. 5. Análise de Textura. I. Título. 


\section{FOLHA DE JULGAMENTO}

Candidato: Engenheiro JOB NICOLAU TRAVAINI.

Título da dissertação: "Descritores de textura local para reconhecimento biométrico da íris humana".

Data da defesa: 02/10/2015

\section{Comissão Julgadora:}

Prof. Associado Adilson Gonzaga

(Orientador)

(Escola de Engenharia de São Carlos/EESC)

Prof. Dr. Marcelo Andrade da Costa Vieira

(Escola de Engenharia de São Carlos/EESC)
Resulfado:

APROVADO

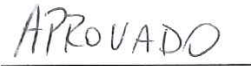

Profa. Dra. Inês Aparecida Gasparotto Boaventura APROVADO

(Universidade Estadual Paulista "Júlio de Mesquita Filho"/UNESP - São José do Rio Preto)

Coordenador do Programa de Pós-Graduação em Engenharia Elétrica: Prof. Associado Luis Fernando Costa Alberto

Presidente da Comissão de Pós-Graduação: Prof. Associado Paulo César Lima Segantine 



\section{Resumo}

TRAVAINI, J. N. Descritores de Textura Local para Reconhecimento Biométrico da Íris Humana. 2015. 104f. Dissertação (Mestrado) - Escola de Engenharia de São Carlos, Universidade de São Paulo, São Carlos, 2015.

Técnicas biométricas procuraram identificar usuários pela textura da íris, impressão digital, traços faciais, entre outros. A íris humana apresenta características de textura que a classificam como uma peculiaridade biométrica de grande poder de discriminação no reconhecimento de pessoas. O objetivo deste trabalho é avaliar a eficiência de uma nova metodologia de análise de texturas em desenvolvimento no LAVI (Laboratório de Visão Computacional da EESC-USP) na identificação de indivíduos por meio da textura de sua íris. A metodologia denomina-se Local Fuzzy Pattern e tem sido utilizada com excelente desempenho com texturas gerais, naturais e artificiais. Este documento detalha as técnicas utilizadas para extração e normalização da textura da íris, a utilização e os resultados obtidos com o método Local Fuzzy Pattern aplicado à classificação biométrica da íris humana. Os resultados obtidos apresentam sensibilidade de até 99,7516\% com a aplicação da metodologia proposta em bancos de imagens de íris humana disponíveis na internet demonstram a viabilidade da técnica proposta.

Palavras Chave: Biometria, LFP, Íris, Classificação de Padrões, Análise de Texturas. 



\begin{abstract}
TRAVAINI, J. N. Local Texture Descriptors applied in Human Iris Biometric Recognition. 2015. 104f. Dissertação (Mestrado) - Escola de Engenharia de São Carlos, Universidade de São Paulo, São Carlos, 2015.

Biometric Techniques sought to identify users by the texture of the iris, fingerprint, facial features, among others. The human iris have texture characteristics that rank it as a powerful biometric peculiarity on human recognition. The objective of this Masters proposal is to investigate the efficiency of a new methodology of iris texture analysis currently in development in LAVI (Laboratório de Visão Computacional da EESC-USP). The methodology is called LFP (Local Fuzzy Pattern) and has been used with excellent overall performance on artificial and natural textures. This document details the techniques used for the extraction and normalization of the iris texture, the use and results of the Local Fuzzy Pattern method applied to biometric classification of the human eye. The results show a sensibility of value up to $99.7516 \%$, obtained by applying the proposed methodology on human iris photos from image database available on the internet does showing the viability of the technique.
\end{abstract}

Key Word: Biometric, LFP, Iris, Pattern Classification, Texture Analisys. 



\section{Sumário}

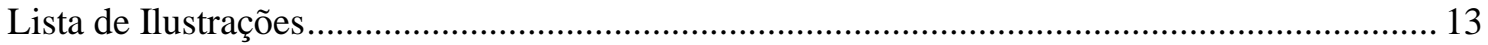

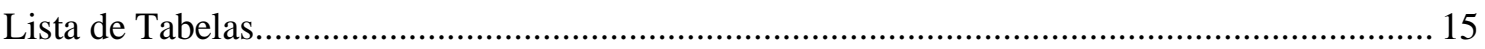

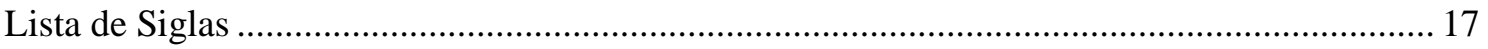

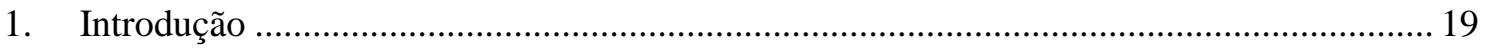

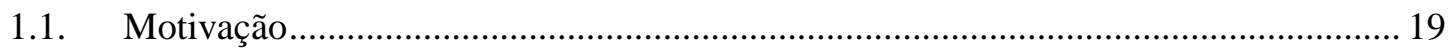

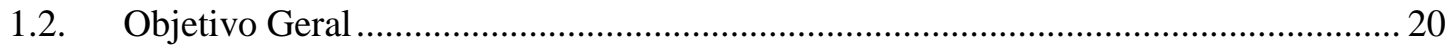

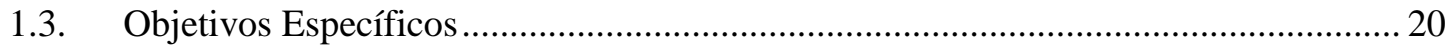

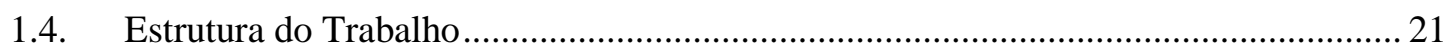

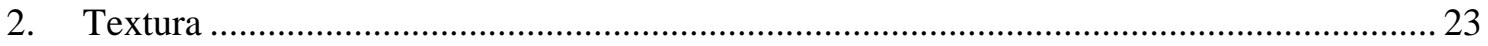

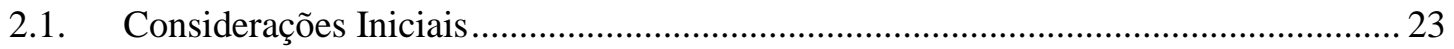

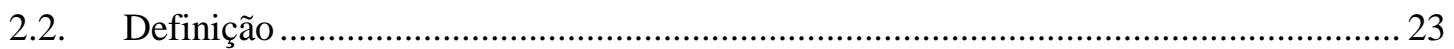

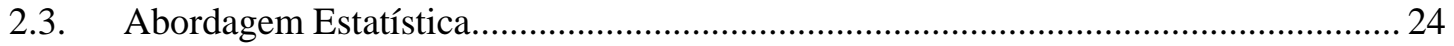

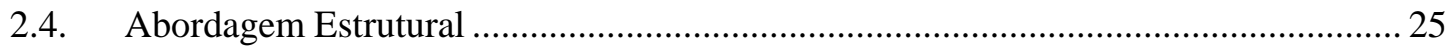

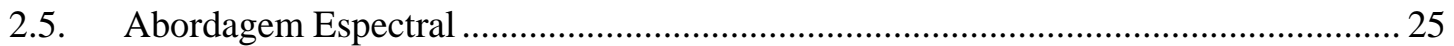

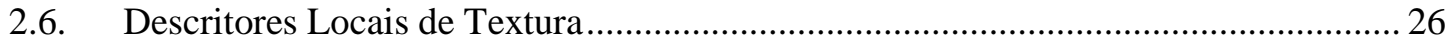

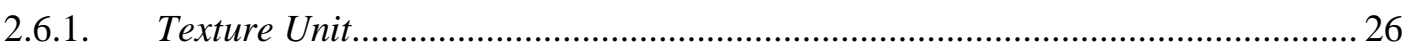

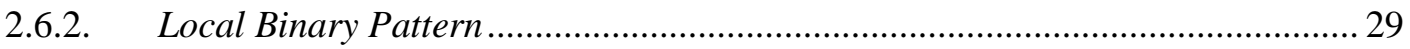

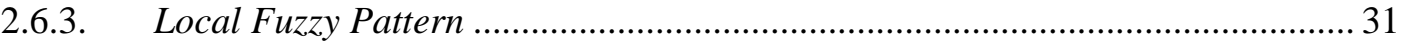

2.6.4. Função de Pertinência ............................................................................................ 35

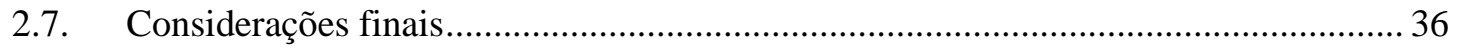

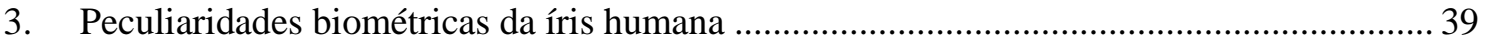

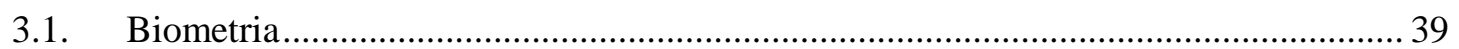

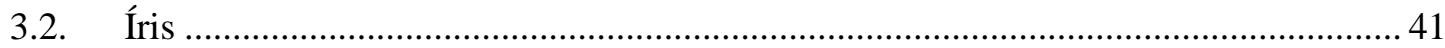

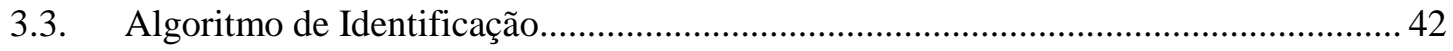

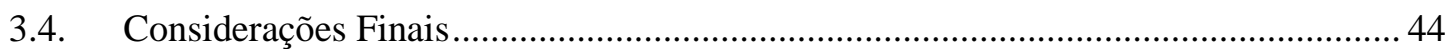

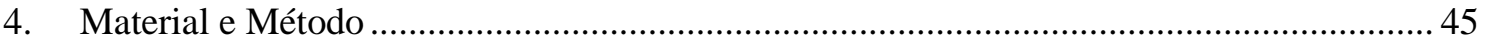

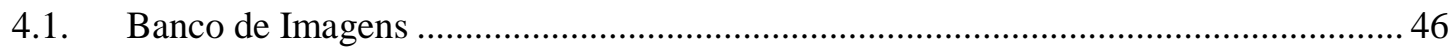

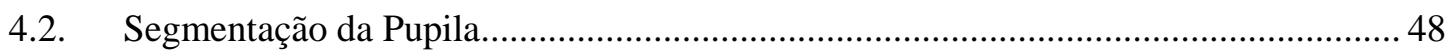




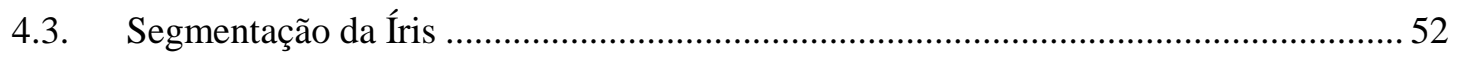

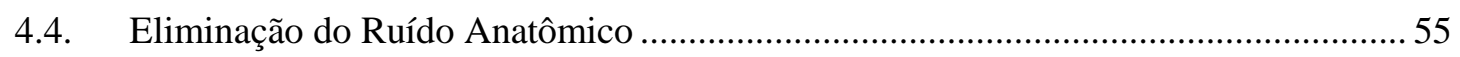

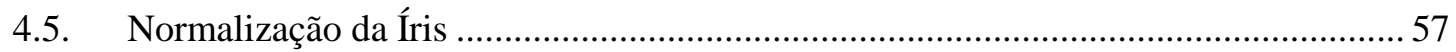

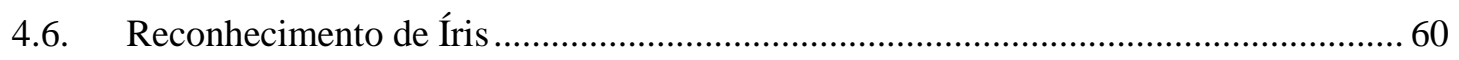

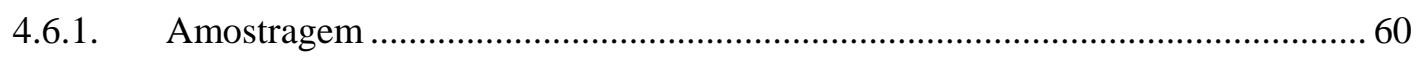

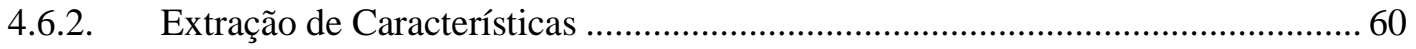

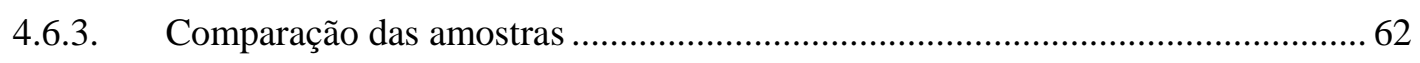

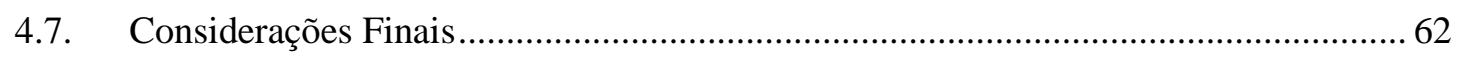

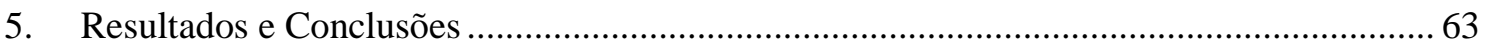

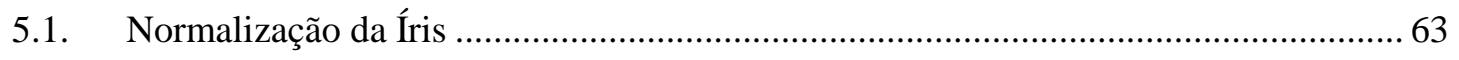

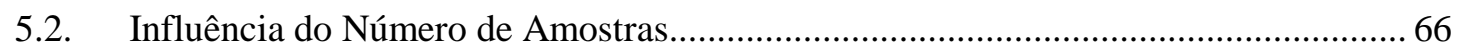

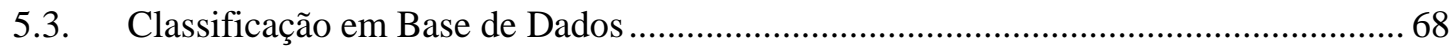

5.3.1. Base de imagens da Universidade de Notre Dame ............................................. 68

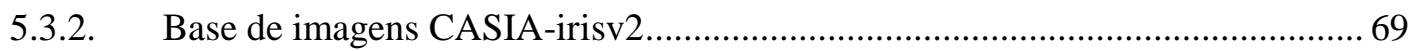

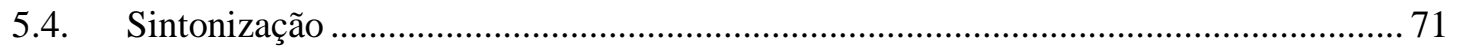

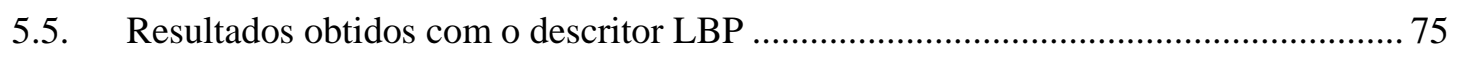

5.5.1. Sensibilidade para a base de imagens Notre Dame .......................................... 75

5.5.2. Sensibilidade para a base de imagens CASIA-irisv2. ...................................... 75

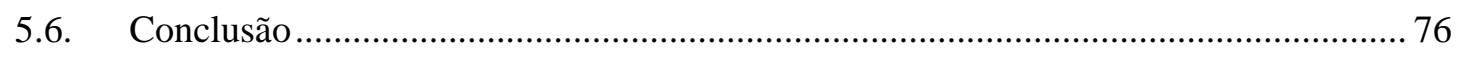

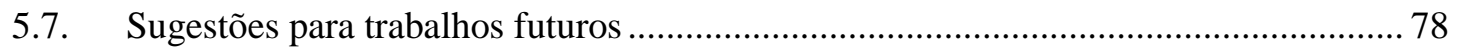

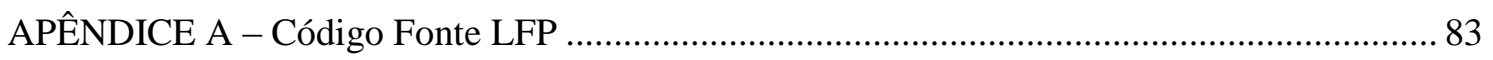

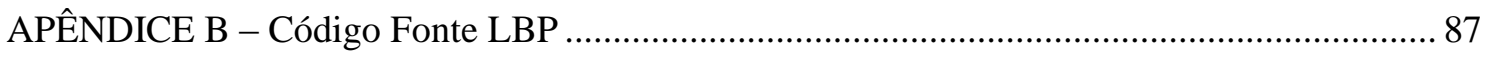

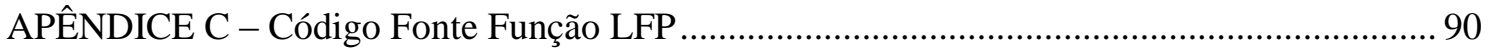

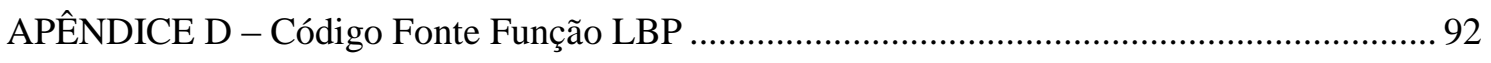

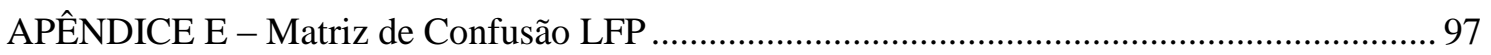

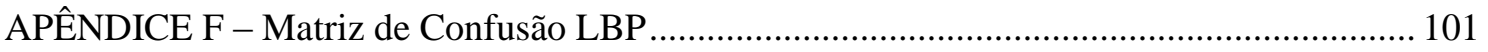




\section{Lista de Ilustrações}

Figura 1 - Conversão da vizinhança em Texture Unit................................................................. 27

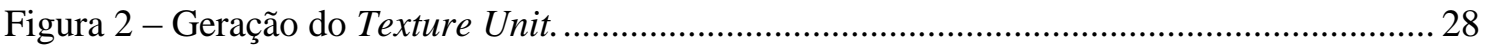

Figura 3 - Exemplo de geração de um código pelo método Local Binary Pattern. .................... 31

Figura 4 - Vizinhança circular de um Pixel. (OJALA; PIETIKÄINEN; MÄENPÄ̈̈, 2002).... 31

Figura 5 - Exemplo de geração de um código pelo método Local Fuzzy Pattern....................... 33

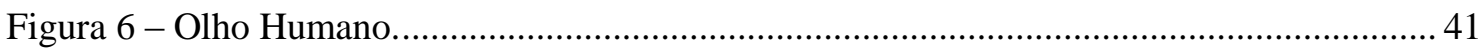

Figura 7 - Modelo de Identificação pessoal por biometria da Íris............................................... 42

Figura 8 - Exemplo de Imagem da base Iris Access LG2200 .................................................. 47

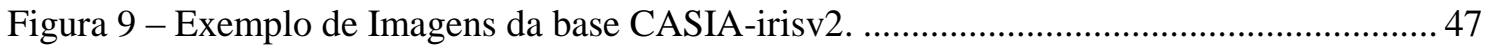

Figura 10 - Histograma Médio de Imagens do Olho Humano da Base de Notre Dame.............. 48

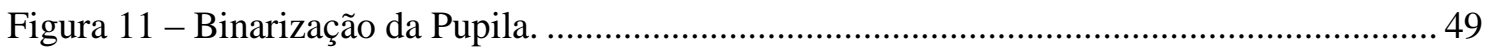

Figura 12 - Funcionamento do método Connected Component Labeling ................................... 50

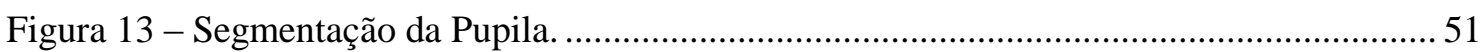

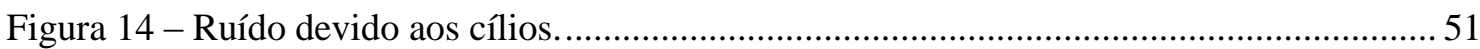

Figura 15 - Imagem filtrada por Canny sem um pré-processamento. ...................................... 53

Figura 16 - Comparação visual de pré-processamento utilizando filtro da mediana.................... 54

Figura 17 - Resultado do método de detecção de bordas. ............................................................ 54

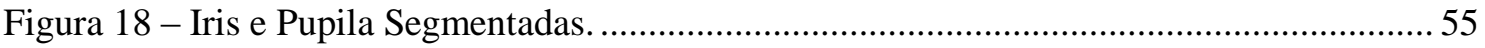

Figura 19 - Extração da pálpebra superior e inferior..................................................................... 56

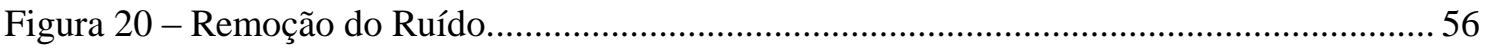

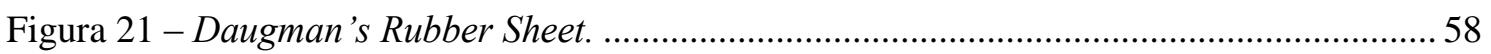

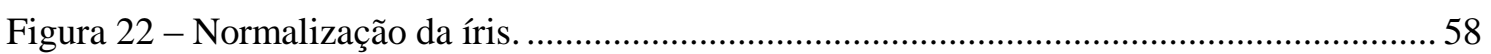

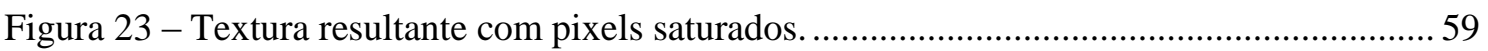

Figura 24 - Máscara para localização do ruído......................................................................... 59

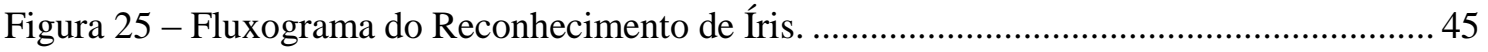

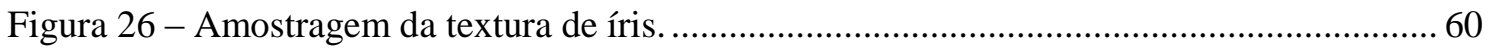

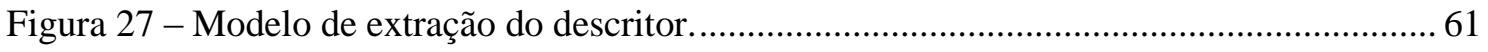

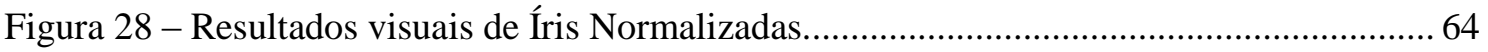

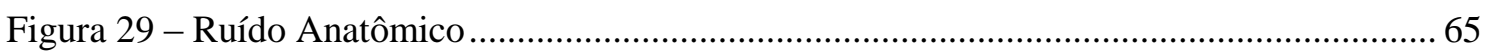

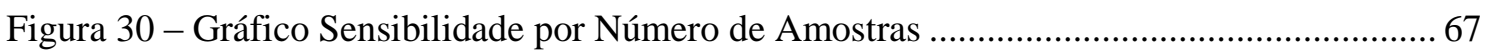

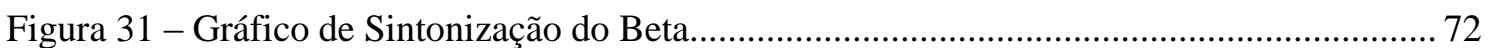

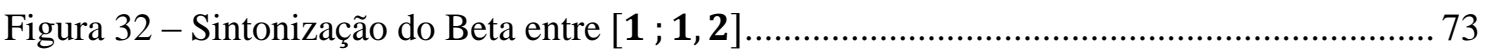





\section{Lista de Tabelas}

Tabela 1 - Comparação entre peculiaridades biométricas. (JAIN; ROSS; PRABHAKAR, 2004)

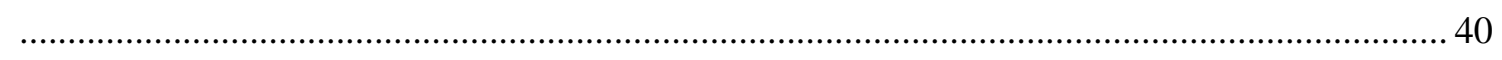

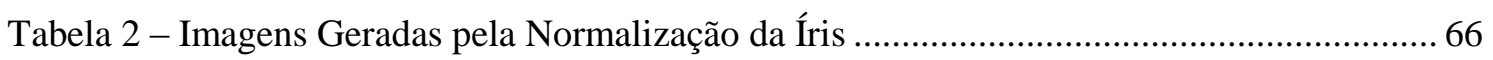

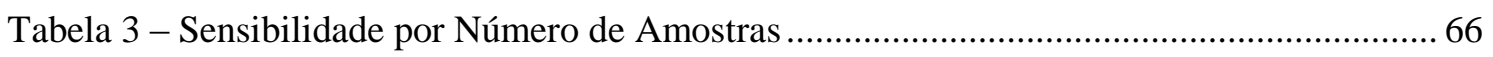

Tabela 4 - Exemplo de parte da Matriz de Confusão para base de imagens de Notre Dame. .... 69

Tabela 5 - Exemplo de parte da Matriz de Confusão para a base de imagens CASIA-irisv2 .... 70

Tabela 6 - Resultados estatísticos obtidos com 25 execuções do algoritmo proposto para o

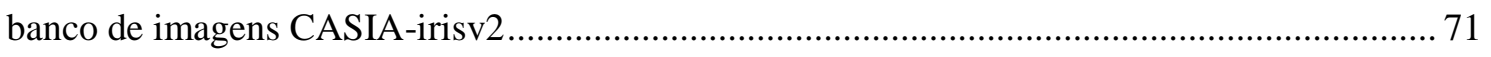

Tabela 7 - Média e Desvio Padrão da Sensibilidade por Classe................................................. 72

Tabela 8 - Resultados da Sensibilidade obtida com a sintonização do parâmetro $\boldsymbol{\beta}$ no intervalo

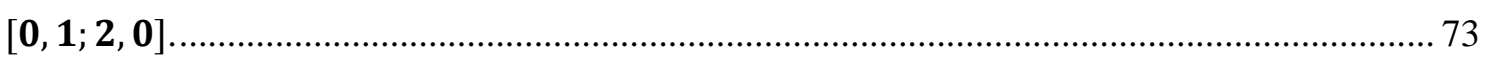

Tabela 9 - Resultados da variação da Sensibilidade com a sintonização do parâmetro $\boldsymbol{\beta}$ no intervalo $[1 ; 1,2]$. .74

Tabela 10 - Resultados obtidos com a aplicação do descritor LBP na base de imagens CASIAirisv2. .76

Tabela 11 - Comparação dos resultados obtidos com os descritores LBP e LFP nas bases de imagens de Notre Dame e CASIA-irisv2 77 



\section{Lista de Siglas}

LBP

LFP

$\mathrm{TU}$

TS
Local Binary Pattern

Local Fuzzy Patern

Texture Unit

Texture Spectrum 



\section{Introdução}

Métodos para identificação de indivíduos são amplamente abordados em pesquisas científicas e em empreendimentos que variam desde a área de segurança até equipamentos de entretenimento como o Kinect para o XBOX360.

As técnicas mais comuns de identificação pessoal utilizam-se de objetos como, por exemplo, um cartão de acesso, uma tarja magnética ou um crachá. Há também a utilização de meios mais robustos, como métodos que lidam com informações que apenas um ou mais indivíduos conhecem, como um password ou Personal Identification Number (PIN).

Entretanto, existe outra categoria de métodos que procuram tratar cada indivíduo como sendo único no mundo. Essas técnicas procuram identificar pessoas por meio do seu comportamento ou características biológicas, sendo assim chamadas de Biometrias. Existem vários meios de utilizar a biometria de um indivíduo para a sua identificação. Porém, nenhuma biometria é ótima e/ou livre de defeitos, cada peculiaridade biométrica possui um conjunto de vantagens e desvantagens associadas ao seu uso.

\subsection{Motivação}

Existe uma extensa gama de abordagens na literatura para a identificação de indivíduos utilizando medidas biométricas e várias técnicas são desenvolvidas visando tal propósito como, por exemplo, a identificação por meio da impressão digital, da face e da íris, do formato da mão, da assinatura e identificação por padrões de voz. Dentre as técnicas para reconhecimento biométrico, aquelas que utilizam a íris humana como descritor são amplamente abordadas pela comunidade científica. O Local Binary Pattern (LBP) (OJALA; PIETIKÄINEN; MÄENPÄÄ, 2001) é um exemplo de técnica desenvolvida inicialmente para gerar descritores de texturas gerais e que, com o avançado da investigação de suas aplicações, foi utilizada na análise de textura da íris para a identificação de pessoas (ZHENAN; TIENIU; XIANCHAO, 2005) (RASHAD et al., 2011). 
Um estudo recente, realizado no Laboratório de Visão Computacional da EESC-USP (LAVI) na área de análise de texturas e denominado de Local Fuzzy Pattern (LFP), vem demonstrando desempenho superior ao LBP (TAVARES et al., 2012) na classificação de vários tipos de texturas naturais e artificiais.

É notável na literatura que os métodos que inspiraram o Local Fuzzy Pattern obtiveram bons resultados na área de biometria, como na identificação pela íris (ZHENAN; TIENIU; XIANCHAO, 2005) (HE et al., 2011) e identificação por impressões digitais da palma de uma mão (WANG et al., 2006). Levando-se em consideração os resultados obtidos em testes com texturas estáticas (TAVARES, 2013) (TAVARES et al., 2012), onde o Local Fuzzy Pattern demonstrou desempenho superior ao Local Binary Pattern, propõe-se neste trabalho a utilização do Local Fuzzy Pattern em aplicações biométricas para identificação da textura de íris humana.

Motivado pela aplicação do LBP na classificação de indivíduos pela íris, em adição ao método LFP ser capaz de produzir resultados melhores na classificação de texturas naturais e artificias, propõe-se neste trabalho a investigação da eficiência do LFP na classificação da textura de íris humana visando o reconhecimento biométrico de indivíduos, e a comparação do LFP ao método LBP, para verificar se o LFP se comporta de maneira superior, assim como foi demonstrado em aplicações realizadas com texturas gerais.

\subsection{Objetivo Geral}

O objetivo geral deste trabalho de Mestrado é avaliar o desempenho do descritor de textura denominado de LFP na classificação biométrica de indivíduos utilizando a textura da íris humana em imagens estáticas.

\subsection{Objetivos Específicos}

Os objetivos específicos são:

- Investigar o desempenho da técnica de análise de textura denominado de Local Fuzzy Pattern aplicada em classificação de íris humanas e comparar os resultados obtidos com o método LBP.

- Normalizar uma base de dados formada por íris de diferentes indivíduos. 
- Propor soluções para os principais desafios encontrados na área, como a oclusão, reflexos e ruídos de aquisição na imagem do olho.

\subsection{Estrutura do Trabalho}

Esta dissertação de mestrado está assim constituída:

Neste primeiro capítulo introduzimos as motivações para o trabalho e os objetivos a serem atingidos.

No segundo capítulo serão introduzidos conceitos gerais sobre textura dentro da área de processamento de imagens.

No terceiro capítulo serão introduzidos conceitos sobre peculiaridades biométricas, algoritmos de identificação junto de suas vantagens e desvantagens.

No quarto capítulo será explicada a metodologia proposta neste trabalho de mestrado assim como o material utilizado para a sua realização.

No quinto capítulo será mostrado os resultados experimentais obtidos e as conclusões retiradas a partir de sua análise. 


\section{Textura}

Este capítulo aborda algumas técnicas de análise de texturas usadas pela comunidade científica na atualidade e relevantes para o entendimento do trabalho.

\subsection{Considerações Iniciais}

A textura de um objeto é uma característica visual importante durante o procedimento para classificá-lo e reconhecê-lo com algoritmos de visão computacional. Na literatura, a textura tem uma grande relevância e é utilizada em diversas aplicações que variam desde o auxílio ao diagnóstico de imagens médicas (CASTELLANO et al., 2004) até a identificação facial para rostos humanos (AHONEN; HADID; PIETIKAINEN, 2006).

Analisando texturas é possível distinguir regiões de uma imagem que apresenta padrões semelhantes e, portanto, podem ser classificadas como parte de um mesmo grupo. A análise de textura estabelece o relacionamento de um pixel com sua vizinhança, assim como seu posicionamento em relação aos demais (conectividade), o número de elementos por unidade espacial (densidade) e a sua regularidade (homogeneidade) (THEODORIDIS; KOUTROUMBAS, 2008).

\subsection{Definição}

Textura é considerada como uma característica de região e, apesar de ser um termo amplamente utilizado na literatura e em diversas aplicações, não possui uma definição precisa e nem uma aproximação matemática definida. Pesquisadores discorrem sobre a textura de acordo com o interesse de suas respectivas áreas de pesquisa e a definição aceita por uma área tende a ser aquela que proporciona os melhores resultados para sua aplicação. 
Logo, diversas definições podem ser encontradas na literatura e cada uma delas varia de acordo com a aplicação desejada, não havendo um consenso sobre o assunto. Algumas das definições criadas ao longo dos anos podem ser encontradas, tais como:

"Um textura pode ser descrita pelo número e tipos de suas primitivas e pela organização espacial ou layout de suas primitivas. A organização espacial pode ser aleatória ou pode obedecer a um padrão relativamente uniforme entre uma primitiva e suas primitivas vizinhas. Esta dependência pode ser estrutural, probabilística ou funcional.” (HARALICK, 1979)

"Textura é definida como o arranjo espacial e a natureza de componentes estruturais que podem ser pontos individuais em uma imagem ou textons mais complexos." (JULESZ, 1984)

"Textura pode ser definida como uma estrutura composta de uma área contendo um número grande de elementos relativamente ordenados ou padrões, que individualmente não representam muito. Mas se observados globalmente, tais elementos podem ser usados para identificar uma determinada área.” (GOOL; DEWAELE; OOSTERLINCK, 1985)

Pode ser definida, também, como uma região macroscópica de estrutura onde seus padrões são repetitivos, ou seja, seus elementos ou primitivas são dispostos de acordo com uma regra específica de posicionamento. (TAMURA; MORI; YAWAMAKI, 1978)

Conforme se aprofunda a investigação sobre texturas, percebe-se que sua definição é aberta e passível de modificação correlacionando-a com a aplicação a ser utilizada. As principais abordagens usadas no processamento de imagens para descrever a textura de uma região são a Estatística, a Estrutural e a abordagem Espectral. (GONZALEZ; WOODS, 2008)

\subsection{Abordagem Estatística}

A abordagem estatística descreve a textura com regras estatísticas que governam a distribuição de, e relação entre, os níveis de cinza de uma imagem. A interação, ou falta dela, é medida por meio de coeficientes probabilísticos. (HARALICK, 1979)

Existem diversos coeficientes e/ou características que podem ser extraídos de uma textura e a utilização de cada um deles varia de acordo com a aplicação. Essas características podem ser classificadas em dois grupos (HARALICK, 1979):

a) Coeficientes baseados em estatística de primeira ordem: avaliam a distribuição de níveis de cinza na imagem. Utiliza-se do histograma para realizar a extração de características. 
Como a abordagem é de primeira ordem, ela é de baixo custo computacional, porém não leva em consideração o pixel com sua vizinhança.

b) Coeficientes baseados em estatística de segunda ordem: abordam a relação entre um pixel e seus vizinhos, criando uma maior significância para o descritor e concebendo coeficientes que podem ser invariantes à rotação e translação de uma imagem.

\subsection{Abordagem Estrutural}

$\mathrm{Na}$ abordagem estrutural procura-se buscar primitivas e padrões bidimensionais que podem ser construídos utilizando-se de um conjunto de regras. Assim que obtidas as primitivas da textura, o método de descrição é realizado com estatísticas das propriedades extraídas desses padrões. O ideal para o funcionamento desta abordagem é a extração de padrões da textura, grandes o suficiente para que possam ser segmentados individualmente e depois descritos.

Os primeiros estudos realizados para esta abordagem vieram com Julesz em 1962, surgindo desse trabalho a Teoria Texton que levou a uma abordagem estrutural na qual se extrai primitivas da textura que a caracterizam localmente no processo de descrição. (JULESZ, 1962)

Haralick em 1979 fez um levantamento das abordagens estruturais para análise de texturas junto de um estudo de análises estatística. (HARALICK, 1979)

Devido à natureza do método, a abordagem estrutural, diferentemente da abordagem Estatística, provê uma boa descrição para reconstrução da textura em questão. Essa característica torna o método muito mais efetivo em áreas de síntese do que em análise e reconhecimento de texturas.

Outra dificuldade desta abordagem ocorre devido à dificuldade de identificar tais primitivas e encontrar padrões regulares que possibilitem sua utilização.

\subsection{Abordagem Espectral}

$\mathrm{Na}$ abordagem espectral trabalha-se com o espectro frequências em imagens de textura. O espectro Fourier é indicado para descrever padrões semi-periódicos ou periódicos em uma imagem 2D. Esses padrões de textura global são facilmente distinguíveis como concentrações de alta energia no espectro. 
Existem três características que se distinguem do espectro Fourier para a descrição de texturas:

1. Picos proeminentes no espectro são capazes de fornecer o padrão de textura.

2. A localização dos picos no plano da frequência fornecem informações sobre o período espacial fundamental do padrão de textura.

3. Eliminar qualquer componente periódico com o uso de filtros fornece como resultado espectros não periódicos da imagem que podem ser descritos por técnicas estatísticas.

Devido à natureza do método, texturas globais podem ser facilmente identificadas como concentração de alta energia, porém dificilmente distinguíveis devido à interpretação local. (GONZALEZ; WOODS, 2008)

Trabalhos como o Filtro de Gabor (GABOR, 1946) e as Transformadas Wavelets (VAN DE WOUMER; SCHEUDERS; VAN DYCK, 1999) exploram a abordagem espectral das texturas para a extração de descritores.

\subsection{Descritores Locais de Textura}

Essa seção aborda as principais técnicas de extração de textura por meio de descritores locais como o Texture Unit (TU), LBP e, especificamente a técnica LFP (Local Fuzzy Pattern) que foi desenvolvida no LAVI, com excelentes resultados na análise de micro padrões. Esta ferramenta será utilizada neste trabalho para a criação dos descritores capazes de classificar as imagens de textura das íris em classes distintas.

Descritores Locais de Textura é classificado como uma abordagem por micropadrões locais, diferentes das três grandes abordagens citadas pela literatura. Os descritores de textura local realizam a análise de propriedades da superfície do objeto analisando uma vizinhança e codificando cada uma delas, gerando desse modo as relações das intensidades relativas entre os pixels em uma vizinhança e não sobre os valores de intensidade absolutos.

\subsubsection{Texture Unit}


O Texture Unit é uma técnica que relaciona níveis de cinza de uma vizinhança para a classificação de micro padrões de textura.

O Texture Unit é usado para extrair a informação de uma textura local utilizando-se de uma janela de pixels $3 \times 3$ retirada de uma imagem, ou seja, a menor representação de vizinhos de um pixel central em suas oito direções.

$\mathrm{Na}$ vizinhança da Figura $1 \boldsymbol{V}=\left\{V_{0}, V_{1}, V_{2}, \ldots, V_{8}\right\}$, onde $V_{0}$ representa o valor em escala de cinza do pixel central e $V_{i} \quad(i \neq 0)$ o valor em escala de cinza dos vizinhos localizados nas oito direções adjacentes. O conceito chave para o funcionamento do Texture Unit é o uso da intensidade relativa dos pixels ao invés da intensidade absoluta para representar a textura local. O Texture Unit é definido como um conjunto contendo oito elementos: $\boldsymbol{T} \boldsymbol{U}=\left\{E_{1}, E_{2}, \ldots, E_{8}\right\}$, onde $E_{i}$ é obtido comparando-se os $V_{i}$ com o pixel central $V_{0}$.

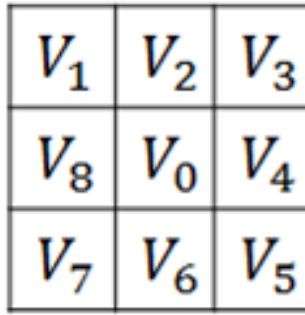

Janela da Imagem

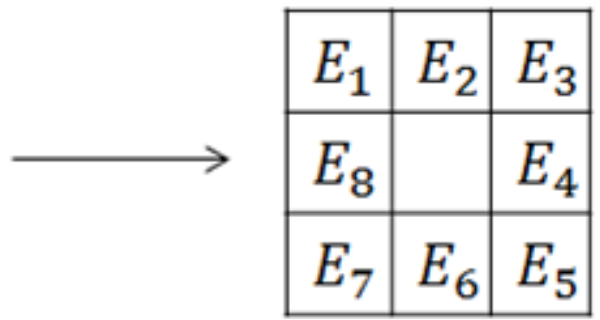

Texture Unit

Figura 1 - Conversão da vizinhança em Texture Unit.

A comparação é feita considerando-se três possíveis situações: caso o pixel central e o seu vizinho possuam valores iguais, caso o pixel central seja maior que o pixel vizinho e, por fim, caso o pixel central seja menor que o pixel vizinho, conforme mostra a equação (2.1).

$$
E_{i}= \begin{cases}0, & \text { se } V_{i}<V_{0} \\ 1, & \text { se } V_{i}=V_{0} \\ 2, & \text { se } V_{i}>V_{0}\end{cases}
$$

Após o cálculo do Texture Unit é possível a geração de um código. Esse código é gerado multiplicando-se ponto a ponto a matriz do Texture Unit por uma matriz de pesos, que relaciona dessa maneira cada pixel a um peso. Após realizar o cálculo da multiplicação, realizase a soma de todos os valores resultantes dessa multiplicação para obter-se o código TU, calculado pela equação (2.2), capaz de caracterizar um determinado micropadrão da imagem. 


$$
\operatorname{Code}_{T U}=\sum_{i=1}^{8} E_{i} * 3^{i-1}
$$

A descrição da imagem é criada a partir do histograma gerado contendo os valores dos cálculos obtidos pelo Texture Unit. Esse histograma é denominado Texture Spectrum. Este método acrescenta a vantagem de associar uma determinada imagem a um histograma ao invés de um simples conjunto de medidas. A Figura 2 exemplifica o funcionamento do Texture Unit.

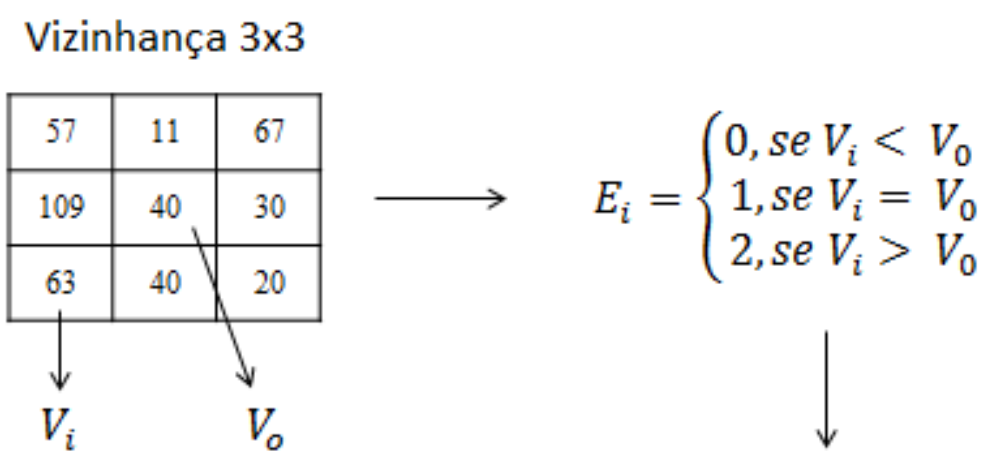

Texture Unit
\begin{tabular}{|c|c|c|}
\hline 2 & 0 & 2 \\
\hline 2 & & 0 \\
\hline 2 & 1 & 0 \\
\hline
\end{tabular}

Matriz de Pesos

$x$

\begin{tabular}{|c|c|c|}
\hline 1 & 3 & 9 \\
\hline 2187 & & 27 \\
\hline 729 & 243 & 81 \\
\hline
\end{tabular}

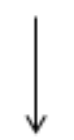

Code $_{T U}=6095$

Figura 2 - Geração do Texture Unit.

Infelizmente o método não é muito efetivo; o maior problema ocorre devido a grande quantidade de códigos gerados: 6561 possibilidades diferentes. Isso faz com que o método a 
utilizar regiões muito grandes da imagem para que seja possível obter distribuições que permitam um cálculo de similaridades e dissimilaridades confiáveis.

\subsubsection{Local Binary Pattern}

O Texture Unit inspirou Ojala, Pietikäinen e Hardwood (1996) a proporem um novo método de análise por micropadrões, chamado de LBP (Local Binary Pattern). Similar ao trabalho anterior, o $L B P$ busca realizar a comparação do pixel central com seus oito vizinhos com o intuito de adquirir um código que caracterize a micro região selecionada.

Considerando-se uma vizinhança de $3 \times 3$ pixels $\boldsymbol{V}=\left\{V_{0}, V_{1}, V_{2}, \ldots, V_{8}\right\}$, onde $V_{0}$ representa o valor em escala de cinza do pixel central e $V_{i}$ representa o valor em escala de cinza dos seus oito vizinhos, aplica-se uma comparação similar à realizada no Texture Unit. O Local Binary Pattern é definido como um conjunto contendo oito elementos: $\boldsymbol{L} \boldsymbol{B} \boldsymbol{P}=\left\{E_{1}, E_{2}, \ldots, E_{8}\right\}$, sendo que $E_{i}$ é obtido comparando-se os $V_{i}$ com o pixel central $V_{0}$ tal que:

$$
E_{i}= \begin{cases}0, & \text { se } V_{i}<V_{0} \\ 1, & \text { se } V_{i} \geq V_{0}\end{cases}
$$

Durante a comparação, se o valor do pixel vizinho for igual ou superior ao valor do pixel central, o resultado é igual a ' 1 '. Se o valor do pixel vizinho for menor ao valor do pixel central, o resultado é igual a ' 0 '. Calculada a nova matriz da vizinhança de pixels, o código resultante é gerado multiplicando-se ponto a ponto o Local Binary Pattern por uma matriz de pesos e somando-se os valores resultantes para a obtenção do código LBP, capaz de caracterizar um determinado micropadrão da imagem de acordo com a equação (2.4)

$$
\operatorname{Code}_{L B P}=\sum_{i=1}^{8} E_{i} * 2^{i-1}
$$


A maior diferença entre o Texture Unit e o Local Binary Pattern é o fato de o segundo possuir apenas 256 códigos resultantes, enquanto o Texture Unit possui 6561 valores. Isto significa que o LBP é capaz de gerar apenas 256 códigos para representar os diferentes micropadrões de uma imagem, esse fato torna-o mais sensível a ruído do que o Texture Unit para a criação de vetores de características, mas em contrapartida torna-o mais rápido sem que haja uma perda significativa de acurácia.

Em sequência ao cálculo do código LBP é formado um histograma. Este histograma é considerado um vetor de características utilizado para definir o micropadrão analisado. A Figura 3 exemplifica a geração de um código do LBP.

O trabalho de Mäenpää e outros (MÄENPÄÄ et al., 2000) envolvendo o Local Binary Pattern investiga a diminuição do número de elementos dentro do vetor de características. $\mathrm{O}$ método proposto por esses autores sugere a consideração apenas dos padrões "uniformes", os quais possuem um valor limitado na transição dos valores dos bits de um para zero, e viceversa.

Vizinhança $3 \times 3$

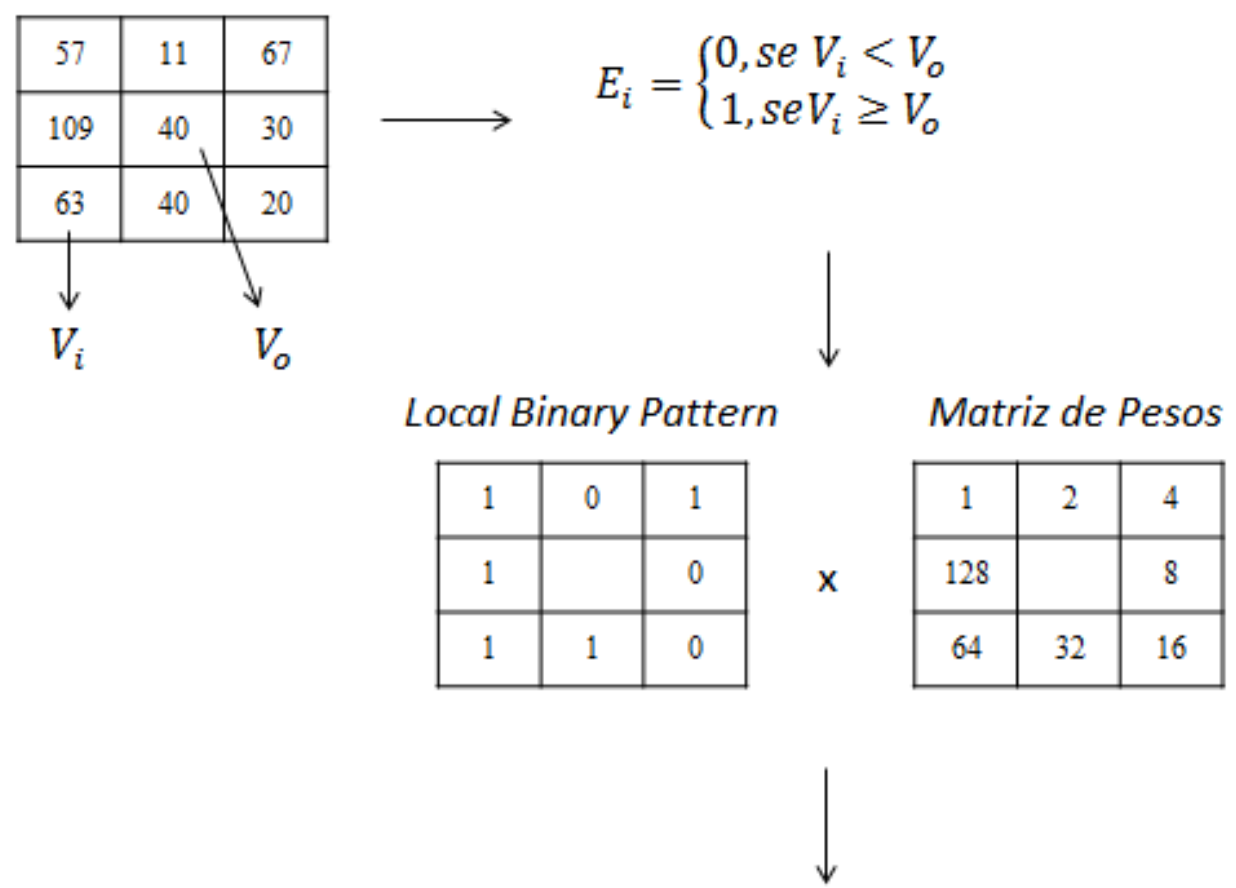

Code $_{L B P}=229$ 


\section{Figura 3 - Exemplo de geração de um código pelo método Local Binary Pattern.}

Para tornar o LBP invariante a rotações na imagem e capaz de realizar análises multiescalares, foi proposto o LBP circular. A vizinhança circular é representada pela Figura 4 e a quantidade de vizinhos (P) é escolhida a partir do tamanho do perímetro circular (R). Para obter o valor em escala de cinza dos pixels, é realizada uma interpolação da vizinhança com espaçamento igual no círculo. (OJALA; PIETIKÄINEN; MÄENPÄÄ, 2002)

Portanto, para um número de vizinhos igual a $P=12$ dentro de um perímetro circular de $R=1,5$. Será feita uma interpolação dos pixels utilizando-se dos pontos $P$ igualmente espaçados circularmente, com distância $R$ do centro para gerar a vizinhança utilizada para realizar o cálculo do código LBP. A unidade de $R$ é a distância entre o centro de dois pixels adjacentes.

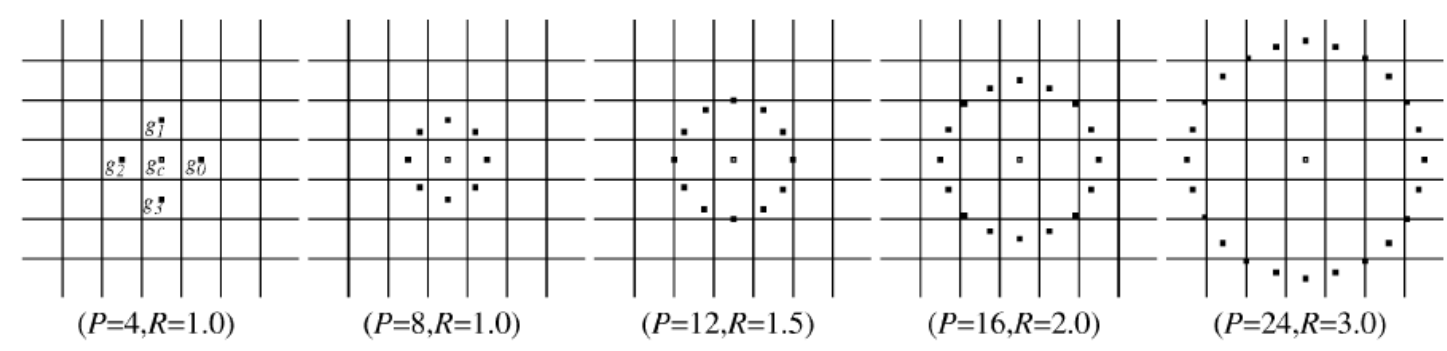

Figura 4 - Vizinhança circular de um Pixel. (OJALA; PIETIKÄINEN; MÄENPÄÄ, 2002)

\subsubsection{Local Fuzzy Pattern}

O TU, relaciona os níveis de cinza da vizinhança com o pixel central como modo de caracterizar e classificar uma região ou uma textura dentro de uma imagem. O método tem a desvantagem de gerar muitos códigos não correlatos, desenvolvendo a necessidade de que as regiões examinadas sejam maiores para que as distribuições obtidas possam classificar com uma boa margem de confiança. O Local Binary Pattern resolve esse problema, diminuindo o número de códigos de 6561 para 256. Contudo, essa redução faz com que o método se torne menos robusto contra ruídos devido ao resultado da sua comparação levar os valores binários 0 e 1 e não levar em conta o quão discrepante é a diferença entre os pixels vizinhos. 
Para resolver esse problema, em 2012 foi proposto o LFP (TAVARES et al., 2012), baseado em conjuntos fuzzy que é capaz de lidar com problemas que envolvem graus de incerteza e ambiguidade. Considerando que existem incertezas sobre os valores de dois pixels vizinhos em uma imagem devido a diversos fatores, como ruído de aquisição, interpolações por software e iluminação, cada vizinhança de um pixel pode ser considerada como um conjunto de números fuzzy, permitindo gerenciar essas informações vagas com mais confiabilidade e proporcionar um método de classificação mais flexível. Uma grande vantagem do método LFP é que ele não é baseado em regras fuzzy, esse fato contribui em muito para a redução do seu custo computacional.

O método LFP utiliza uma representação por números fuzzy, portanto ele é paramétrico e passível de otimização dos seus parâmetros. Sua função de pertinência é heurística e não única, portanto, qualquer função pode ser definida de acordo com a aplicação. A definição da função é baseada nas propriedades da vizinhança do micro padrão da imagem e do seu pixel central.

Seja uma janela representando o micro padrão $A$ de tamanho $W x W$ e uma matriz de pesos $\mathrm{P}$ representada por $P(k, l)$. O pixel central desse micropadrão A é chamado de $g(i, j)$ e uma função de pertinência relaciona os vizinhos ao pixel central $f_{g(i, j)}$. A forma paramétrica do LFP é descrita pela seguinte equação (2.5).

$$
\hat{\mu}_{g(i, j)}=\frac{\sum_{k=1}^{W} \sum_{l=1}^{W}\left[f_{g(i, j)} * P(k, l)\right]}{\sum_{k=1}^{W} \sum_{l=1}^{W} P(k, l)}
$$

na qual $\hat{\mu}_{g(i, j)}$ é o grau de pertinência do pixel central à região definida pela janela $W$. O valor final é dado pela média ponderada dos valores de pertinência individuais de cada pixel, este valor define o código LFP. O código, como nos outros métodos, reflete a estrutura do micro padrão dentro da vizinhança considerada. (TAVARES et al., 2012)

A Figura 5 exemplifica a geração de um código pelo método LFP. Observa-se como uma janela $3 \times 3$ é transformada em um micropadrão pela da função de pertinência utilizada pelo LFP. Esse micropadrão é representado por uma janela de tamanho idêntico à primeira janela, porém o valor de cada pixel representa sua pertinência em relação ao pixel central da janela. Para a obtenção do código LFP multiplica-se ponto a ponto os valores de pertinência do micropadrão por uma matriz de pesos, e o resultado dessa multiplicação é dividido pela soma dos pesos. 
Janela $3 \times 3$

Janela $3 \times 3$

\begin{tabular}{|c|c|c|}
\hline 57 & 11 & 67 \\
\hline 109 & 40 & 30 \\
\hline 63 & 40 & 20 \\
\hline & \multicolumn{1}{|c}{$\downarrow$}
\end{tabular}$\quad$\begin{tabular}{|l|l|l|}
\hline$A(1,1)$ & $A(1,2)$ & $A(1,3)$ \\
\hline$A(2,1)$ & $g(2,2)$ & $A(2,3)$ \\
\hline$A(3,1)$ & $A(3,2)$ & $A(3,3)$ \\
\end{tabular}

$A(k, l) \quad g(i, j)$

Pertinência relativa ao pixel central Matriz de Pesos

\begin{tabular}{|l|l|l|}
\hline$\mu_{A(1,1)}$ & $\mu_{A(1,2)}$ & $\mu_{A(1,3)}$ \\
\hline$\mu_{A(2,1)}$ & $\mu_{g(2,2)}$ & $\mu_{A(2,3)}$ \\
\hline$\mu_{A(3,1)}$ & $\mu_{A(3,2)}$ & $\mu_{A(3,3)}$ \\
\hline
\end{tabular}
\begin{tabular}{|l|l|l|}
\hline$p(1,1)$ & $p(1,2)$ & $p(1,3)$ \\
\hline$p(2,1)$ & $p(2,2)$ & $p(2,3)$ \\
\hline$p(3,1)$ & $p(3,2)$ & $p(3,3)$ \\
\hline
\end{tabular}

$$
\hat{\mu}_{g(2,2)}=\frac{\sum_{k=1}^{3} \sum_{l=1}^{3}\left[f_{g(2,2)} * P(k, l)\right]}{\sum_{k=1}^{3} \sum_{l=1}^{3} P(k, l)}
$$

Figura 5 - Exemplo de geração de um código pelo método Local Fuzzy Pattern.

$\mathrm{Na}$ Figura 5 a janela $3 \times 3$ tem seus pixels vizinhos $\left\{A_{(1,1)}, A_{(1,2)}, A_{(1,3)}, A_{(2,1)}, A_{(2,3)}, A_{(3,1)}, A_{(3,2)}, A_{(3,3)}\right\}$ tratadas pela função de pertinência $f_{g(i, j)}$ referente ao pixel central $g_{(2,2)}$. Esse procedimento gera a matriz de pertinência relativa ao pixel central que deve ser multiplicada pela matriz de pesos estipulada.

A teoria que embasa o método LFP permite demonstrar que os métodos TU e o LBP podem ser obtidos do LFP. A escolha apropriada da função de pertinência e da matriz de pesos utilizadas no método é capaz de demonstrar esse fato. Utilizando-se da matriz de pesos e da função de pertinência apresentadas na equação (2.6) é possível obter o TU.

$$
\begin{gathered}
P(k, l)=\left[\begin{array}{ccc}
1 & 3 & 9 \\
2187 & 0 & 27 \\
729 & 243 & 81
\end{array}\right] \\
f_{g(i, j)}=1+\operatorname{sgn}[A(k, l)-g(i, j)]
\end{gathered}
$$


sendo a função $\operatorname{sgn}(x)$ uma função sinal representada pela equação (2.7).

$$
\operatorname{sng}(x)= \begin{cases}-1, & \text { se } x<0 \\ 0, & \text { se } x=0 \\ 1, & \text { se } x>0\end{cases}
$$

Para demonstrar que o LBP é outro caso particular do LFP é necessária a utilização da matriz de pesos em conjunto com a função de pertinência mostrada na equação (2.8).

$$
\begin{gathered}
P(k, l)=\left[\begin{array}{ccc}
1 & 2 & 4 \\
128 & 0 & 8 \\
64 & 32 & 16
\end{array}\right] \\
f_{g(i, j)}=\operatorname{step}[A(k, l)-g(i, j)]
\end{gathered}
$$

sendo $\operatorname{step}(x)$ a função degrau representada pela equação (2.9).

$$
\operatorname{step}(x)= \begin{cases}0, & \text { se } x<0 \\ 1, & \text { se } x \geq 1\end{cases}
$$

Portanto, a componente paramétrica do método, chamada de função de pertinência, é de extrema importância para a otimização em diferentes aplicações. Cada função utilizada pode trazer uma nova perspectiva e uma nova vantagem à investigação. No entanto, não há uma função ótima para todos os casos, sendo necessária uma investigação juntamente de testes para a determinação de qual deva ser utilizada. 


\subsubsection{Função de Pertinência}

Apesar da função de pertinência poder ser definida pelo usuário durante a aplicação do método, segundo Tavares (TAVARES, 2013), o LFP é proposto com três principais funções.

A função proposta, de modo que o método possa ser comparado ao LBP, é a função sigmoide. A função sigmoide possibilita a captação melhorada de nuances entre a diferença de valor dos pixels com níveis de cinza próximos do que a proposta pelo LBP, onde a comparação é realizada de maneira crisp ( 0 ou 1 ) o que ocasiona em perda de informações que relacionam a quantidade real da diferença entre os valores comparados.

A função de pertinência que descreve o LFP -sigmoid é a dada pela equação (2.10).

$$
f_{g(i, j)}=\frac{1}{1+e^{\frac{-[A(k, l)-g(i, j)]}{\beta}}}
$$

na qual $\beta$ é um parâmetro que corresponde à inclinação da sigmoide, $A(k, l)$ são os pixels de uma vizinhança $W x W$ e $g(i, j)$ é o pixel central da vizinhança $W x W$. A variável $\beta$ pode ser ajustada empiracamente para que o método seja otimizado e, portanto, possua uma maior acurácia.

Para o descritor com a função sigmoide, utiliza-se a seguinte matriz de pesos:

$$
P(k, l)=\left[\begin{array}{lll}
1 & 1 & 1 \\
1 & 1 & 1 \\
1 & 1 & 1
\end{array}\right]
$$

Inspirado pelo trabalho de Boaventura (BOAVENTURA, 2010), no qual foi proposto uma nova abordagem para detecção de bordas em imagens baseada no conceito de números fuzzy, a função de pertinência triangular foi adotada devido ao seu potencial observado para a detecção de bordas do método de Boaventura. A função de pertinência utilizada para esta versão, denominada LFP-triangular, é explicitada pela equação (2.11).

$$
f_{g(i, j)}=\max \left(0,1-\frac{|g(i, j)-A(k, l)|}{\delta}\right)
$$


na qual $\delta$ é um parâmetro denominado de o espalhamento do número fuzzy, $A(k, l)$ são os pixels de uma vizinhança $W x W$ e $g(i, j)$ é o pixel central da vizinhança $W x W$. A matriz de peso para esta função é:

$$
P(k, l)=\left[\begin{array}{lll}
1 & 1 & 1 \\
1 & 0 & 1 \\
1 & 1 & 1
\end{array}\right]
$$

Outra função explorada por Tavares (TAVARES, 2013) é a função de pertinência gaussiana, criando-se assim um descritor de textura local chamado de LFP-Gaussian. Sua função de pertinência é dada pela seguinte equação (2.12).

$$
f_{g(i, j)}=e^{-\frac{[A(k, l)-g(i, j)]^{2}}{\sigma}}
$$

na qual $\sigma$ é um parâmetro relativo ao desvio padrão, $A(k, l)$ são os pixels de uma vizinhança $W x W$ e $g(i, j)$ é o pixel central da vizinhança $W x W$.

\subsection{Considerações finais}

A partir do conteúdo apresentado neste capítulo, conclui-se que a textura pode ser interpretada de diversas maneiras; onde cada interpretação é voltada para diferentes aplicações dentro do campo de Visão Computacional (segmentação de florestas em mapas, reconhecimento de movimentos, entre outras) sendo sua escolha baseada em seu desempenho na particular aplicação.

É possível compreender que não existe uma abordagem única para a análise de texturas, portanto a abordagem a ser empregada deve ser analisada caso a caso. Para esse trabalho, a textura é a matéria prima para a extração de descritores que possam identificar individualmente todas as íris pertencentes a uma base de dados. A abordagem de análise de textura a ser empregada no reconhecimento de íris humana neste trabalho será a de micro-padrões locais 
devido ao fato que um novo descritor LFP desenvolvido por (TAVARES, 2013) e o objetivo desta dissertação é avaliar seu desempenho neste tipo de aplicação.

É importante ressaltar que os métodos citados podem ser derivados do Local Fuzzy Pattern alterando-se a função de pertinência e a matriz de pesos. Esse fato motiva a comparação do método LFP com o LBP sobre o quesito desempenho para a determinação da eficácia da abordagem. 


\section{Peculiaridades biométricas da íris humana}

\subsection{Biometria}

O reconhecimento de uma pessoa por meio de alguma peculiaridade biométrica (biometric trait) é baseado na identificação de características físicas ou comportamentais que permitem identificá-la por "algo que o indivíduo é" ao invés de "algo que o indivíduo possua", como um cartão ou um crachá, ou "algo que o indivíduo saiba", como uma senha ou um Personal Identification Number. (JAIN; ROSS; PRABHAKAR, 2004)

Dentro do espectro de peculiaridades biométricas existentes no ser humano, é perceptível que cada uma seja possuidora de suas próprias vantagens e desvantagens para a utilização em métodos de identificação. Dentre as mais utilizadas destacam-se: impressões digitais, íris, padrões de movimento, padrões de voz, geometria da face, geometria da mão, DNA, veias da retina, dentre outros.

É visível o fato de que não há uma peculiaridade biométrica ótima para todos os casos e o grande número de características que podem ser utilizadas são divididas, em sua maioria, em dois grupos:

Características Físicas e Biológicas como características da face, mãos, DNA, veias.

Características Comportamentais referem-se a características que o indivíduo adquire com o passar da vida, como padrões do movimento, pressão ao apertar objetos.

A Tabela 1 explicita as vantagens e desvantagens das peculiaridades biométricas. Os atributos fundamentais destas são:

Universalidade é o atributo que identifica o quão baixa é a probabilidade de pessoas possuírem características semelhantes desta peculiaridades;

Distinção é o atributo que indica o quão fácil é a distinção de um indivíduo do outro a partir das características extraídas desta peculiaridades;

Permanência é o atributo que indica o quão invariante são as características desta peculiaridades ao longo do tempo; 
Coletividade é o atributo que indica o quão fácil é a extração das característica de um indivíduo;

Desempenho é o atributo que indica o quão rápida e precisa é a identificação de indivíduos por meio desta peculiaridade;

Erro é o atributo que indica o grau de dificuldade do sistema de identificação cometer um erro ao classificar indivíduos utilizando esta peculiaridade. (JAIN; ROSS; PRABHAKAR, 2004)

Tabela 1 - Comparação entre peculiaridades biométricas. (JAIN; ROSS; PRABHAKAR, 2004)

\begin{tabular}{|c|c|c|c|c|c|c|}
\hline 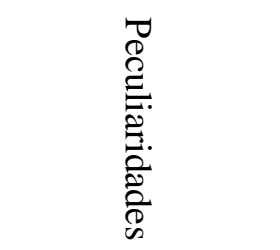 & 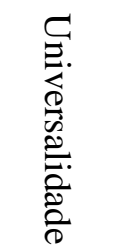 & 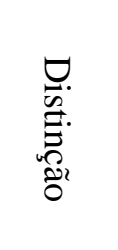 & 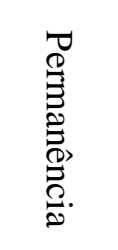 & 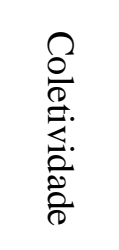 & 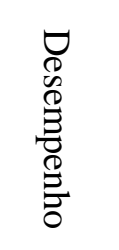 & $\frac{T}{9}$ \\
\hline DNA & Alta & Alta & Alta & Baixa & Alta & Baixa \\
\hline Orelha & Média & Média & Alta & Média & Média & Média \\
\hline Face & Alta & Baixa & Média & Alta & Baixa & Alta \\
\hline $\begin{array}{c}\text { Termograma } \\
\text { Facial }\end{array}$ & Alta & Alta & Baixa & Alta & Média & Baixa \\
\hline Impressão Digital & Média & Alta & Alta & Média & Alta & Média \\
\hline Marcha & Média & Baixa & Baixa & Alta & Baixa & Média \\
\hline $\begin{array}{l}\text { Geometria da } \\
\text { Mão }\end{array}$ & Média & Média & Média & Alta & Média & Média \\
\hline Veias da Mão & Média & Média & Média & Média & Média & Baixa \\
\hline Íris & Alta & Alta & Alta & Média & Alta & Baixa \\
\hline $\begin{array}{l}\text { Pressão sobre } \\
\text { botão }\end{array}$ & Baixa & Baixa & Baixa & Média & Baixa & Média \\
\hline Odor & Alta & Alta & Alta & Baixa & Baixa & Baixa \\
\hline $\begin{array}{c}\text { Impressão da } \\
\text { Palma } \\
\end{array}$ & Alta & Alta & Alta & Média & Alta & Média \\
\hline Retina & Alta & Alta & Média & Baixa & Alta & Baixa \\
\hline Assinatura & Baixa & Baixa & Baixa & Alta & Baixa & Alta \\
\hline Voz & Média & Baixa & Baixa & Média & Baixa & Alta \\
\hline
\end{tabular}

Através da Tabela 1 pode-se concluir que a íris humana apresenta uma ótima capacidade de descriminação entre indivíduos devido a sua alta Universalidade e alta Distinção. Sua Permanência ser alta permite que uma amostra retirada em qualquer momento da vida do indivíduo possa ser usada mais tarde para a sua identificação, sem que se enfrente a possibilidade desta peculiaridade sofrer variação ao longo do tempo. Devido ao fato da íris ser uma parte do olho exposta, a extração de características da sua textura é um ato não invasivo. Corroborando os fatos é evidente que a íris é ótima para identificação de pessoas o que permite 
alta precisão e baixo erro. Sua textura apresenta características com alto poder de discriminação, sendo portanto, a peculiaridade biométrica motivo desta investigação por análise de textura local.

\section{2. Íris}

A Íris é uma estrutura fina e circular do olho humano. A sua responsabilidade é de controlar o diâmetro da pupila, permitindo assim a entrada de mais ou menos luz dentro da retina.

A textura da íris humana se desenvolve durante os dois primeiros anos de vida de um ser humano. Essa textura carrega informações capazes de serem utilizadas para a identificação do indivíduo. A Figura 6 mostra as principais estruturas do olho humano.

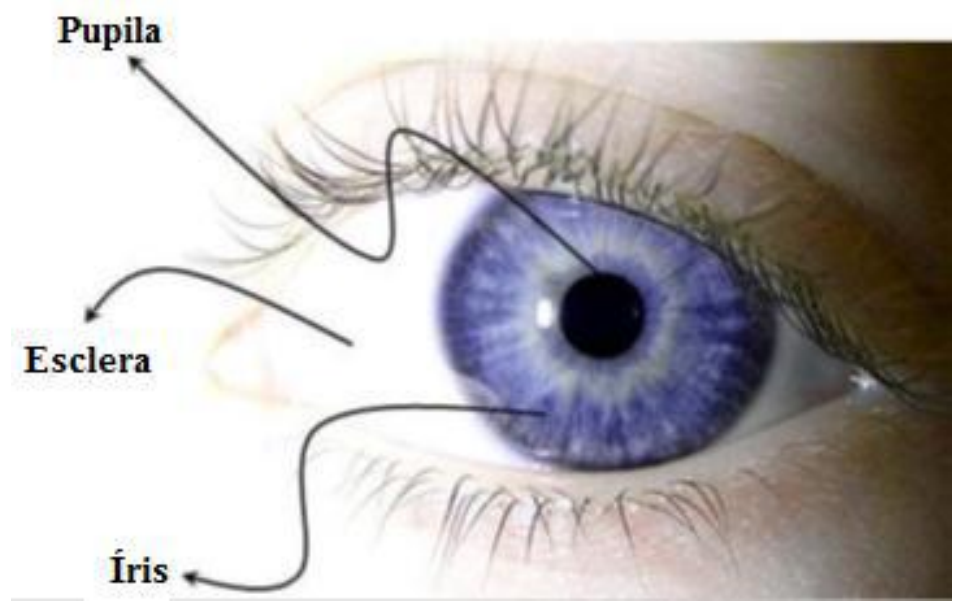

Figura 6 - Olho Humano.

A utilização da íris humana como peculiaridade biométrica agrega uma série de vantagens ao sistema de identificação de indivíduos. A taxa de erros utilizando íris humana é muito baixa devido à grande quantidade de dados que podem ser extraídos de sua textura. Devido a sua estrutura ser permanente, seus padrões são estáveis durante toda a vida do ser humano. Além disso, como a íris é uma estrutura externa, as características podem ser extraídas sem a utilização de um método invasivo, facilitando em muito a aceitação dos usuários. 
Os padrões da íris não se modificam com pose, maquiagem ou expressões. Eles também são independentes da carga genética do indivíduo, e podem ser diferentes para cada um dos olhos de uma mesma pessoa. No entanto, a íris é uma estrutura pequena e isso torna difícil sua aquisição a distância, sendo necessário um equipamento apropriado para sua captura.

A sua estrutura também se move com o olhar da pessoa, sendo necessário que o usuário se concentre em um ponto para a aquisição de uma imagem apropriada para a identificação. Devido ao resto da estrutura biológica do olho, também é possível que ocorra oclusão da íris por cílios ou pálpebras e a reflexão da luz utilizada para a captura da imagem.

\subsection{Algoritmo de Identificação Genérico}

O algoritmo genérico de identificação de pessoas por meio da íris pode ser descrito passo a passo pelo fluxograma apresentado na Figura 7.

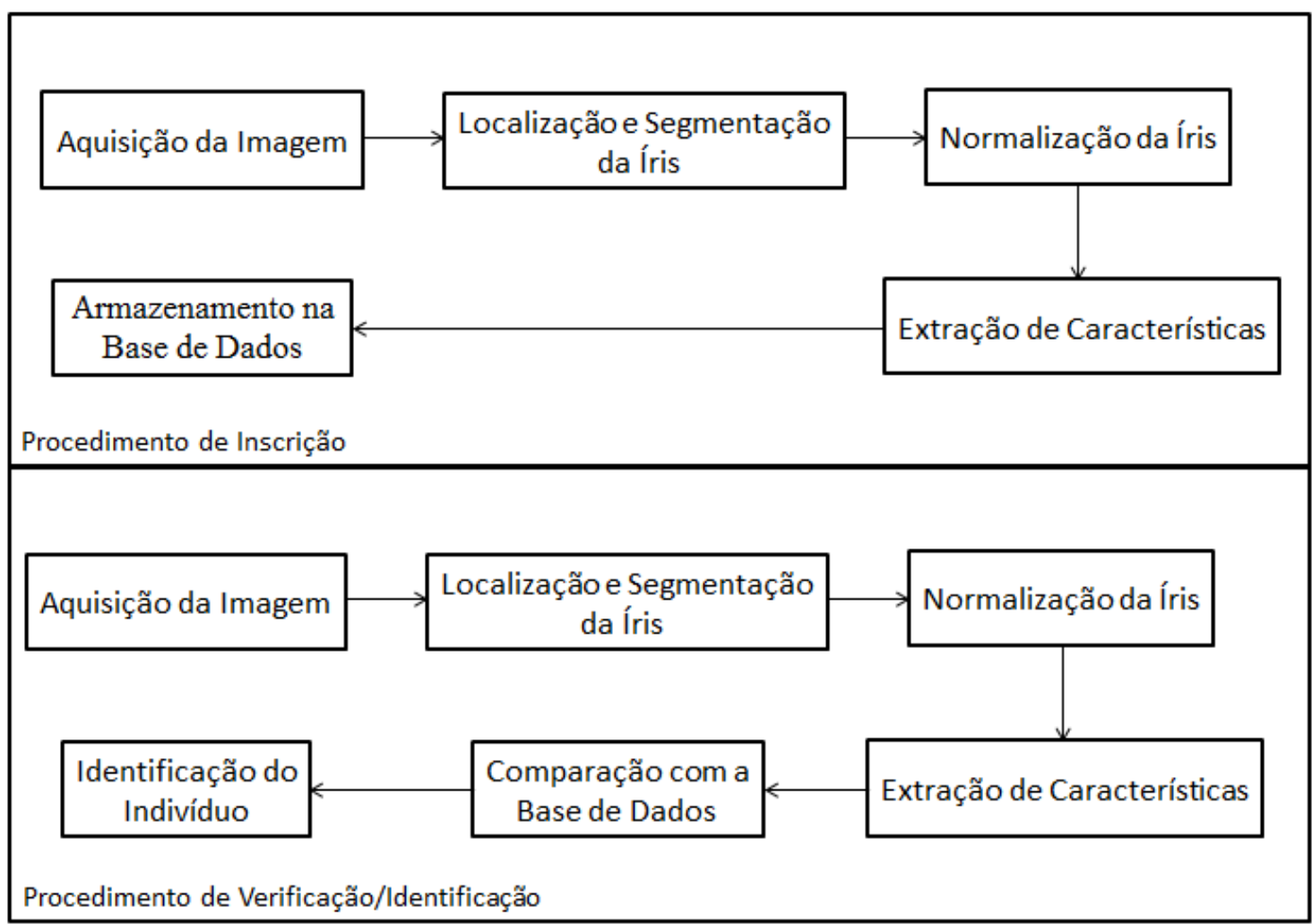

Figura 7 - Modelo Genérico de Identificação pessoal por biometria da Íris. 
O algoritmo é dividido em duas etapas: o Procedimento de Inscrição, no qual a entrada é utilizada para a criação de uma base de dados, essa base será usada posteriormente pela outra etapa, denominada de Procedimento de Verificação/Identificação. Nesta segunda etapa a entrada é utilizada para a classificação do indivíduo como um dos que existem na base de dados adquirida. Cada etapa será explorada superficialmente nesta seção, mais a frente neste documento, as técnicas empregadas serão aprofundadas e explicitadas para maior compreensão.

A Aquisição da Imagem, consiste em adquirir uma imagem adequada para a extração de características durante o procedimento de identificação. São utilizados diversos equipamentos apropriados para fotografar a íris de uma pessoa, como, por exemplo, o Iris Access LG2200 ou Iris Access LG4000. (LGIRIS)

A Segmentação e Localização da Íris, consiste na identificação e segmentação da pupila e da íris utilizando-se de métodos de processamento de imagem tais como binarização, Crescimento de Região e Transformada Circular de Hough. (GONZALEZ; WOODS, 2008)

A Normalização da Íris, é uma transformada geométrica realizada por processamento da imagem capturada que consiste em transformar o disco de textura da íris em uma forma retangular sem que haja uma perda significante de informação. Esta normalização geralmente utiliza o método de Daugman. (DAUGMAN, 2004)

A Extração de Características, consiste na identificação e extração de características capazes de designar uma imagem como pertencente a uma classe dentro de um conjunto de classes pré-determinadas. (JAIN; ROSS; PRABHAKAR, 2004)

Um Banco de Dados armazena diversas referências para a identificação de usuários. Este banco é obtido durante a etapa de registro de usuários e consiste de características biométricas extraídas das imagens de pessoas cadastradas. Tais características são comparadas com as do usuário durante a fase de reconhecimento.

A identificação de indivíduos pode se basear em duas abordagens:

A Verificação consiste na análise da identidade do indivíduo comparando sua entrada com suas próprias entradas armazenadas na base de dados. Em sistemas que operam utilizando essa abordagem, o indivíduo deve clamar sua identidade antes de realizar o processo de verificação. De uma forma mais simples pode ser encarado como: "Esta íris é do Marcos?".

A Identificação consiste em uma comparação de um-para-todos com o intuito de atribuir uma das classes pré-estabelecidas na base de dados à entrada fornecida ao sistema. Esta abordagem não necessita que o indivíduo clame sua identidade antes de utilizar o sistema. $\mathrm{O}$ 
sistema visto de uma forma mais simples pode ser encarado como: "Quem é o indivíduo que possui essa íris?”. (JAIN; ROSS; PRABHAKAR, 2004)

Para realizar a identificação é necessária a etapa de Comparação com a Base de Dados. Esse passo consiste na comparação das características extraídas da entrada com as características armazenadas na base de dados durante o Procedimento de Inscrição. Essa comparação pode ser feita de diversas maneiras, como o cálculo de distância entre vetores de características, o uso de classificadores estatísticos e por redes neurais, além da comparação entre códigos binários como o realizado pelo método de Daugman. (DAUGMAN, 2004)

O trabalho apresentado nesta dissertação envolve tanto o procedimento de Inscrição quanto o procedimento de Identificação presentes na Figura 7. No entanto, a aquisição de imagem é facilitada utilizando-se base de dados já consolidadas, como a CASIA-Irisv2 (IDEALTEST, 2013).

\subsection{Considerações Finais}

A Íris é uma ótima peculiaridade biométrica para identificação de usuários, pois sua capacidade de permanecer praticamente constante durante toda a vida de um indivíduo e sua unicidade permitem que o reconhecimento atinja alta precisão.

Este trabalho propõe utilizar o método LFP para realizar a extração dos vetores de características durante a quarta etapa (Extração de Características) de um sistema de reconhecimento biométrico por meio da íris humana. Com a informação de textura extraída pretende-se classificar íris humanas previamente armazenadas em uma base de imagens com o procedimento de identificação para investigar a capacidade do método LFP como extrator de características discriminantes da íris humana.

As dificuldades de utilizar a íris estão em obter imagens de qualidade que sejam adequadas, pois a oclusão, falta de foco, reflexão e baixa qualidade de iluminação podem causar problemas durante o processamento. A normalização e criação da base de dados pode também ser um passo custoso devido à sensibilidade do algoritmo investigado neste trabalho. 


\section{Material e Método}

Neste capítulo é explicitado o método proposto para localizar a pupila, segmentar e normalizar a região da íris e analisar sua textura com o LFP visando o reconhecimento.

O algoritmo de Reconhecimento de Íris proposto nesse trabalho é representado pelo fluxograma da Figura 8. O processo é dividido em duas etapas, o Procedimento de Inscrição e o Procedimento de Verificação/Identificação. Ambos os processos foram descritos em mais detalhes na seção 3.3 .

O bloco denominado de Imagem de Entrada foi discutida nesse documento pela seção 4.1.

A Localização e Segmentação da Íris foi discutida nesse documento pelas seções 4.2, 4.3, 4.4 .

A Normalização da Íris é discutida nesse documento pela seção 4.5.

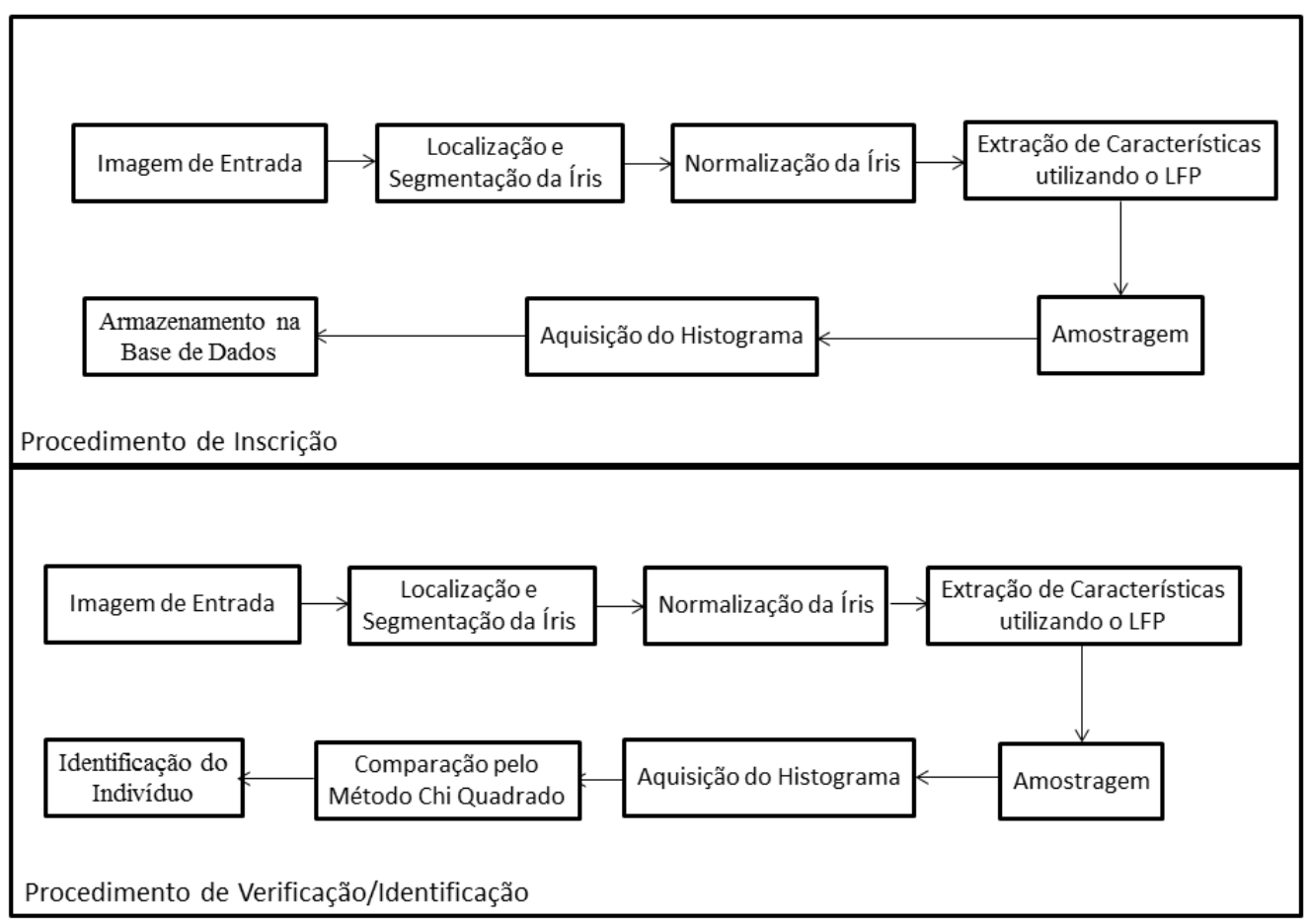

Figura 8 - Fluxograma Proposto do Reconhecimento de Íris. 


\subsection{Banco de Imagens}

Um dos principais desafios no reconhecimento automatizado de íris humanas é a aquisição de imagens com qualidade apropriada para a execução do algoritmo e sem que o processo de aquisição seja invasivo.

As principais preocupações na obtenção de imagens de boa qualidade permeiam entre:

- A resolução da imagem, a qual deve ser o suficiente para que seja possível a extração de dados relevantes à classificação.

- A obtenção de um bom contraste na íris e uma iluminação apropriada para que o processo de segmentação e localização da pupila e íris seja possível.

- Boa centralização da imagem sem a necessidade de um operador.

- Eliminação de ruído, o que facilitará o processo de matching.

As imagens utilizadas neste trabalho foram obtidas utilizando os equipamentos Iris Access LG2200 e Iris Access LG4000 (LGIRIS) pela Universidade de Notre Dame (ND, 2013). Todas as imagens desta base possuem o formato *.tiff com 8bits de níveis de cinza e resolução de 640x480 pixels. Foram utilizadas imagens de íris de 100 pessoas diferentes. Uma imagem dessa base de dados é ilustrada pela Figura 9.

Paralelamente, o trabalho também utiliza a base de dados CASIA-Irisv2 (IDEALTEST, 2013) constituída por imagens em formato *.bmp em níveis de cinza e resolução de 640x480 pixels. Um exemplo de imagem desta base de dados é mostrado na Figura 10. As imagens são todas obtidas com o uso de iluminação na faixa do infravermelho próximo (near infra red). 


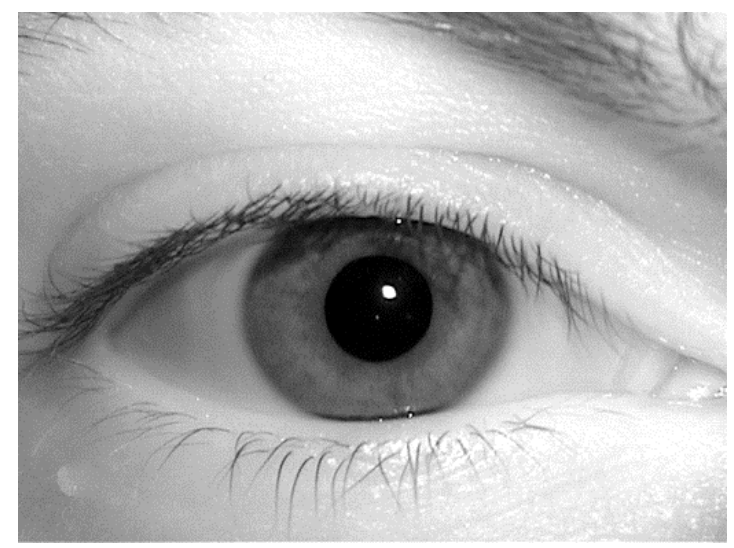

Figura 9 - Exemplo de Imagem da base Iris Access LG2200.

A base de dados CASIA-irisv2 contém imagens geradas por dois equipamentos, onde cada pasta de amostras corresponde a um desses equipamentos. Cada pasta contém sessenta subpastas representando indivíduos e cada indivíduo contribuiu com vinte fotos de olhos. Portanto, a base de dados é totalizada em 2400 imagens de íris humanas.

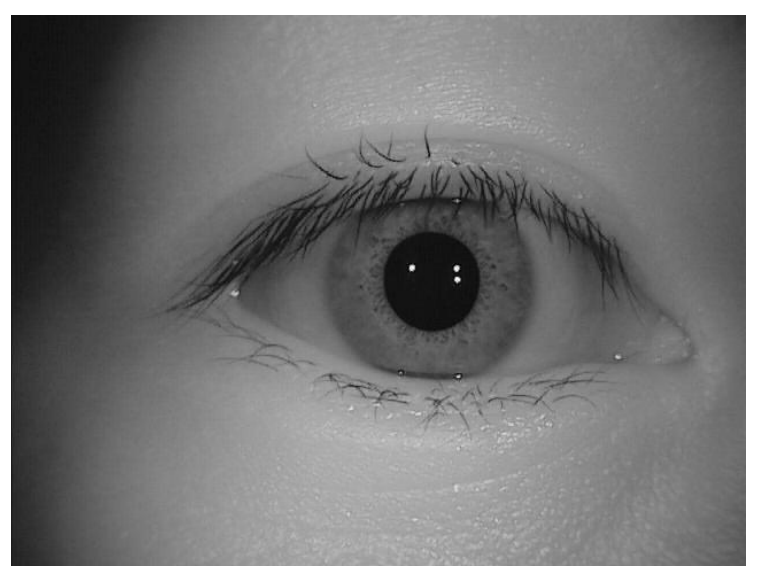

Figura 10 - Exemplo de Imagens da base CASIA-irisv2. 


\subsection{Segmentação da Pupila}

O primeiro passo na extração de características biométricas de um olho humano é localizar a pupila. Esse procedimento é importante para encontrar o limite do raio inferior da íris, facilitando o procedimento de sua segmentação e extração de textura da imagem digital.

Para realizar a segmentação da íris, inicialmente faz-se a binarização da imagem (GONZALEZ; WOODS, 2008). A binarização consiste em saturar os níveis de cinza para um valor inferior e outro superior comparando-os a um limiar de Threshold (T).

Devido à cor negra da pupila humana, a intensidade dos tons de cinza dos pixels pertencentes à pupila de uma imagem digital é baixa, próxima de zero. Com o intuito de melhorar o desempenho da binarização da imagem é realizada uma equalização do histograma da imagem original. (KENNELL; IVES; GAUN, 2006)

Levando em consideração que a pupila humana possui sempre tons negros (próximos do valor de zero), utilizando-se de um histograma médio feito com as imagens da base de dados, é possível determinar um valor adequado para o Threshold $\mathrm{T}$ para que a binarização da imagem forneça como resultado apenas a pupila. A Figura 11 ilustra o histograma médio das imagens utilizadas da base de dados de Notre Dame.

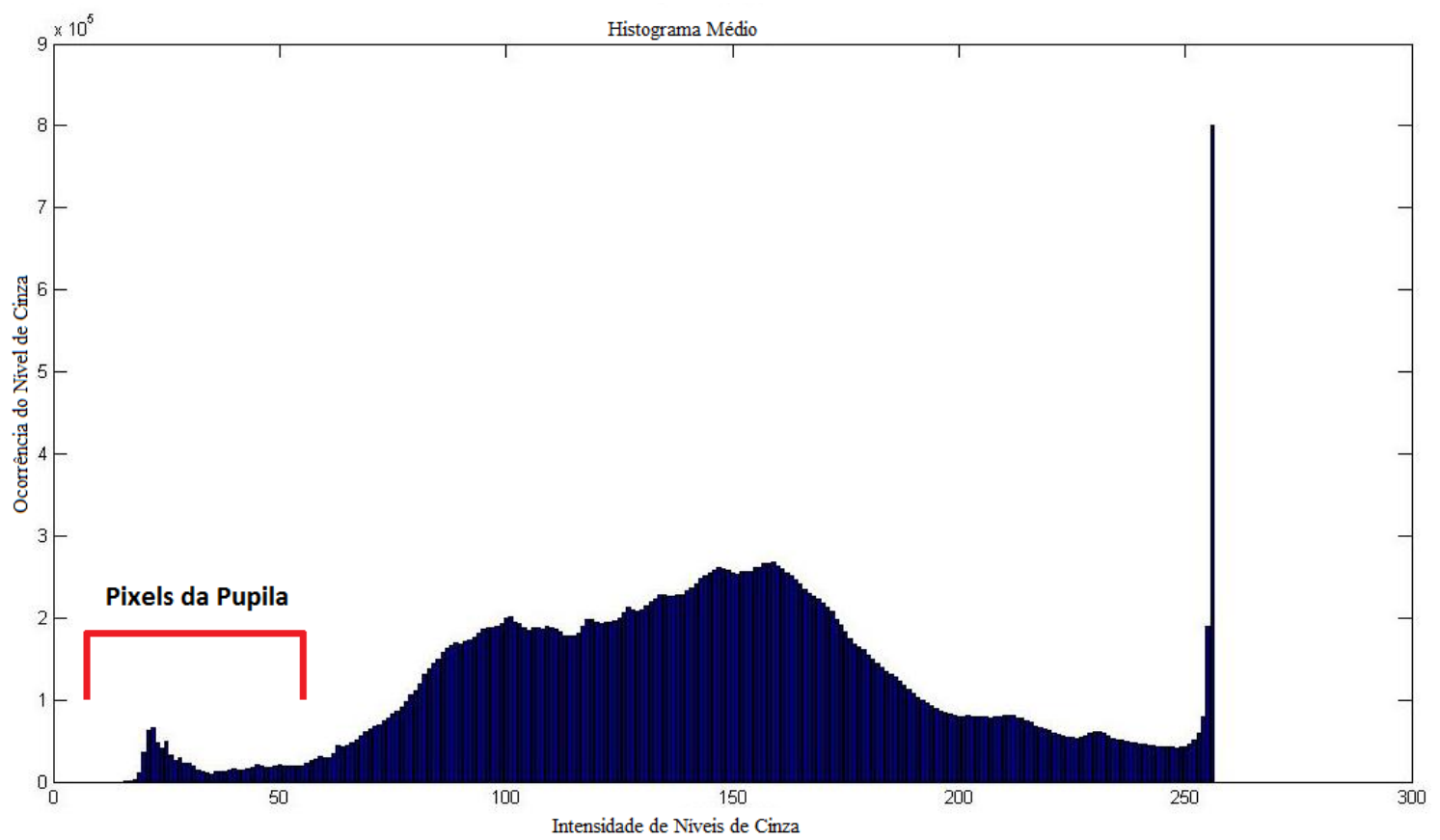

Figura 11 - Histograma Médio de Imagens do Olho Humano da Base de Notre Dame. 
Essa aproximação possui o intuito de facilitar o encontro da pupila sem um processamento complexo para a sua localização, como por exemplo, a utilização da Transformada de Hough. Se a base de dados utilizada for mal comportada em termos de iluminação, recomenda-se estudar um novo limiar $\mathrm{T}$ ou utilizar-se da abordagem por Transformada de Hough.

Com a informação sobre a aproximação de quais pixels de um histograma que constituem a pupila das imagens da base, é necessário formular um método automatizado para a obtenção de um valor de $\mathrm{T}$ para a binarização.

Para resolver esse problema, optou-se por aglutinar os bins do histograma de forma homogênea, ou seja, diminuir o número de bins do histograma sem alterar a sua representatividade: dois bins são somados e então realocadas na média de seus valores.

Transformou-se assim um histograma de 256 bins em um histograma de apenas 5 bins. Utilizando-se desse histograma, é escolhido o valor do primeiro de seus bins (o mais próximo do zero) como o valor limiar T para a binarização da imagem do olho humano. A Figura 12 ilustra o processo de binarização da pupila.

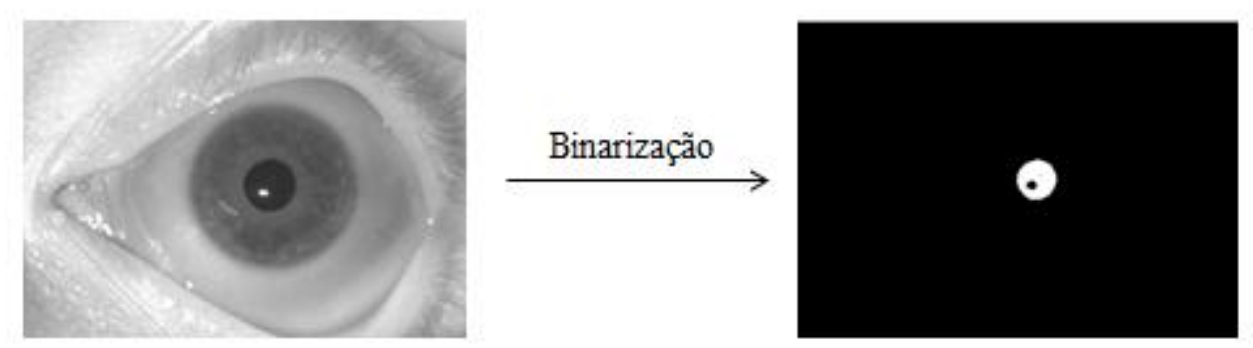

Figura 12 - Binarização da Pupila.

Para a localização da borda da pupila também é necessária a obtenção das coordenadas do centro e do raio da pupila. Para adquirir essa informação optou-se por aplicar o método connected component labeling. Este é um algoritmo utilizado para extração de regiões (ou áreas) de uma imagem, tornando possível a obtenção do raio e do centro da pupila segmentada. (GONZALEZ; WOODS, 2008)

O connected component labeling é um algoritmo que varre a imagem em busca de regiões. Seu funcionamento consiste na varredura pixel a pixel e a comparação de um pixel com 
seus vizinhos (4-conectividade ou 8-conectividade) procurando casos onde haja a mesma intensidade de níveis de cinza. Esse nível de intensidade pode ser um intervalo de valores, facilitando assim o funcionamento do algoritmo.

Uma vez encontradas as regiões da imagem, o algoritmo retorna as coordenadas dos pixels pertencentes a cada uma das regiões. Algumas versões do método podem até colorir ou circundar a região encontrada, facilitando a compreensão visual do usuário. A Figura 13 exemplifica o funcionamento do connected component labeling.

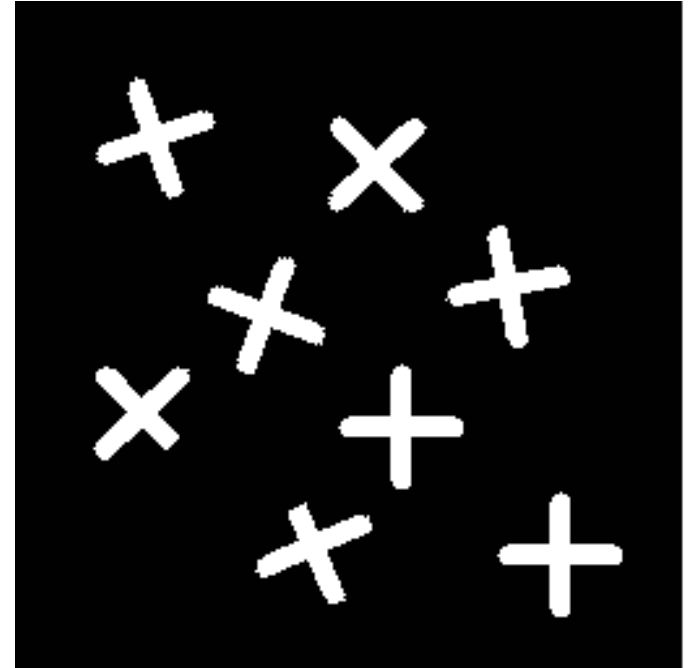

Imagem Original

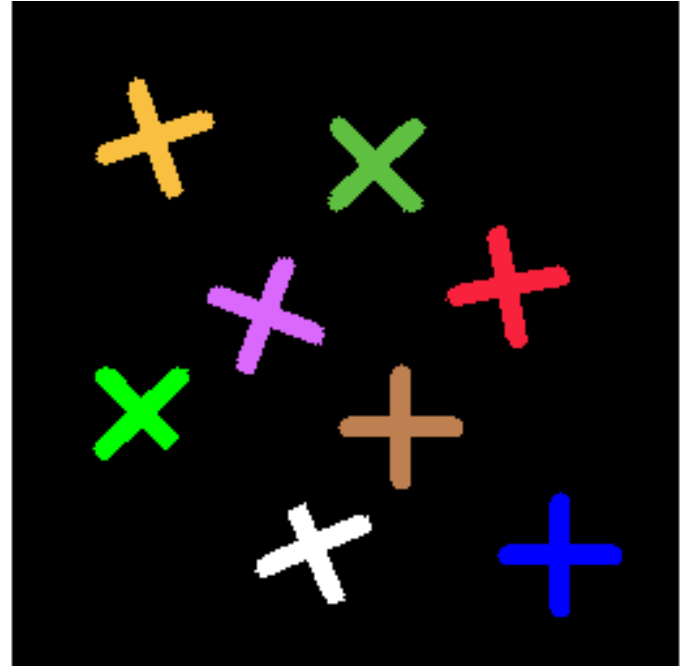

connected component labeling

Figura 13 - Funcionamento do método Connected Component Labeling.

Uma vez obtida tal região e as coordenadas dos pixels pertencentes a ela, calcula-se o centro de massa e as coordenadas do centro da pupila. O cálculo do centro de massa é dado pelas equações (4.1) e (4.2).

$$
\begin{aligned}
& \bar{x}=\frac{\sum_{x=1}^{n} \sum_{y=1}^{n} x * I(x, y)}{\sum_{x=1}^{n} \sum_{y=1}^{n} I(x, y)} \\
& \bar{y}=\frac{\sum_{x=1}^{n} \sum_{y=1}^{n} y * I(x, y)}{\sum_{x=1}^{n} \sum_{y=1}^{n} I(x, y)}
\end{aligned}
$$


nas quais $(x, y)$ são as coordenadas dos pixels de uma imagem e $I(x, y)$ é a intensidade em níveis de cinza do pixel de uma imagem.

O resultado da aplicação das técnicas explicitadas nesta seção é ilustrado pela Figura 14, destacando-se a pupila segmentada de uma imagem digital de íris de olho humano.

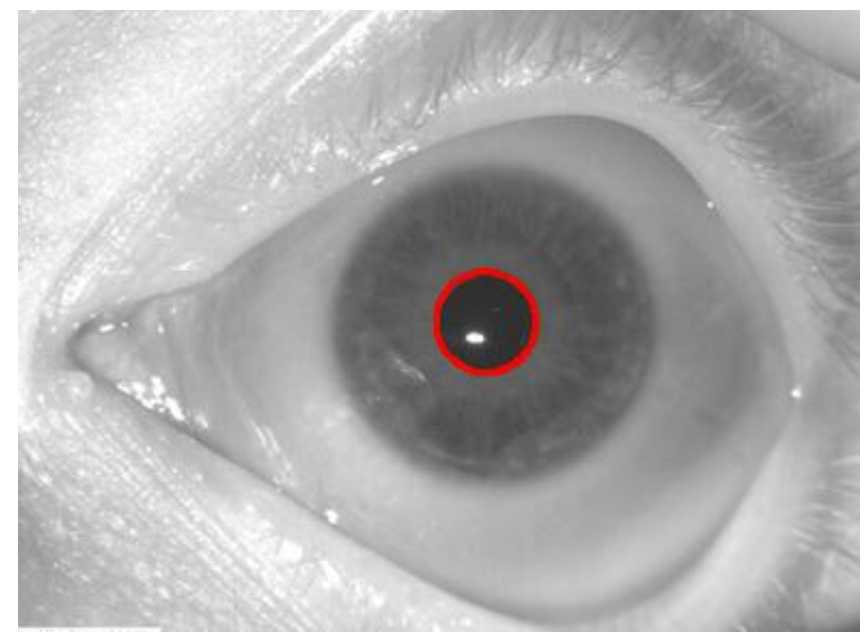

Figura 14 - Segmentação da Pupila.

Um problema que pode ser encontrado na segmentação da pupila é o ruído restante na figura binarizada gerado pelos cílios, pois essa estrutura do olho humano possui tons de cinza muito próximos aos pertencentes à pupila. A Figura 15 exemplifica o ruído existente devido aos cílios em algumas imagens.

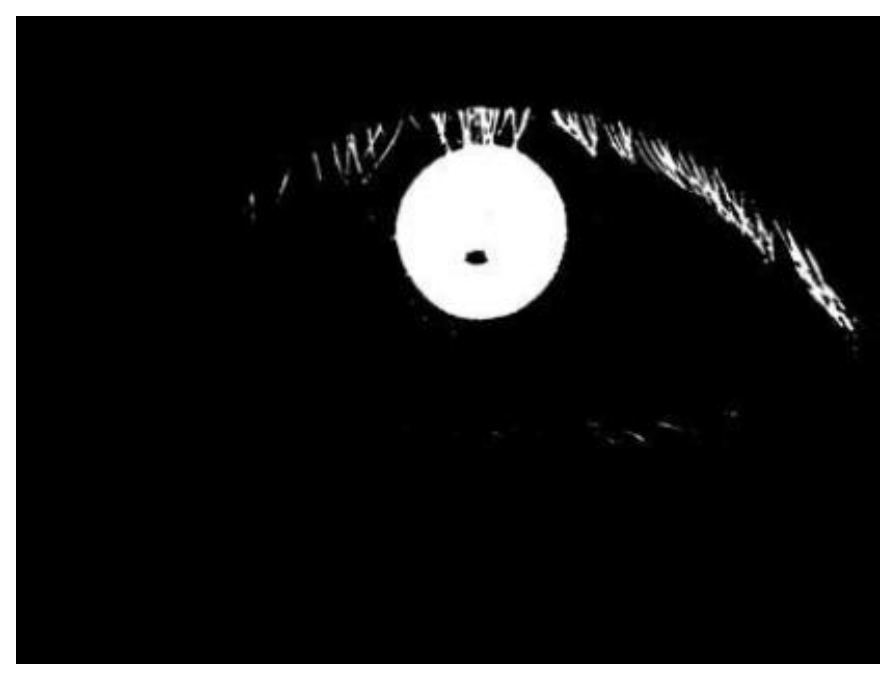

Figura 15 - Ruído devido aos cílios. 
O problema pode ser resolvido utilizando-se um filtro da mediana (filtro passa-baixa) como pré-processamento da imagem para eliminação do ruído (cílios são considerados ruído de alta frequência espectral). $\mathrm{O}$ tratamento do problema também pode ser abordado com o uso de morfologia binária: (1) utilizar-se um fill para complementar os buracos nas massas. (2) Utilizase uma erosion para eliminar boa parte ou todo o ruído. (3) Utiliza-se dilatation para complementar os espaços abertos pela erosão. (KENNELL; IVES; GAUN, 2006)

\subsection{Segmentação da Íris}

A segmentação da Íris é um passo importante para a operacionalização do método. Após a segmentação realiza-se a normalização da íris e após este passo a textura da íris é extraída da imagem.

Para a segmentação, analisa-se o contraste existente entre a íris e a esclera e realizandose a detecção de bordas. Existem diversos métodos na literatura utilizados para a detecção de bordas, todos com vantagens e desvantagens. No entanto, a grande maioria desses métodos pode ser dividida em dois grandes grupos: métodos laplacianos e métodos gradiente.

Métodos gradiente caracterizam a borda de uma imagem por meio da verificação de máximos e mínimos da primeira derivada da imagem. Métodos laplacianos caracterizam a borda de uma imagem buscando os locais onde há o cruzamento por zero nas segundas derivadas de uma imagem.

Para a escolha do detector de bordas utilizado para a segmentação da íris, realizou-se um breve estudo empírico para se encontrar o filtro que gerasse o resultado com menor ruído e maior eficiência.

Para as bases de dados utilizadas neste trabalho, optou-se pelo método de detecção de bordas de Canny. O método de Canny introduzido em 1986 (CANNY, 1986) é baseado no laplaciano da gaussiana. (RASHAD et al., 2011)

No entanto, apenas a detecção de bordas não é o suficiente para realizar a segmentação da íris de uma imagem digital de um olho humano. É necessário um pré-processamento já que em muitos casos resta uma grande quantidade de ruído na imagem após o processamento com o filtro de Canny. Esse ruído decorre do fato de haver muitos detalhes característicos da pele e dos cílios. A Figura 16 exemplifica um resultado utilizando-se somente a técnica de Canny. 


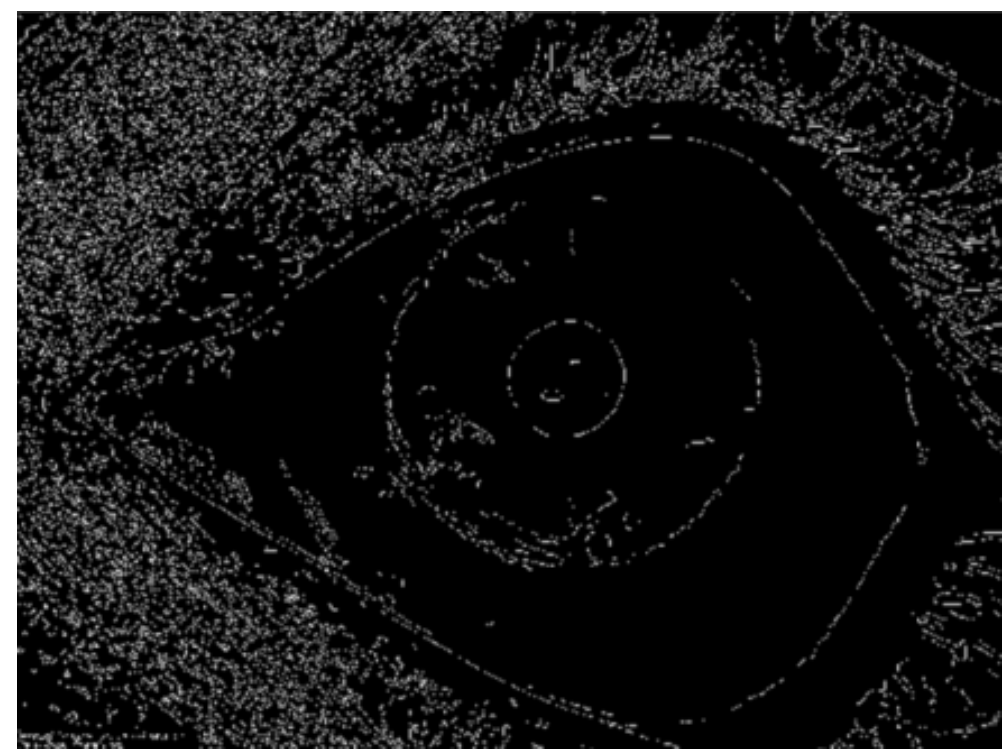

Figura 16 - Imagem filtrada por Canny sem um pré-processamento.

É necessária a aplicação de um pré-processamento para tratar as imagens da íris eliminando os ruídos que acontecem devido aos contornos da pele e dos cílios do olho, facilitando assim a detecção de bordas pelo método de Canny. Para o caso das imagens de íris utilizadas neste trabalho foram suavizadas por um filtro da mediana.

É perceptível pelos testes que a escolha do tamanho da matriz utilizada pelo filtro da mediana é um fator de impacto durante a realização deste pré-processamento. Há duas possíveis abordagens utilizando filtros com janela maiores ou menores. A primeira abordagem, utilizando filtros de janelas maiores, consiste em utilizar um filtro de mediana com janela grande (maiores que 15x15) e utilizar apenas uma iteração de filtragem para buscar o resultado desejado.

A segunda abordagem, utilizando filtros de janelas menores, consiste em utilizar um filtro de mediana com janela pequena (menores que 10x10). Porém, diferente da anterior, o processo consistirá de diversas iterações de filtragem ao invés de apenas uma.

O resultado de ambas as abordagens pode ser visualizado na Figura 17. 


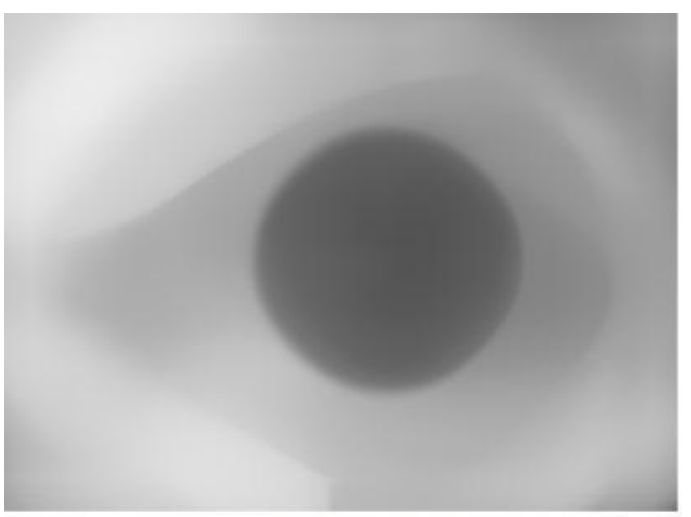

Filtro de janela grande

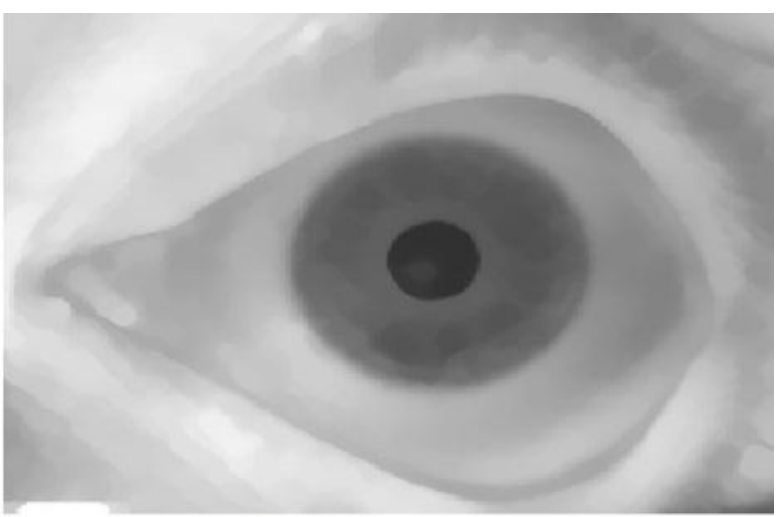

Iterações com filtro de janela pequena

Figura 17 - Comparação visual de pré-processamento utilizando filtro da mediana.

Os resultados obtidos com as imagens da base de íris de Notre Dame indicaram um melhor desempenho para os filtros com janelas pequenas $(7 \mathrm{x} 7)$ e iterações sequenciais. Utilizando o detector de bordas de Canny na imagem filtrada é possível obter-se a borda exterior da íris, conforme mostra a Figura 18.

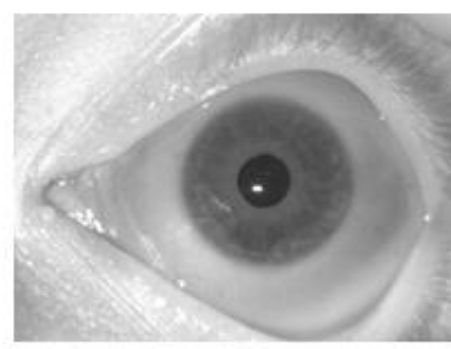

Pré-processamento

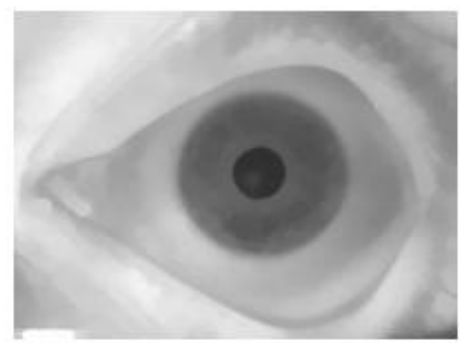

Detecção de bordas por Canny

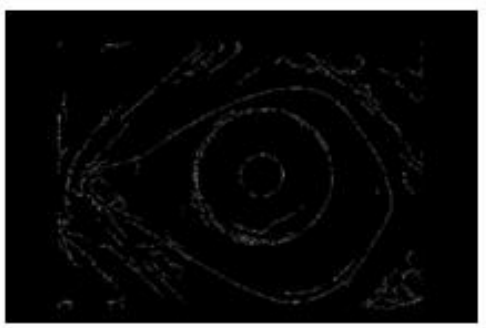

Figura 18 - Resultado do método de detecção de bordas. 
A íris é segmentada usando-se a circunferência interior (centro e raio da pupila) e a Transformada de Hough para círculos (DUDA; HART, 1972) para se obter o raio e o centro de sua circunferência exterior.

A Figura 19 exemplifica o resultado final do processo de segmentação da íris de uma imagem digital.

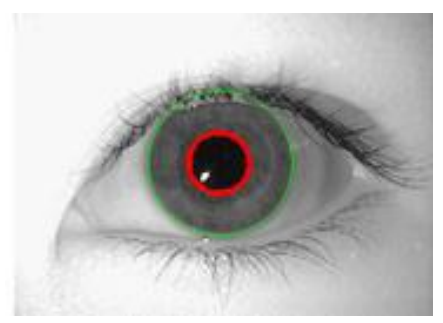

Figura 19 - Iris e Pupila Segmentadas.

\subsection{Eliminação do Ruído Anatômico}

Devido à natureza do olho humano, muitas vezes durante a aquisição da textura da íris, a própria íris pode sofrer oclusão devido aos cílios e/ou as pálpebras. Infelizmente para o processamento de imagens, a oclusão pode causar muitos problemas durante o processo de classificação das imagens. Portanto, é de suma importância que a imagem seja tratada de maneira a remover ou minimizar o ruído anatômico

Implementou-se um procedimento automatizado para a remoção do ruído anatômico das imagens de íris.

O primeiro passo para a eliminação deste tipo de ruído é encontrar o local do olho onde mais provavelmente ele possa ocorrer. Esse processo consiste em encontrar os limiares entre o olho e as pálpebras usando-se a Transformada de Hough, mas dessa vez na sua forma linear.

Após a segmentação da íris e da pupila o algoritmo processa o resultado e realiza dois recortes na imagem original com o intuito de se obter duas imagens menores contendo a pálpebra superior em uma delas e a pálpebra inferior em outra. A Figura 20 exemplifica o resultado dos recortes. 


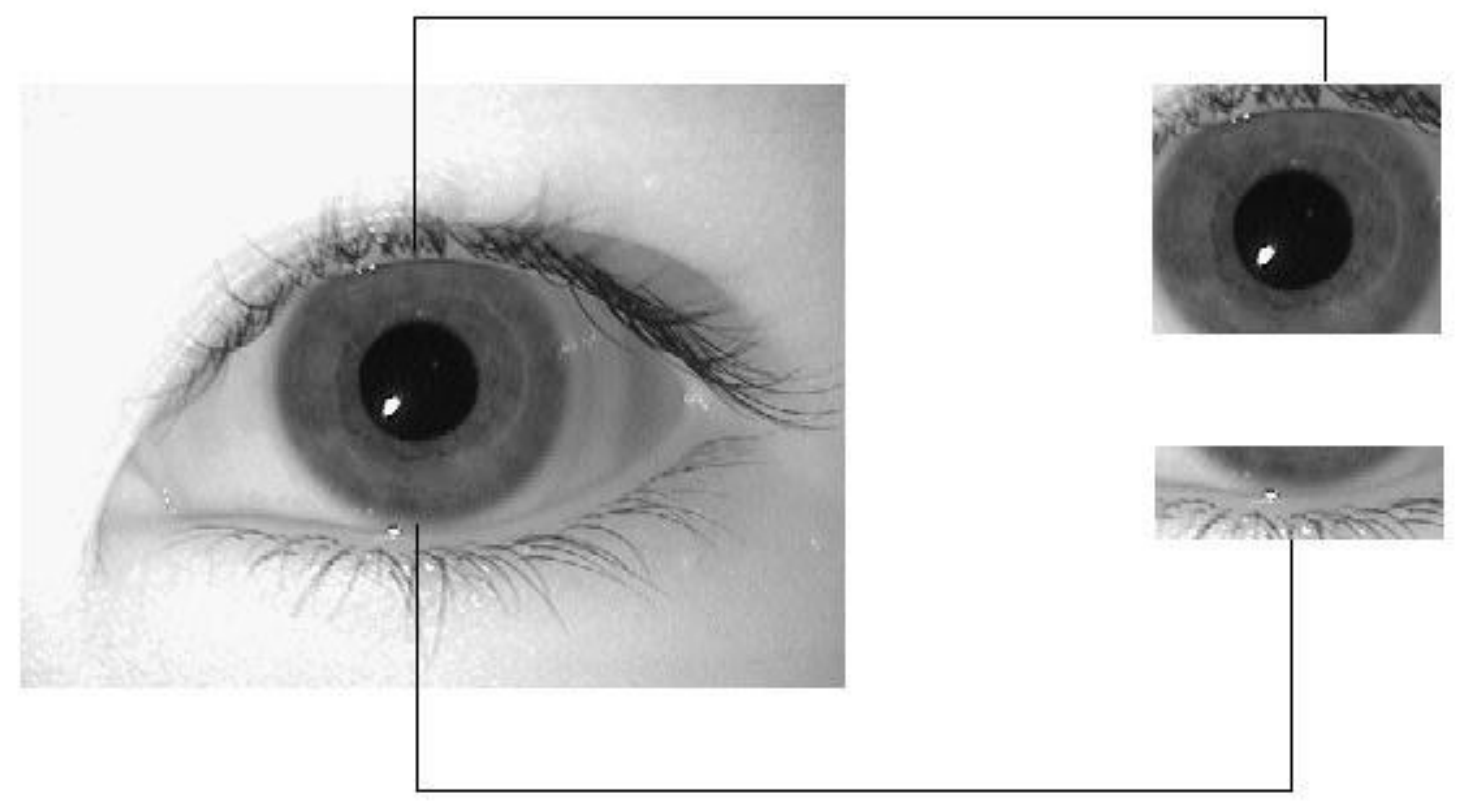

Figura 20 - Extração da pálpebra superior e inferior.

Tudo acima da pálpebra superior e abaixo da pálpebra inferior é removido e considerado ruído. Para realizar essa remoção, todos os pixels pertencentes às áreas de ruído são saturados para o preto. A Figura 21 exemplifica a remoção de ruído, onde se encontram os pontos de interesse na imagem do olho para a inserção de uma máscara de ruído, eliminando-se assim o ruído anatômico.

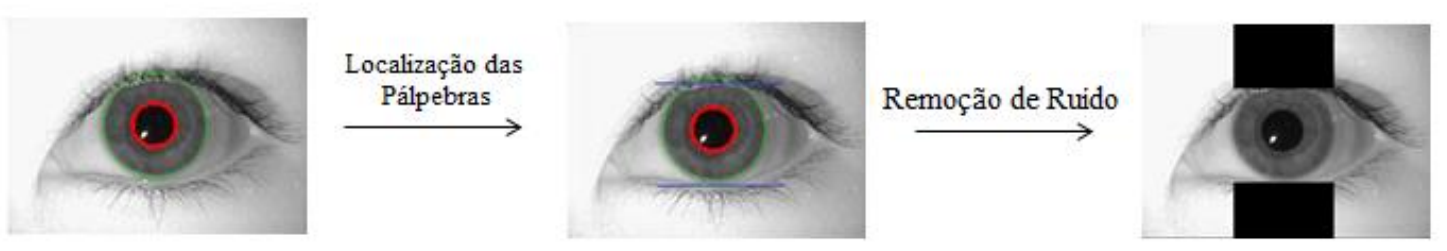

Figura 21 - Remoção do Ruído. 


\subsection{Normalização da Íris}

A textura da íris está concentrada no formato de disco ocasionado pela fisiologia humana. Mostra-se necessário um processamento da imagem dessa textura com o intuito de transformá-la em um formato linear para facilitar os algoritmos de análise.

Essa técnica de linearização do disco de textura da íris é chamado de Normalização da Íris e tem como objetivo a sua transformação em uma imagem retangular que represente a textura sem perdas significativas de informação. Para a normalização utilizam-se coordenadas polares, o que facilita a manipulação dos pontos do disco. Sua escolha é feita devido à íris e a pupila poderem ser aproximadas a círculos. A equação que rege a normalização é expressa pela equação (4.3).

$$
P(r, \theta)=(1-r) * P_{\text {pupila }}(\theta)+r * P_{\text {límbico }}(\theta)
$$

na qual $P(r, \theta)$ é a combinação linear dos pontos que estão entre as bordas da pupila com até os pontos que são delimitados pela borda da íris e a esclera. $P_{\text {pupila }}(\theta)$ representa a borda da íris em contato com a pupila e $P_{\text {límbico }}(\theta)$ representada a borda da pupila com a esclera. $r$ é o raio do disco que contém a textura da pupila e $\theta$ representa o ângulo.

Este método de normalização é conhecido na literatura como Daugman's Rubber Sheet (DAUGMAN, 2004). O número de pontos extraído depende somente do número de passos escolhidos para as variáveis livres $\theta$ e $r$. O retângulo resultante possuirá altura igual a $r$ e comprimento igual a $\theta$. A Figura 22 representa a o disco da íris e as variáveis envolvidas na normalização. 


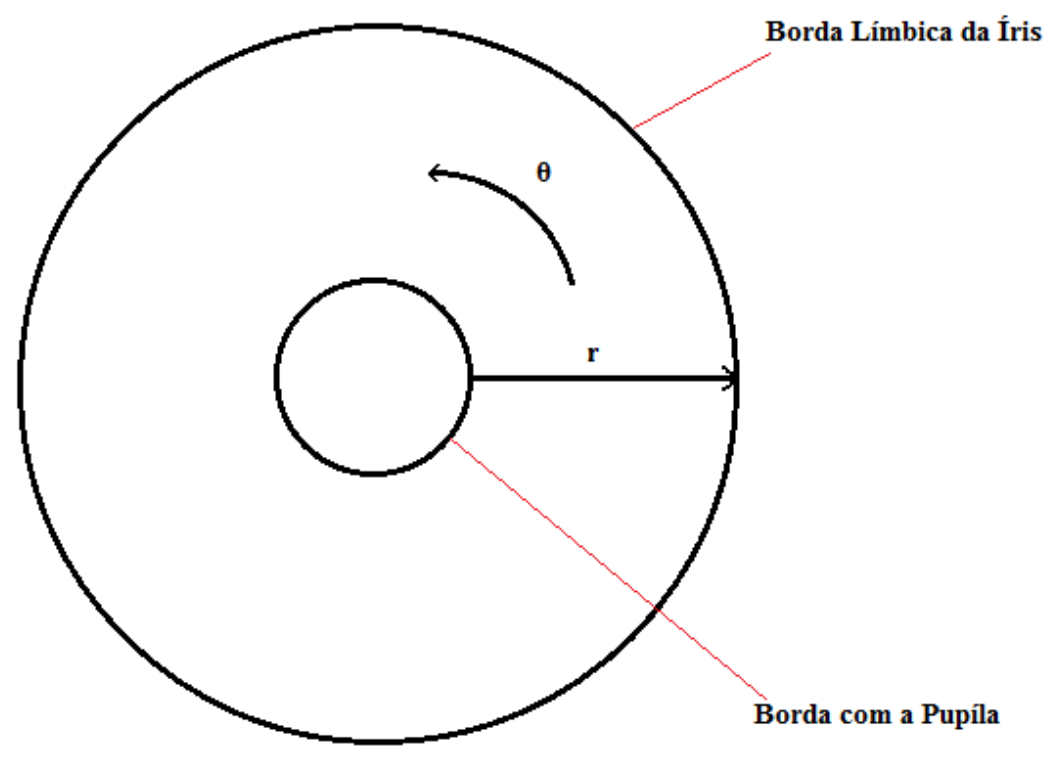

Figura 22 - Daugman's Rubber Sheet.

Para o trabalho, utilizou-se amostragem em $r$ de 60 passos igualmente espaçados e uma amostragem em $\theta$ de 240 passos igualmente espaçados, gerando assim uma imagem 240x60 pixels.

Com a normalização da íris obtém-se a textura de forma linear conforme mostra a Figura 23. Este retângulo que contém a íris normalizada deverá ser amostrado para se obter o conjunto de treinamento e o conjunto de testes do algoritmo a ser proposto neste trabalho.

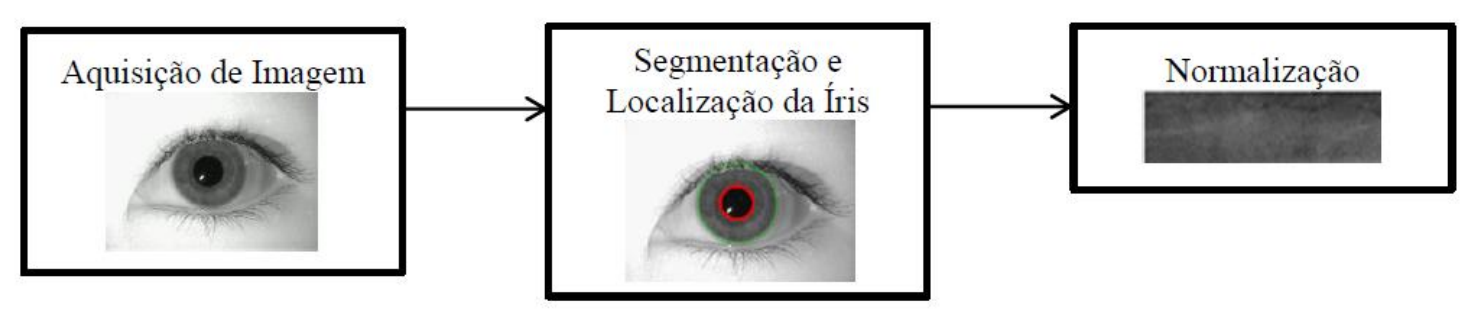

Figura 23 - Normalização da íris. 
Devido ao ruído inserido na imagem em alguns casos, como explicitado na seção 4.4, é necessária a criação de uma máscara para a identificação de pontos onde há ou não pixels saturados.

As Figura 24 e Figura 25 exemplificam uma textura normalizada com pixels saturados e sua máscara de ruído (cílios e pálpebras). Durante o processo de amostragem, o algoritmo deve verificar se as amostras retiradas da textura não estão contaminadas pelos pixels saturados. Esse processo é feito verificando-se se a amostra apresenta valores não numéricos de pixel ( $N a N$ no caso de MatLab, null no caso de OpenCV).

O ruído inserido é utilizado para evitar amostragem de ruídos anatômicos, como os cílios e a esclera. Diversas vezes a inserção dessas características do olho não pode ser evitada devido ao caráter automático do algoritmo de normalização da Íris.

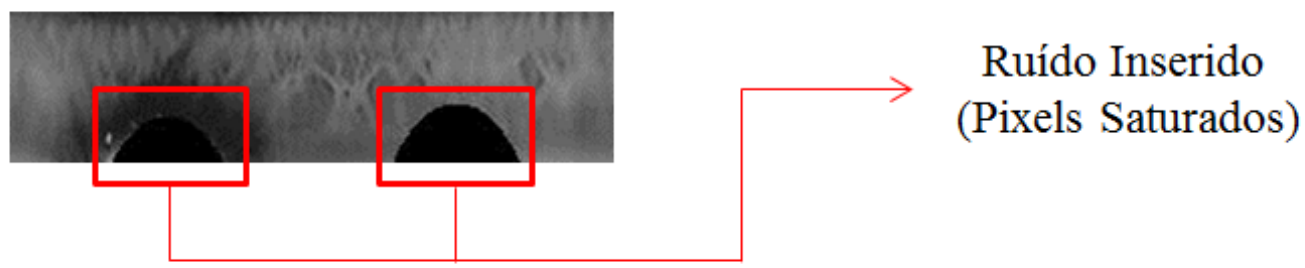

Figura 24 - Textura resultante com pixels saturados.

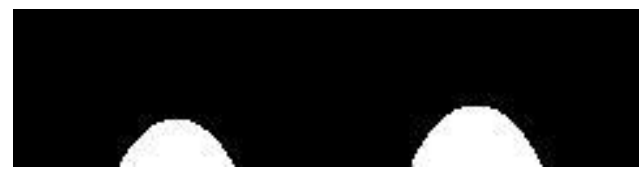

Figura 25 - Máscara para localização do ruído. 


\subsection{Reconhecimento de Íris}

\subsubsection{Amostragem}

O objetivo da amostragem é a coleção de diversas regiões de diferentes imagens da íris para a formação de um banco de amostras das imagens das íris humana. Essa base de amostras servirá de suporte para a classificação de uma nova imagem apresentada ao sistema.

A amostragem é utilizada, pois o descritor de texturas LFP provou ser mais eficaz conforme é maior o número de amostras. (TAVARES, 2013)

O tamanho de uma íris normalizada neste trabalho é de 240x60 pixels. Portanto, levando-se em consideração os pixels saturados inseridos e a necessidade de diversas amostras por imagem utilizou-se 50 amostras de tamanho de $25 \times 25$ pixels e a retirada aleatória de qualquer posição da imagem. Deve ser levado em consideração a máscara de ruído, utilizada para retirar o ruído anatômico algumas vezes presente na imagem da íris. Tal máscara foi explicada na seção 4.5 deste documento e utilizada durante a amostragem para evitar amostras inválidas.

A Figura 26 apresenta um procedimento de amostragem em uma textura de íris.

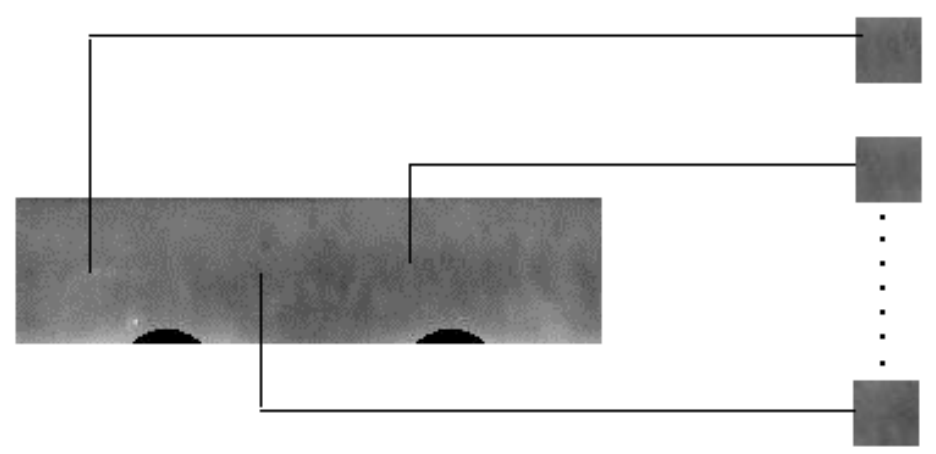

Figura 26 - Amostragem da textura de íris.

\subsubsection{Extração de Características}


Um descritor pode ser definido como um vetor de características extraídas de uma imagem como cor, textura, forma, entre outros. O descritor deve ser capaz de classificar uma imagem como pertencente ou não pertencente a uma classe quando comparado a outro descritor de classe previamente conhecida. Se o descritor for suficientemente próximo do descritor comparado, ele deve ser classificado como pertencente à classe. Se o descritor for muito discrepante do descritor comparado, ele deve ser classificado como não pertencente à classe.

A proposta deste trabalho é utilizar como descritor de textura da íris o histograma resultante de uma amostra $25 \times 25$ após ela ser tratada pelo método Local Fuzzy Pattern (TAVARES et al., 2012). O tratamento dessas amostras é realizado utilizando-se uma janela $3 x 3$ píxels em conjunto com uma Matriz de Pesos 3x3 todos de valor igual a 1 . Após o processamento com o método Local Fuzzy Pattern, a imagem resultante terá a resolução de $23 \times 23$ pixels, pois, devido ao método operar com janelas, a borda da imagem não é processada.

Como os resultados numéricos do $L F P$ explicitados na seção 2.6 .3 possuem valores no intervalo $[0,1]$ estes são quantizados e arredondados para representarem números inteiros no intervalo $[0,255]$ representando intensidades de nível de cinza na forma de um histograma, dado pela equação (4.4).

$$
\text { Intensidade }=\operatorname{round}\left(255 * L F P_{\text {code }}\right)
$$

na qual round é a função que aproxima o número real para o natural mais próximo, $L F P_{\text {code }}$ é o valor entre $[0,1]$ resultante do cálculo do LFP. A Figura 27 exemplifica o processo de geração do descritor, sendo uma amostra processada pelo LFP e da imagem resultante retira-se o Histograma, o qual será utilizado como vetor características neste trabalho.

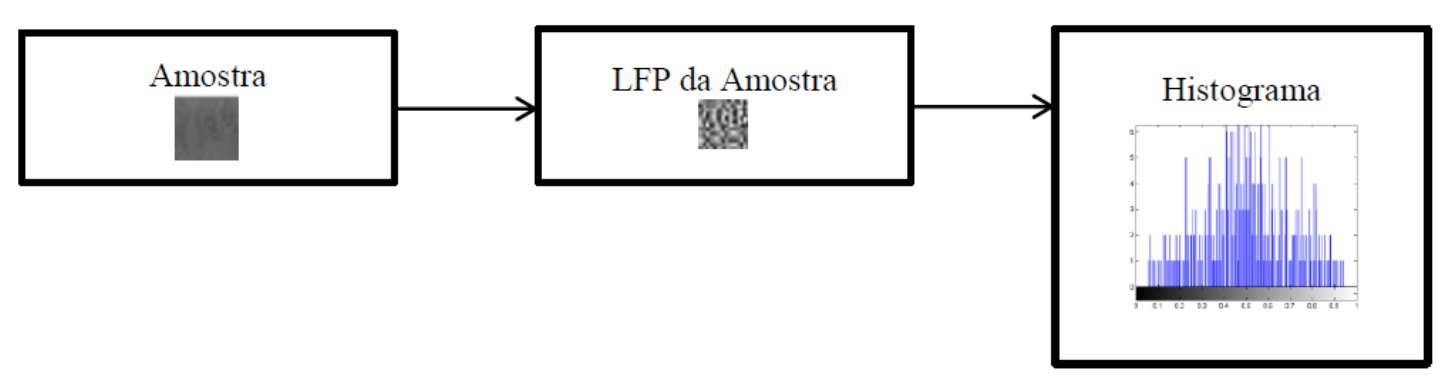

Figura 27 - Modelo de extração do descritor. 


\subsubsection{Classificação das amostras}

A comparação entre descritores pode ser realizada por meio de métricas de distâncias. Diversas métricas podem ser utilizadas tais como a distância euclidiana, a distância de Mahalanobis, a distância chessboard, dentre outras. Neste trabalho será utilizada a comparação entre dois histogramas com a distância Chi Quadrado (PELE; WERMAN, 2010). A distância Chi Quadrado compara todos os bins de um histograma seguindo a equação (4.5).

$$
\frac{1}{2} \sum_{i=1}^{256} \frac{\left(H_{\text {referência }}(i)-H_{\text {comparação }}(i)\right)^{2}}{H_{\text {referência }}(i)+H_{\text {comparação }}(i)}
$$

na qual $i$ refere-se a cada bin dos histogramas.

\subsection{Considerações Finais}

Neste capítulo foram apresentados o material e a metodologia adotados para a realização deste trabalho.

É relevante ressaltar que os métodos discutidos dentro deste capítulo não são aplicáveis a todas as bases de dados de íris humana e alguns ajustes podem ser necessários para que o algoritmo possua um bom desempenho.

Algumas íris utilizadas como entrada, por exemplo, podem não ser normalizadas com sucesso. Fatores que podem causar esse resultado são: falta de foco, oclusão excessiva da íris, iluminação, rotação e baixa qualidade da imagem. Muitas vezes torna-se necessário a remoção de parte do banco da íris que causa o mal comportamento do sistema para impedir que amostras não válidas contaminem o banco de amostras.

A metodologia proposta nesse capítulo também não busca um processamento computacional rápido. O objetivo é analisar a capacidade do descritor LFP de classificar íris humanas em um conjunto, portanto o esforço computacional não foi levado em consideração para a elaboração da metodologia.

Os códigos escritos para a metodologia estão na linguagem do Software MATLAB (*.m) e são apresentados nos APÊNDICES A, B, C e D. 


\section{Resultados e Conclusões}

Este capítulo mostra os resultados obtidos durante a realização do trabalho e as conclusões obtidas.

Os resultados incluem:

- Normalização e testes com a base da Universidade de Notre Dame.

- Normalização e testes com a base de dados CASIA-irisv2.

- Treinamento para a base CASIA-irisv2.

- Comparações com os resultados obtidos pelo descritor LBP.

\subsection{Normalização da Íris}

A Normalização da Íris obteve como resultado a normalização da porção utilizada da base de dados de Notre Dame e da base de dados CASIA-irisv2.

Devido ao grande número de imagens existentes nas duas bases não é possível incluir neste documento todos os resultados envolvendo a normalização de íris geradas ao decorrer do trabalho. A Figura 28 mostra alguns resultados visuais obtidos.

\begin{tabular}{|c|c|c|c|}
\hline $\mathbf{N}^{\mathbf{0}}$ & Imagem Original & Imagem Segmentada & Íris Normalizada \\
\hline 1 & 0 & 0 & \\
& & & \\
& & 0 & \\
2 & & 0 & \\
\hline
\end{tabular}




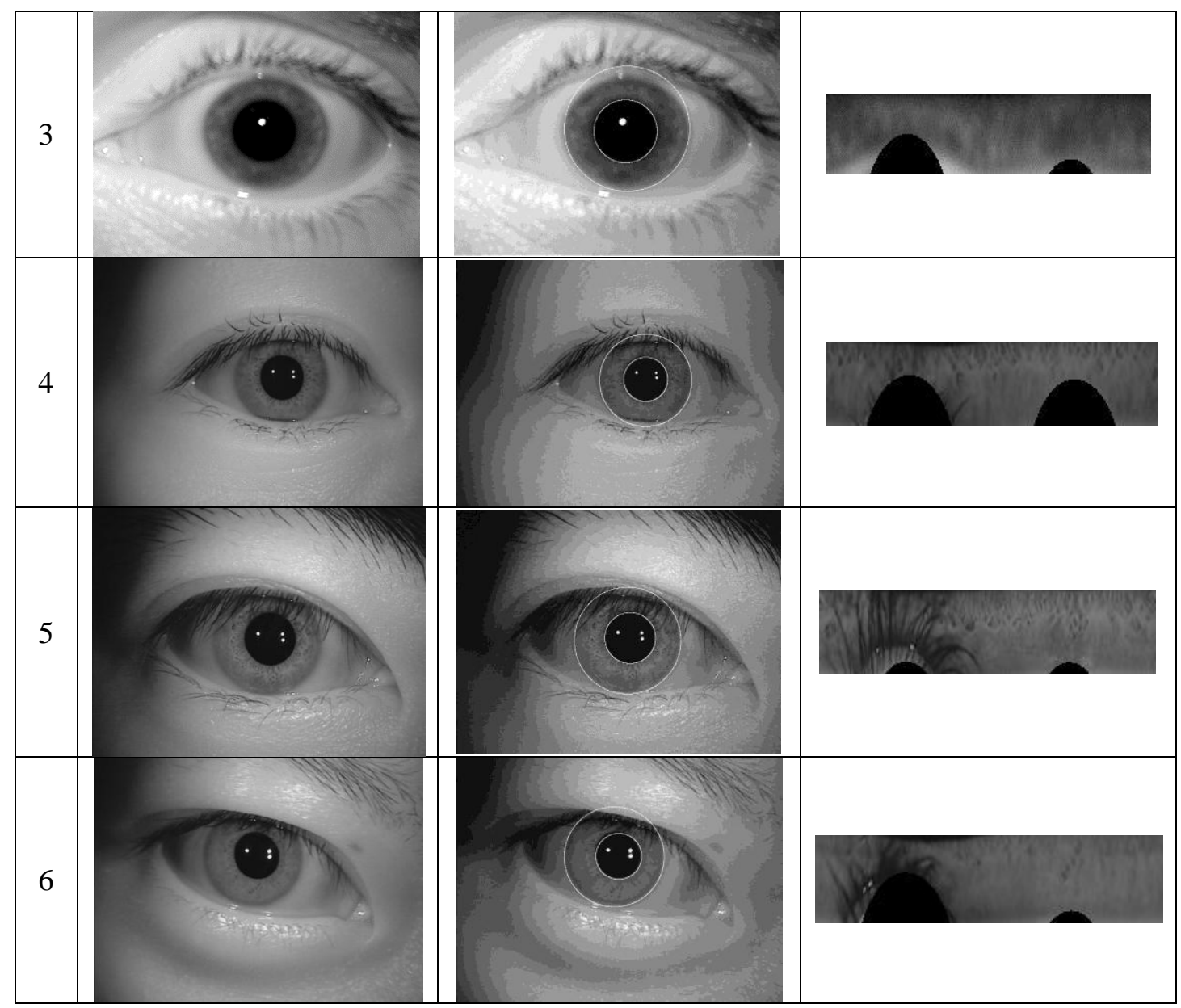

Figura 28 - Resultados visuais de Íris Normalizadas.

Pode-se observar na Figura 28, íris número 2, que apesar de utilizar-se do procedimento de tratamento para o ruído anatômico apresentado na Seção 4.4, há a presença na imagem da íris normalizada de partes da esclera do indivíduo. O resultado obtido com a íris número 5 também apresenta ruído anatômico, como a grande interferência dos cílios e também uma parte da pele. A Figura 29.A mostra o ruído anatômico para a íris número 5 enquanto a Figura 29.B mostra o ruído anatômico para a íris número 2: 


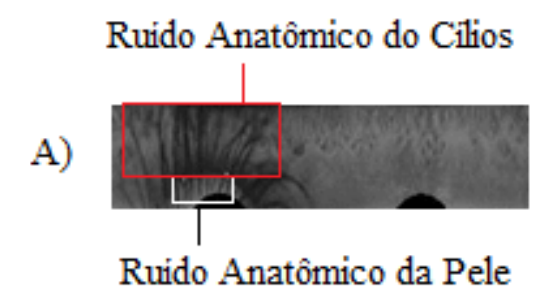

B)

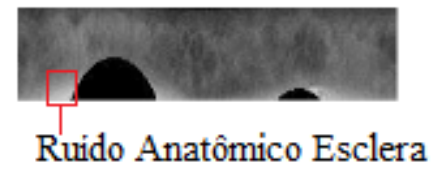

Figura 29 - Ruído Anatômico

Um revés do método automatizado de normalização de íris é que apesar de toda a calibração para a remoção do ruído, é inevitável a convivência com parte dele. Esse ruído pode influenciar na classificação das amostras, tornando o desempenho menor. No entanto, a maior parte da íris foi capturada com sucesso dentro dessas normalizações, e portanto a imagem ainda pode ser utilizada para classificação de indivíduos.

Após o processamento das imagens, uma análise dos resultados obtidos foi feita e descartou-se imagens as quais o ruído persistiu e inutilizou grande parte da imagem gerada para a íris normalizada.

Durante a execução do trabalho, normalizou-se 500 íris presentes na Base de Dados de Notre Dame. Normalizou-se, também, 46 classes diferentes do CASIA-Irisv2, onde casa classe possuía 20 fotos diferentes da mesma íris, totalizando 920 possíveis imagens geradas.

No entanto, não foi possível normalizar todas as amostras presentes no CASIA, o principal motivo para o descarte foi o fato de algumas imagens resultantes apresentarem ruído persistente ao ponto de inutiliza-la como amostra. Ao todo, gerou-se 695 íris normalizadas para a base de dados CASIA-Irisv2, um aproveitamento de 75,2\% das imagens.

A Tabela 2 apresenta o número de imagens normalizadas para cada uma das duas bases de imagens de íris humanas utilizadas. 
Tabela 2 - Imagens Geradas pela Normalização da Íris

\begin{tabular}{|c|c|}
\hline $\begin{array}{c}\text { Número de Imagem } \\
\text { Notre Dame }\end{array}$ & 500 \\
\hline $\begin{array}{c}\text { Número de Imagens } \\
\text { Geradas } \\
\text { CASIA-Irisv2 }\end{array}$ & 695 \\
\hline
\end{tabular}

\subsection{Influência do Número de Amostras}

O número de amostras é uma variável importante tanto para a sensibilidade quanto para o esforço computacional necessário para a realização do procedimento de classificação. É necessário um balanço entre ambos os resultados desejados caso a aplicação do método busque uma funcionalidade para o dia a dia.

No entanto, o trabalho busca avaliar o desempenho da classificação das íris utilizandose o descritor de textura LFP. Portanto, obteve-se os valores numéricos de sensibilidade para números específicos de amostras dentro da base de dados CASIA-irisV2 como mostra a Tabela 3.

Tabela 3 - Sensibilidade por Número de Amostras

\begin{tabular}{|c|c|c|}
\hline $\begin{array}{c}\text { Número de } \\
\text { Amostras }\end{array}$ & $\begin{array}{c}\text { Sensibilidade } \\
\text { LFP }\end{array}$ & $\begin{array}{c}\text { Sensibilidade } \\
\text { LBP }\end{array}$ \\
\hline 5 & 70,9065 & 67,7248 \\
\hline 10 & 90,518 & 87,8941 \\
\hline 15 & 96,0767 & 93,4179 \\
\hline 20 & 97,7338 & 95,6190 \\
\hline 25 & 98,7971 & 97,8095 \\
\hline 30 & 99,2758 & 98,8190 \\
\hline 35 & 99,5355 & 99,2063 \\
\hline 40 & 99,5827 & 99,5102 \\
\hline 45 & 99,6675 & 99,6190 \\
\hline 50 & 99,7721 & 99,6905 \\
\hline 55 & 99,8326 & 99,7524 \\
\hline 60 & 99,8345 & 99,7749 \\
\hline
\end{tabular}

A sensibilidade mostrada na Tabela 3 foi calculada utilizando a fórmula (6.1) 
Sensibilidade $=\frac{\text { Verdadeiros Positivos }}{\text { Verdadeiros Positivos }+ \text { Falsos Negativos }}$

Interpolando-se os dados dessa tabela se obteve uma curva representativa do comportamento da sensibilidade perante ao número de amostras. A Figura 30 representa o gráfico obtido da função interpolada.

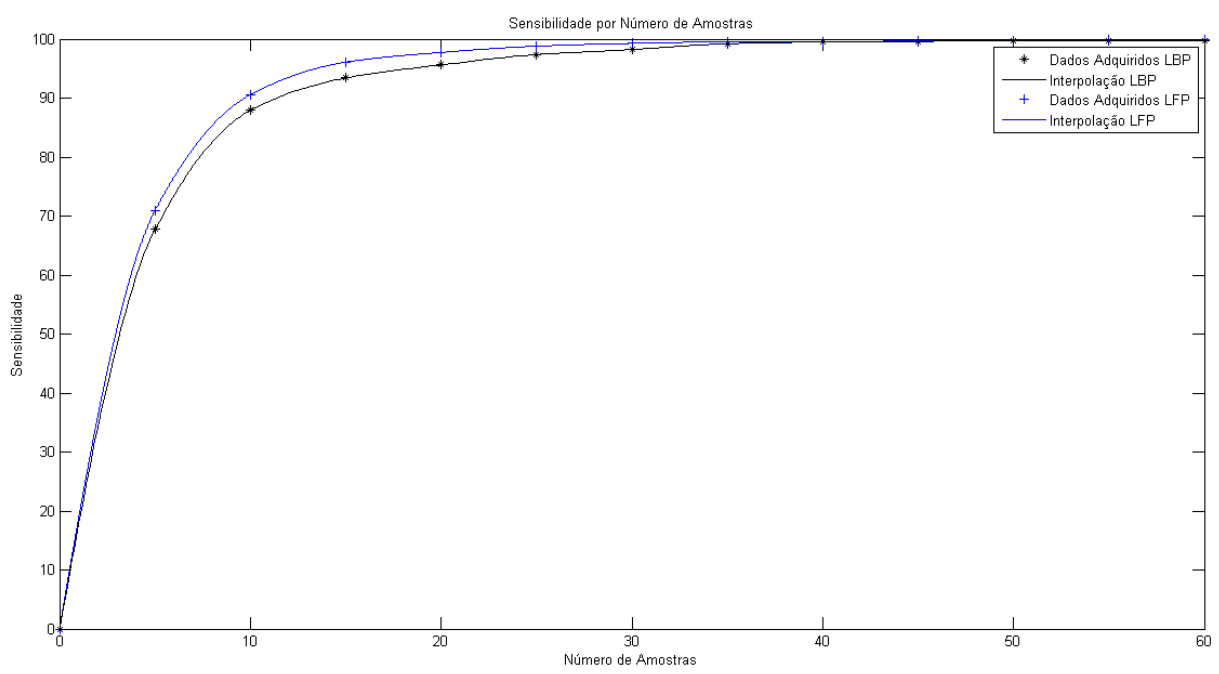

Figura 30 - Gráfico da Sensibilidade dos Classificadores por Número de Amostras

Analisando-se o gráfico obtido e os resultados pontuais, percebe-se que a partir de 35 amostras o algoritmo entra em uma região estabilizada de sensibilidade. A base de Notre Dame foi utilizada para a gerar os primeiros resultados com o LFP e, como suas imagens não são bem comportadas com o CASIA-Irisv2, focou-se em uma análise de como o LFP se comporta no início da estabilização da curva de sensibilidade. Optou-se por 20 amostras buscando também uma agilidade maior na realização dos testes.

Como o esforço computacional baixo não é o foco buscado no resultado final, escolheuse trabalhar com 50 amostras para a base de dados CASIA-Irisv2. Como essa base de dados possui imagens bem comportadas e é amplamente utilizada como referência para testes, o número de amostras foi escolhido por estar na faixa mais estável da curva, possuir um bom índice de sensibilidade e não demandar um esforço computacional inviável como, por exemplo, ao se utilizar 70 amostras. 


\subsection{Classificação em Base de Dados}

Esta seção apresenta os resultados obtidos utilizando as íris normalizadas da base de dados de Notre Dame e a base de dados CASIA-irisv2.

O cálculo da sensibilidade que é mostrada dentre os resultados é realizado pela equação (6.1).

\subsubsection{Base de imagens da Universidade de Notre Dame}

O procedimento de comparação (matching) para a base de dados de Notre Dame foi feito utilizando-se 88 classes de íris, cada uma possuindo cinco imagem distintas e de cada imagem foram retiradas 20 amostras.

Utilizou-se da validação cruzada leave-one-out para realizar a comparação das amostras e aplicou-se a distância chi quadrado entre histogramas. Devido ao tamanho da matriz de confusão ser desproporcional para sua inserção no documento, a Tabela 4 apresenta uma parcela dos resultados obtidos. Um número dentro da matriz de confusão representa quantas amostras da classe representada pela linha foram classificadas dentro da classe representada pela coluna, por exemplo: 99 amostras da Classe 1 foram classificadas como pertencentes à Classe 1 .

A sensibilidade calculada utilizando a matriz de confusão foi de $98,20 \%$.

Analisando a matriz de confusão é perceptível que há classes mais distintas de outras, ocasionando em uma taxa de acerto de $100 \%$. Enquanto há algumas poucas classes com taxa de acerto menor, por exemplo, 94\%. Uma possível explicação para tal comportamento pode ser considerada o ruído que, em alguns casos, não foi possível ser removido pelo processamento proposto na seção 4.4. Algumas íris, apesar de estarem normalizadas ainda apresentam ruídos devido aos cílios não removidos ou parte da esclera capturada pela Transformada de Hough. 
Tabela 4 - Exemplo de parte da Matriz de Confusão para base de imagens de Notre Dame.

\begin{tabular}{|l|c|c|c|c|c|c|c|c|c|}
\hline & Classe 1 & Classe 2 & Classe 3 & Classe 4 & Classe 5 & Classe 6 & Classe 7 & Classe 8 & Classe 9 \\
\hline Classe 1 & 99 & 0 & 0 & 0 & 0 & 0 & 0 & 0 & 0 \\
\hline Classe 2 & 0 & 99 & 0 & 0 & 0 & 0 & 0 & 0 & 0 \\
\hline Classe 3 & 0 & 0 & 100 & 0 & 0 & 0 & 0 & 0 & 0 \\
\hline Classe 4 & 0 & 0 & 0 & 99 & 0 & 0 & 0 & 0 & 0 \\
\hline Classe 5 & 0 & 0 & 0 & 0 & 99 & 0 & 0 & 0 & 0 \\
\hline Classe 6 & 0 & 0 & 0 & 0 & 0 & 100 & 0 & 0 & 0 \\
\hline Classe 7 & 0 & 0 & 0 & 0 & 0 & 0 & 98 & 0 & 0 \\
\hline Classe 8 & 0 & 0 & 0 & 0 & 0 & 0 & 0 & 99 & 0 \\
\hline Classe 9 & 0 & 0 & 0 & 0 & 0 & 0 & 0 & 0 & 94 \\
\hline
\end{tabular}

\subsubsection{Base de imagens CASIA-irisv2}

O procedimento de matching para a base de dados de CASIA-irisv2 foi feito utilizandose 46 classes de íris diferentes. Cada classe possui um número diferente de imagem, devido ao fato de algumas delas não serem passíveis de tratamento pelo algoritmo. De cada imagem foram retiradas 50 amostras.

Totalizou-se por fim 695 imagens de íris normalizadas e 34750 amostras coletadas a partir dessas imagens.

Utilizou-se da validação cruzada leave-one-out para realizar a comparação das amostras e aplicou-se a distância chi quadrado entre histogramas. Devido ao tamanho da matriz de confusão ser desproporcional para sua inserção no documento, a Tabela 5 mostra uma parcela dos resultados obtidas na matriz de confusão. Um número dentro da matriz de confusão representa quantas amostras da classe representada pela linha foram classificadas dentro da classe representada pela coluna, por exemplo: 995 amostras da Classe 1 foram classificadas como Classe 1, uma amostra da Classe 1 foi classificada como Classe 3, outra amostra da Classe 1 foi classificada como Classe 4 e assim por diante. 
Tabela 5 - Exemplo de parte da Matriz de Confusão para a base de imagens CASIAirisv2.

\begin{tabular}{|l|c|c|c|c|c|c|c|c|c|}
\hline & Classe 1 & Classe 2 & Classe 3 & Classe 4 & Classe 5 & Classe 6 & Classe 7 & Classe 8 & Classe 9 \\
\hline Classe 1 & 995 & 0 & 1 & 1 & 0 & 1 & 0 & 0 & 0 \\
\hline Classe 2 & 0 & 897 & 0 & 0 & 0 & 0 & 0 & 0 & 0 \\
\hline Classe 3 & 0 & 0 & 500 & 0 & 0 & 0 & 0 & 0 & 0 \\
\hline Classe 4 & 0 & 0 & 0 & 799 & 0 & 0 & 0 & 0 & 0 \\
\hline Classe 5 & 1 & 0 & 0 & 0 & 898 & 0 & 0 & 0 & 0 \\
\hline Classe 6 & 0 & 0 & 0 & 1 & 0 & 996 & 0 & 0 & 0 \\
\hline Classe 7 & 0 & 0 & 0 & 0 & 0 & 0 & 999 & 0 & 0 \\
\hline Classe 8 & 0 & 0 & 1 & 0 & 0 & 0 & 0 & 948 & 0 \\
\hline Classe 9 & 1 & 0 & 0 & 0 & 0 & 0 & 0 & 0 & 849 \\
\hline
\end{tabular}

Uma Matriz de Confusão completa pode ser encontrada no APÊNDICE E - Matriz de

\section{Confusão LFP.}

A Tabela 6 demonstra os valores obtidos durante uma bateria de 25 execuções consecutivas do algoritmo. O resultado é apresentado como a média e o desvio padrão da sensibilidade obtida em cada uma das execuções. Optou-se por expor o resultado desse modo, pois levando-se em conta a amostragem aleatória das íris, uma representação estatística fiel deve ser feita com a execução de uma maior quantidade de testes.

Os resultados utilizando a base de dados CASIA-irisv2 mostram uma sensibilidade maior que a base de dados de Notre Dame. Esse resultado pode ser explicado pelo fato de que as imagens de íris da base de dados do CASIA-irisv2 que não foram normalizadas corretamente foram removidas do banco de imagens manualmente. O método, como discutido na Seção 4.7, não é capaz de normalizar todas as íris presentes na base de dados, portanto foi necessária a remoção das imagens que não puderam ser processadas pelo algoritmo.

Outra possível explicação é o fato da base de dados de Notre Dame possuir uma representação mais real da coleta de íris. Esse fato é explicado devido à sua coleta haver sido feita por equipamentos de acesso ao laboratório durante o dia-a-dia, possuir imagens fora de foco, com iluminação inadequada, com oclusão de íris pelas pálpebras e cílios, com ângulos inapropriados para captação da íris entre outros. 
Tabela 6 - Resultados estatísticos obtidos com 25 execuções do algoritmo proposto para o banco de imagens CASIA-irisv2

\begin{tabular}{|c|c|}
\hline $\begin{array}{c}\text { Média da } \\
\text { Sensibilidade }\end{array}$ & $99,7516 \%$ \\
\hline $\begin{array}{c}\text { Desvio Padrão da } \\
\text { Sensibilidade }\end{array}$ & 0.0155 \\
\hline $\begin{array}{c}\text { Número Total de } \\
\text { Amostras }\end{array}$ & 34750 \\
\hline
\end{tabular}

Uma avaliação mais detalhada da classificação foi feita calculando-se a porcentagem de acerto por classe. A Tabela 7 apresenta os resultados obtidos com 25 execuções do algoritmo, utilizando o $\beta$ com o valor de 1,126 .

\subsection{Sintonização}

Durante o procedimento de matching para a base de dados CASIA-irisv2, foi realizado a sintonização (tunning) do parâmetro $\beta$ da função de pertinência sigmoidal do LFP apresentada na equação (2.10) em busca da otimização da classificação das amostras.

A sintonização foi realizada por iterações, onde em cada uma delas o algoritmo modificava o valor de $\beta$ e calculava a taxa de sensibilidade. A Figura 31 mostra o gráfico adquirido entre o intervalo de $[0,1 ; 2]$ para o $\beta$ com passos de 0,1 .

Analisando-se o gráfico da Figura 31 e os valores adquiridos é possível perceber que os melhores valores para o $\beta$ estão no intervalo de $[1 ; 1,2]$. Para valores maiores de $\beta=1,2$ a sensibilidade entra em um declive muito lento. Para encontrar o valor ótimo de $\beta$, realizou-se então um teste utilizando passos de 0,02 variando-se o $\beta$ dentro do intervalo de $[1 ; 1,2]$. A Figura 32 explicita o gráfico obtido. 
Tabela 7 - Média e Desvio Padrão da Sensibilidade por Classe

\begin{tabular}{|c|c|c|}
\hline Classes & $\begin{array}{c}\text { Média da } \\
\text { Sensibilidade }\end{array}$ & $\begin{array}{c}\text { Desvio } \\
\text { Padrão da } \\
\text { Sensibilidade }\end{array}$ \\
\hline Classe 1 & 99,72 & 0,0447 \\
\hline Classe 2 & 99,6444 & 0,3277 \\
\hline Classe 3 & 99,72 & 0,1789 \\
\hline Classe 4 & 99,95 & 0,0685 \\
\hline Classe 5 & 99,7778 & 0,0786 \\
\hline Classe 6 & 99,72 & 0,1304 \\
\hline Classe 7 & 99,56 & 0,2191 \\
\hline Classe 8 & 99,7684 & 0,2025 \\
\hline Classe 9 & 99,6471 & 0,186 \\
\hline Classe 10 & 99,8 & 0,1629 \\
\hline Classe 11 & 99,7474 & 0,1596 \\
\hline Classe 12 & 99,88 & 0,0837 \\
\hline Classe 13 & 99,72 & 0,1789 \\
\hline Classe 14 & 99,7647 & 0,0832 \\
\hline Classe 15 & 99,7714 & 0,239 \\
\hline Classe 16 & 99,6364 & 0,2875 \\
\hline Classe 17 & 99,8118 & 0,1052 \\
\hline Classe 18 & 99,95 & 0,1118 \\
\hline Classe 19 & 99,7053 & 0,1153 \\
\hline Classe 20 & 99,76 & 0,1517 \\
\hline Classe 21 & 99,6222 & 0,1859 \\
\hline Classe 22 & 99,725 & 0,2984 \\
\hline
\end{tabular}

\begin{tabular}{|c|c|c|}
\hline Classe 23 & 99,8 & 0,0707 \\
\hline Classe 24 & 99,6 & 0,0609 \\
\hline Classe 25 & 100 & 0 \\
\hline Classe 26 & 99,6941 & 0,1341 \\
\hline Classe 27 & 99,45 & 0,2739 \\
\hline Classe 28 & 99,7 & 0,0707 \\
\hline Classe 29 & 99,7263 & 0,0942 \\
\hline Classe 30 & 99,84 & 0,0894 \\
\hline Classe 31 & 99,5429 & 0,2556 \\
\hline Classe 32 & 99,8769 & 0,1287 \\
\hline Classe 33 & 99,8 & 0,1394 \\
\hline Classe 34 & 99,68 & 0,228 \\
\hline Classe 35 & 99,8889 & 0,1571 \\
\hline Classe 36 & 99,7684 & 0,1153 \\
\hline Classe 37 & 99,88 & 0,1789 \\
\hline Classe 38 & 99,8 & 0,1414 \\
\hline Classe 39 & 99,7778 & 0,1571 \\
\hline Classe 40 & 100 & 0 \\
\hline Classe 41 & 99,8909 & 0,1626 \\
\hline Classe 42 & 99,92 & 0,0447 \\
\hline Classe 43 & 99,88 & 0,1789 \\
\hline Classe 44 & 100 & 0 \\
\hline Classe 45 & 99,775 & 0,163 \\
\hline Classe 46 & 99,9579 & 0,0577 \\
\hline
\end{tabular}

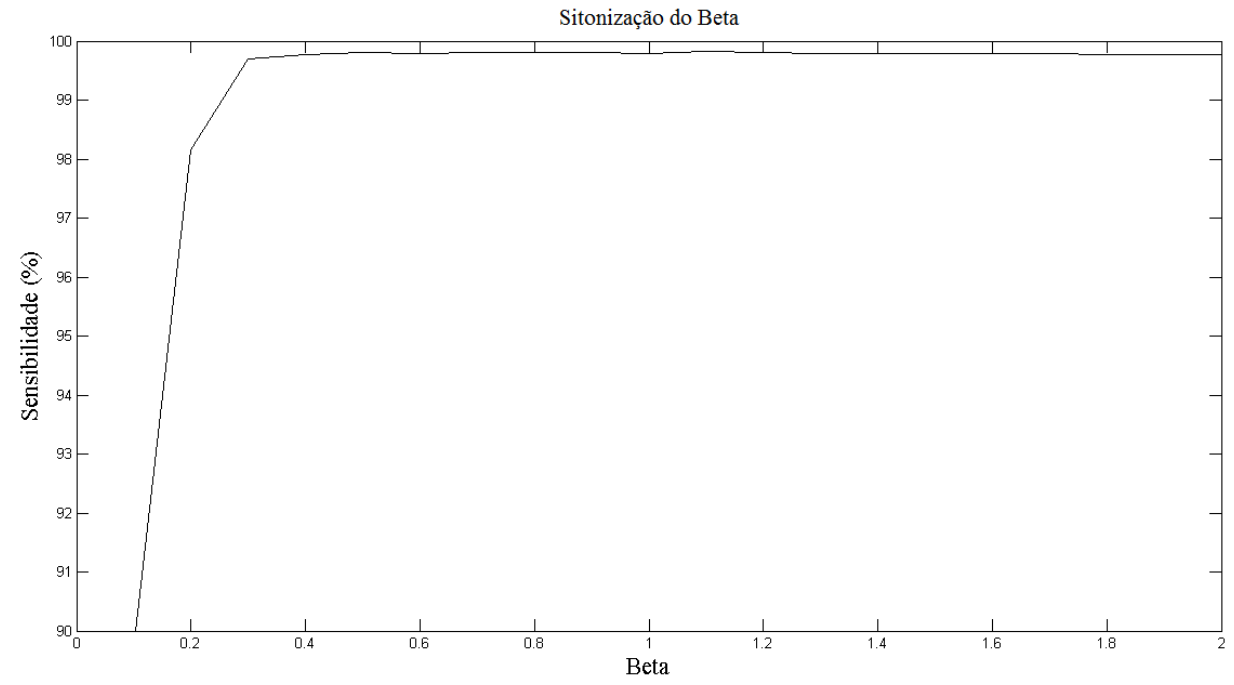

Figura 31 - Gráfico de Sintonização do Beta. 


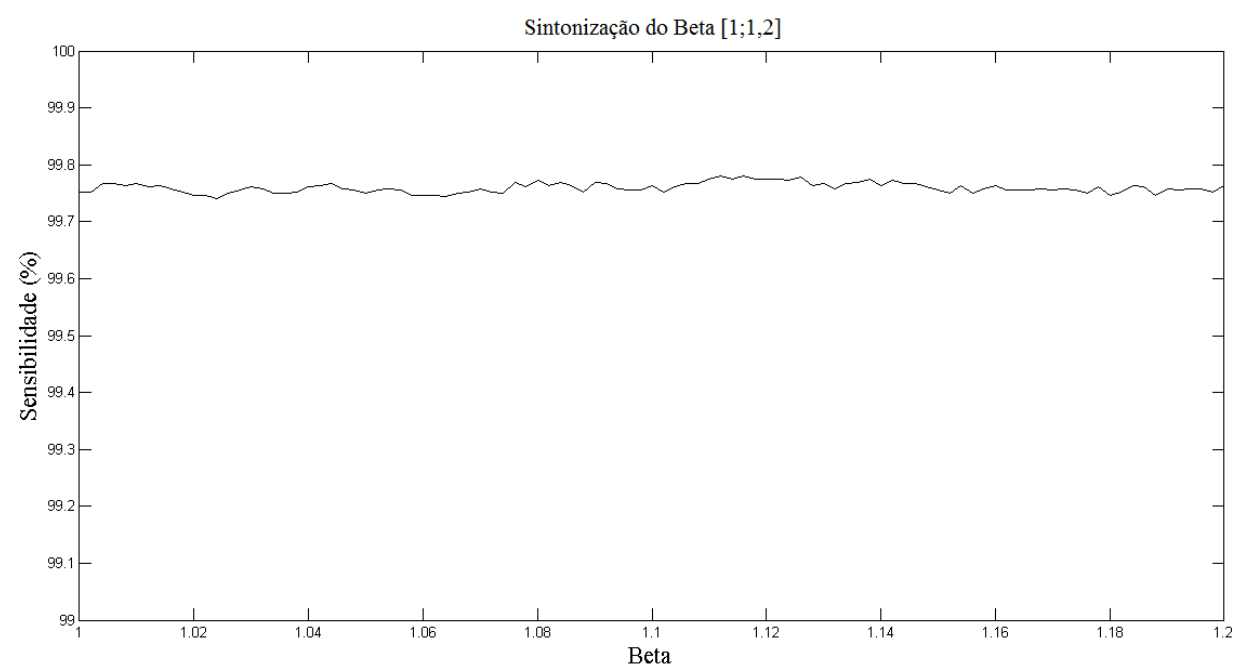

Figura 32 - Sintonização do Beta entre $[1 ; 1,2]$.

A Tabela 8 mostra os resultados numéricos obtidos com a sintonização do parâmetro $\beta$ para o intervalo $[0,1 ; 2,0]$, enquanto a Tabela 9 apresenta a variação de Sensibilidade para variação do parâmetro beta no intervalo $[1 ; 1,2]$.

Tabela 8 - Resultados da Sensibilidade obtida com a sintonização do parâmetro $\beta$ no intervalo $[0,1 ; 2,0]$.

\begin{tabular}{|c|c|}
\hline Beta & Sensibilidade \\
\hline 0,1 & 89,68633 \\
\hline 0,2 & 98,15827 \\
\hline 0,3 & 99,7036 \\
\hline 0,4 & 99,77554 \\
\hline 0,5 & 99,80144 \\
\hline 0,6 & 99,79568 \\
\hline 0,7 & 99,81583 \\
\hline 0,8 & 99,81007 \\
\hline 0,9 & 99,79856 \\
\hline 1 & 99,79568 \\
\hline
\end{tabular}

\begin{tabular}{|c|c|}
\hline Beta & Sensibilidade \\
\hline 1,1 & 99,81871 \\
\hline 1,2 & 99,79856 \\
\hline 1,3 & 99,78993 \\
\hline 1,4 & 99,78993 \\
\hline 1,5 & 99,78705 \\
\hline 1,6 & 99,78705 \\
\hline 1,7 & 99,78417 \\
\hline 1,8 & 99,76978 \\
\hline 1,9 & 99,77266 \\
\hline 2 & 99,77266 \\
\hline
\end{tabular}


Tabela 9 - Resultados da variação da Sensibilidade com a sintonização do parâmetro $\beta$ no intervalo $[1 ; 1,2]$.

\begin{tabular}{|c|c|}
\hline Beta & Sensibilidade \\
\hline 1 & 99,75252 \\
\hline 1,002 & 99,75252 \\
\hline 1,004 & 99,76691 \\
\hline 1,006 & 99,76691 \\
\hline 1,008 & 99,76403 \\
\hline 1,01 & 99,76691 \\
\hline 1,012 & 99,76115 \\
\hline 1,014 & 99,76403 \\
\hline 1,016 & 99,75827 \\
\hline 1,018 & 99,75252 \\
\hline 1,02 & 99,74676 \\
\hline 1,022 & 99,74676 \\
\hline 1,024 & 99,74101 \\
\hline 1,026 & 99,74964 \\
\hline 1,028 & 99,7554 \\
\hline 1,03 & 99,76115 \\
\hline 1,032 & 99,75827 \\
\hline 1,034 & 99,74964 \\
\hline 1,036 & 99,74964 \\
\hline 1,038 & 99,75252 \\
\hline 1,04 & 99,76115 \\
\hline 1,042 & 99,76403 \\
\hline 1,044 & 99,76691 \\
\hline 1,046 & 99,75827 \\
\hline 1,048 & 99,7554 \\
\hline 1,05 & 99,74964 \\
\hline 1,052 & 99,7554 \\
\hline 1,054 & 99,75827 \\
\hline 1,056 & 99,7554 \\
\hline 1,058 & 99,74676 \\
\hline 1,06 & 99,74676 \\
\hline 1,062 & 99,74676 \\
\hline 1,064 & 99,74388 \\
\hline 1,066 & 99,74964 \\
\hline & \\
\hline
\end{tabular}

\begin{tabular}{|c|c|}
\hline Beta & Sensibilidade \\
\hline 1,068 & 99,75252 \\
\hline 1,07 & 99,75827 \\
\hline 1,072 & 99,75252 \\
\hline 1,074 & 99,74964 \\
\hline 1,076 & 99,76978 \\
\hline 1,078 & 99,76115 \\
\hline 1,08 & 99,77266 \\
\hline 1,082 & 99,76403 \\
\hline 1,084 & 99,76978 \\
\hline 1,086 & 99,76403 \\
\hline 1,088 & 99,75252 \\
\hline 1,09 & 99,76978 \\
\hline 1,092 & 99,76691 \\
\hline 1,094 & 99,75827 \\
\hline 1,096 & 99,7554 \\
\hline 1,098 & 99,7554 \\
\hline 1,1 & 99,76403 \\
\hline 1,102 & 99,75252 \\
\hline 1,104 & 99,76115 \\
\hline 1,106 & 99,76691 \\
\hline 1,108 & 99,76691 \\
\hline 1,11 & 99,77554 \\
\hline 1,112 & 99,78129 \\
\hline 1,114 & 99,77554 \\
\hline 1,116 & 99,78129 \\
\hline 1,118 & 99,77554 \\
\hline 1,12 & 99,77554 \\
\hline 1,122 & 99,77554 \\
\hline 1,124 & 99,77266 \\
\hline 1,126 & 99,77842 \\
\hline 1,128 & 99,76403 \\
\hline 1,13 & 99,76691 \\
\hline 1,132 & 99,75827 \\
\hline 1,134 & 99,76691 \\
\hline
\end{tabular}

\begin{tabular}{|c|c|}
\hline Beta & Sensibilidade \\
\hline 1,136 & 99,76978 \\
\hline 1,138 & 99,77554 \\
\hline 1,14 & 99,76403 \\
\hline 1,142 & 99,77266 \\
\hline 1,144 & 99,76691 \\
\hline 1,146 & 99,76691 \\
\hline 1,148 & 99,76115 \\
\hline 1,15 & 99,7554 \\
\hline 1,152 & 99,74964 \\
\hline 1,154 & 99,76403 \\
\hline 1,156 & 99,74964 \\
\hline 1,158 & 99,75827 \\
\hline 1,16 & 99,76403 \\
\hline 1,162 & 99,7554 \\
\hline 1,164 & 99,7554 \\
\hline 1,166 & 99,7554 \\
\hline 1,168 & 99,75827 \\
\hline 1,17 & 99,7554 \\
\hline 1,172 & 99,75827 \\
\hline 1,174 & 99,7554 \\
\hline 1,176 & 99,74964 \\
\hline 1,178 & 99,76115 \\
\hline 1,18 & 99,74676 \\
\hline 1,182 & 99,75252 \\
\hline 1,184 & 99,76403 \\
\hline 1,186 & 99,76115 \\
\hline 1,188 & 99,74676 \\
\hline 1,19 & 99,75827 \\
\hline 1,192 & 99,7554 \\
\hline 1,194 & 99,75827 \\
\hline 1,196 & 99,75827 \\
\hline 1,198 & 99,75252 \\
\hline 1,2 & 99,76403 \\
\hline
\end{tabular}


Da Tabela 9 retira-se o valor utilizado para o $\beta$ da função sigmoidal e a sensibilidade obtida com este valor. A linha marcada em azul na tabela apresenta o valor de Beta que mostrou o melhor resultado dentre todos os calculados durante o treinamento. Portanto, optou-se pelo uso do $\beta=1,126$.

Nota-se também que era possível a obtenção de um valor entre $[0,7 ; 0,8]$. No entanto, uma investigação do intervalo em passos de 0.05 não encontrou valores que ultrapassassem o máximo local obtido pelo valor de $\beta=1,126$.

\subsection{Resultados obtidos com o descritor LBP}

\subsubsection{Sensibilidade para a base de imagens Notre Dame}

Durante a execução do trabalho com a base de dados de Notre Dame, calculou-se a sensibilidade para o LBP utilizando-se de 20 amostras por imagem de Íris. Reproduzindo-se assim a metodologia utilizada para o LFP.

O resultado obtido foi a sensibilidade de $96.95 \%$ calculada utilizando as 88 classes.

\subsubsection{Sensibilidade para a base de imagens CASIA-irisv2.}

Calculou-se a sensibilidade utilizando o extrator de características LBP aplicado nas imagens de íris humana da base CASIA-irisv2. O intuito foi o de comparar com os resultados obtidos com a metodologia de extração LFP dentro do mesmo trabalho.

Uma matriz de confusão completa para utilizando-se do descritor LBP pode ser encontrada no APÊNDICE F - Matriz de Confusão LBP

Os resultados obtidos para o LBP seguem na Tabela 10. 
Tabela 10 - Resultados obtidos com a aplicação do descritor LBP na base de imagens

CASIA-irisv2

\begin{tabular}{|c|c|}
\hline $\begin{array}{c}\text { Média da } \\
\text { Sensibilidade }\end{array}$ & $99.7361 \%$ \\
\hline $\begin{array}{c}\text { Desvio Padrão da } \\
\text { Sensibilidade }\end{array}$ & 0.0295 \\
\hline $\begin{array}{c}\text { Número Total de } \\
\text { Amostras }\end{array}$ & 34750 \\
\hline
\end{tabular}

\subsection{Conclusão}

O trabalho de mestrado propôs-se a investigar a capacidade do Local Fuzzy Pattern em extrair características suficientes para classificar com boa precisão indivíduos por meio de suas íris.

Para tal fim, buscou-se metodologias conhecidas, como a de Daugman, que foram aplicadas em conjunto com o método proposto para atingir o objetivo. Utilizou-se a base de dados de Notre Dame e a conhecida e muito explorada no meio científico CASIA-irisv2 para a realização de tais testes.

Durante a execução e implementação do algoritmo, observou-se a capacidade rápida do LFP em mostrar bons resultados com poucas amostras, saturando sua curva de sensibilidade em torno de 30 amostras como demonstrado na Seção 5.2. Caso busque-se mais adiante um esforço computacional para o uso em tempo real, pode-se utilizar uma menor quantidade de amostras do que no trabalho atual.

O trabalho demonstrou a capacidade do LFP tal qual o LBP na classificação biométrica por meio da Íris. Os estudos sobre a curva de sensibilidade por número de amostras também apontam que o LFP é capaz de obter uma maior sensibilidade com um menor número de amostras, fornecendo assim um melhor resultado com um menor esforço computacional, indicando-o para aplicações em sistemas embarcados ou aplicações onde a memória disponível é reduzida.

A aplicação do método proposto na base de dados de Notre Dame mostrou um ganho de sensibilidade de $1,2 \%$ da metodologia LFP sobre o LBP como mostrado na Tabela 11. Uma 
análise dos resultados e das imagens utilizadas pode indicar que as imagens em condições menos controladas, como as de Notre Dame, são melhores processadas pelo método LFP devido a maior captura de pequenos detalhes, levando em consideração que se é usada uma função de pertinência ao invés de uma lógica Crisp. É adequado ressaltar também que o número de amostras utilizado durante o teste é reduzido em comparação ao CASIA-irisV2, fornecendo o resultado de que o LFP possui uma curva de sensibilidade por número de amostras mais robusta.

A aplicação do método proposto na base de dados CASIA-irisV2 obteve um ganho pequeno $(0,02 \%)$. No entanto, o LFP mostrou-se mais robusto em relação ao LBP, mostrada pelo desvio padrão calculado para ambos como apresentado na Tabela 11. Esse resultado pode ser explicado pelo alto número de amostras para ambos, 50 amostras, e pelo fato da base de dados ser muito bem comportada (baixo-ruído, iluminação constante, não há rotação 2D ou 3D).

Tabela 11 - Comparação dos resultados obtidos com os descritores LBP e LFP nas bases de imagens de Notre Dame e CASIA-irisv2

\begin{tabular}{|c|c|c|c|}
\hline \multicolumn{2}{|c|}{ Local Fuzzy Pattern - CASIA-irisv2 } & \multicolumn{2}{|c|}{ Local Binary Pattern - CASIA-irisv2 } \\
\hline $\begin{array}{c}\text { Média da } \\
\text { Sensibilidade }\end{array}$ & $99,7516 \%$ & $\begin{array}{c}\text { Média da } \\
\text { Sensibilidade }\end{array}$ & $99.7361 \%$ \\
\hline $\begin{array}{c}\text { Desvio Padrão da } \\
\text { Sensibilidade }\end{array}$ & 0.0155 & $\begin{array}{c}\text { Desvio Padrão da } \\
\text { Sensibilidade }\end{array}$ & 0.0295 \\
\hline \multicolumn{2}{|c|}{ Local Fuzzy Pattern - Notre Dame } & \multicolumn{2}{|c|}{ Local Binary Pattern - Notre Dame } \\
\hline Sensibilidade & $98,20 \%$ & Sensibilidade & $96,95 \%$ \\
\hline
\end{tabular}

Um benefício do LFP não explorado ao longo deste trabalho é a aplicação de outras possíveis funções de pertinência para a análise da Íris, assim como o treinamento de um valor de Beta específico para cada uma delas, buscando-se assim uma função ótima para cada base de dados.

A análise do parâmetro Beta mostrou que para essa aplicação, diferente de texturas gerais, a sensibilidade em relação ao beta é estável ao longo da variação estudada. Desse modo seu ajuste fino não gera um grande impacto no ganho final do sistema ao utilizar-se a função de parametrização sigmoide. 


\subsection{Sugestões para trabalhos futuros}

A partir dos resultados obtidos, novas propostas de trabalhos surgem:

- Investigação das diferentes funções de pertinência do LFP aplicadas ao reconhecimento de íris.

- Investigação da aplicação do LFP para reconhecimento em vídeos de Íris.

- Investigação de método para tornar o tempo de processamento viável em aplicações de tempo real. 


\section{Referências Bibliográficas}

AHONEN, T.; HADID, A.; PIETIKAINEN, M. Face description with local binary patterns: Application to face recognition. Pattern Analysis and Machine Intelligence, IEEE Transactions, p. 2037-2041, 2006.

BALLARD, D. H. Generalizing the Hough transform to detect arbitrary shapes. Pattern Recognition, p. 111-122, 1981.

BARROS, L.; BASSANEZI, R. C. Tópicos de Lógica Fuzzy e Biomatemática. 2006. ed. [S.1.]: Coleção IMECC Textos Didáticos, v. 5.

BOAVENTURA, I. A. G. Números fuzzy em processamento de imagens digitais e suas aplicações na deteç̧ão de bordas. Escola de Engenharia de São Carlos - USP. São Carlos. 2010.

CANNY, J. A Computational Approach To Edge Detection. IEEE Trans. Pattern Analysis and Machine Intelligence, p. 679-698, 1986.

CASTEllanO, G. et al. Texture analysis of medical images. Clinical radiology, p. 10611069, 2004.

DAUGMAN, J. How Iris Recogtion Works. Circuits and Systems for Video Technology, IEEE Transactions on, v. 14, p. 21,30, Janeiro 2004.

DUDA, R. O.; HART, P. E. Use of the Hough transformation to detect lines and curves in pictures. Communications of the ACM, p. 11-15, 1972.

GABOR, D. Theory of Communication. Journal of the Institute of Eletrical Engineers, v. 93, p. 429-457, 1946.

GONZALEZ, R. C.; WOODS, R. E. Digital Image Processing. $3^{\text {a }}$. ed. Nova Jersey: Prentice Hall, 2008.

GOOL, L. V.; DEWAELE, P.; OOSTERLINCK, A. Texture analysis Anno 1983. Computer Vision, Ghaphics and Image Processing, p. 336-357, 1985.

HANSS, M. Applied Fuzzy Arithmetic, An Introduction with Engineering Applications. [S.l.]: Springer, 2005.

HARALICK, R. M. Statistical and structural approaches to texture. Proceedings of the IEEE, p. $786-804,1979$. 
HARALICK, R. M.; SHANMUGAM, K.; DISTEIN, I. Textural Features for Imagem Classification. IEEE Transactions on Systems, Man and Cybernetics, p. 610-621, 1973.

HE, D. C.; WANG, L. Texture Unit, Texture Spectrum and Texture Analysis. IEEE Transactions On Geoscience And Remote Sensing, v. 28, p. 509-512, 1990.

HE, D. C.; WANG, L. Simplified Texture Spectrum for Texture Analysis. Journal of Communication and Computer, v. 7, p. 44-53, 2010.

HE, Y. et al. Iris feature extraction method based on LBP and chunked encoding. Natural Computation (ICNC), 2011 Seventh International Conference, p. 1663-1667, 2011.

IDEALTEST. Note on CASIA-IrisV2 - Biometrics Ideal Test. Idealtest.org, 2013. Disponivel em: <www.idealtest.org/downloadDesc.do?id=2>. Acesso em: 27 Janeiro 2013.

JAIN, A. K.; ROSS, A.; PRABHAKAR, S. An Introduction to Biometric Recognition. IEEE Transactions on Circuits and Systems for Video Technology, v. 14, p. 1, Janeiro 2004.

JULESZ, B. Visual pattern discrimination. Information Theory, IRE Transactions on, v. 8, n. 2, p. 84-92, 1962.

JULESZ, B. A brief outline of the texton theory of human vision. Trends in Neurosciences, $p$. 41-45, 1984.

KENNELL, L.; IVES, R.; GAUN, R. Binary Morphology and Local Statistics Applied to Iris Segmentation for Recognition. Image Processing, 2006 IEEE International Conference on, Atlanta, GA, p. 293 - 296, Outubro 2006.

LGIRIS. LG Iris - Iris Recognition Technology. LGIris. Disponivel em: <http://www.irisid.com/>. Acesso em: 27 Janeiro 2013.

MÄENPÄÄ, T. et al. Robust texture classification by subsets of local binary pattern. Proc. 15th International Conference of Pattern Recognition, v. 3, p. 947-950, 2000.

MATLAB. MATLAB - The Langue of Technical Computing. Mathworks, 2013. Disponivel em: <http://www.mathworks.com/products/matlab/ >. Acesso em: 2 Março 2013.

ND, U. University of Notre Dame. University of Notre Dame, 2013. Disponivel em: <http://www.nd.edu/>. Acesso em: 15 Fevereiro 2013.

OJALA, T.; PIETIKÄINEN, M.; HARDWOOD, D. A comparative study of texture measures with classification based on featured distributions. Pattern Recognition, v. 29, p. 51-59, 1996. 
OJALA, T.; PIETIKÄINEN, M.; MÄENPÄÄ, T. A generalized Local Binary Pattern operator for multiresolution gray scale and rotation invariant texture classification. Second International Conference on Advances in Pattern Recognition, Rio de Janeiro, p. 397-406, 2001.

OJALA, T.; PIETIKÄINEN, M.; MÄENPÄÄ, T. Multiresolution gray-scale and rotation invariant texture classification with Local Binary Patterns. IEEE Transactions on Pattern Analysis and Machine Intelligence, v. 24, p. 981-987, 2002.

PELE, O.; WERMAN, M. The quadratic-chi histogram distance family. Proceedings of the 11th European conference on Computer Vision, p. 749-762, 2010.

RASHAD, M. Z. et al. Iris Recognition Based on LBP and Combined LVQ Classifier. International Journal of Computer Science \& Information Technology, 2011.

RASHAD, M. Z. et al. IRIS RECOGNITION BASED ON LBP AND COMBINED LVQ CLASSIFIER. International Journal of Computer Science \& Information Technology, v. 3, n. 5, p. 67-78, Outubro 2011.

SUN, Z.; TAN, T.; QIU, X. Graph Matching Iris Image Blocks with Local Binary Pattern. Advances in Biometrics Lecture Notes in Computer Science, p. 366-372, 2005.

TAMURA, H.; MORI, S.; YAWAMAKI, T. Textural Features Corresponding to Visual Perception. IEEE Transactions on Systems, Man and Cybernetics, v. 8, p. 460-473, 1978.

TAVARES, R. Análise de micropadrões em imagens digitais baseada em números fuzzy. Escola de Engenharia de São Carlos - USP. São Carlos. 2013.

TAVARES, R. et al. Local Fuzzy Pattern: A New Way for Micro-Pattern Analysis. Intelligent Data Engineering and Automated Learning - IDEAL 2012, Natal, p. 602,611, Agosto 2012. ISSN 0302-9743.

THEODORIDIS, S.; KOUTROUMBAS, K. Pattern Recognition. Orlando: Academic Press, 2008.

VAN DE WOUMER, G.; SCHEUDERS, P.; VAN DYCK, D. Statistical texture characterization from discrete wavelet representations. Image Processing, IEEE Transactions on, v. 8, n. 4, p. 592-598, 1999.

WANG, X. et al. Palmprint Identification using Boosting Local Binary Pattern. Pattern Recognition, 2006. ICPR 2006. 18th International Conference, p. 503-506, 2006. 
ZADEH, L. A. Fuzzy sets. Information and Control, v. 8, p. 338-53, 1965.

ZHENAN, S.; TIENIU, T.; XIANCHAO, Q. Graph Matching Iris Image Blocks with Local Binary Pattern, p. 366-372, 2005. 


\section{APÊNDICE A - Código Fonte LFP}

○Main LFP

close all

clear all

clc

oVariáveis

TamJ = [ $\left.\begin{array}{lll}25 & 25\end{array}\right]$;

radius $=1$;

neighbor $=8$;

$\circ \mathrm{nAm}=50$;

nFolder $=60$;

nImage $=695 ;$

$\operatorname{mark}=1$;

$\operatorname{marc}=1$;

beta $=1.226$

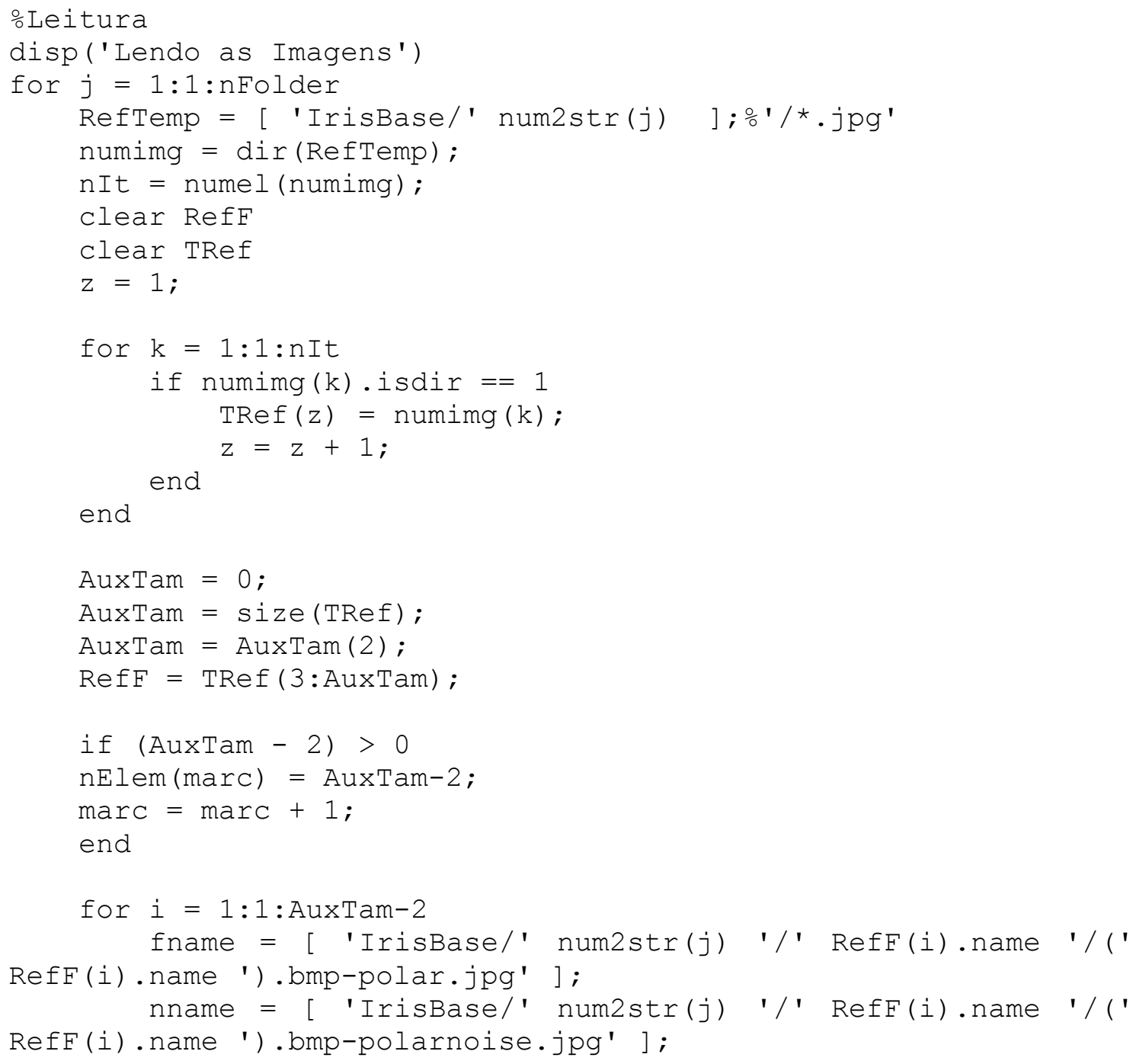




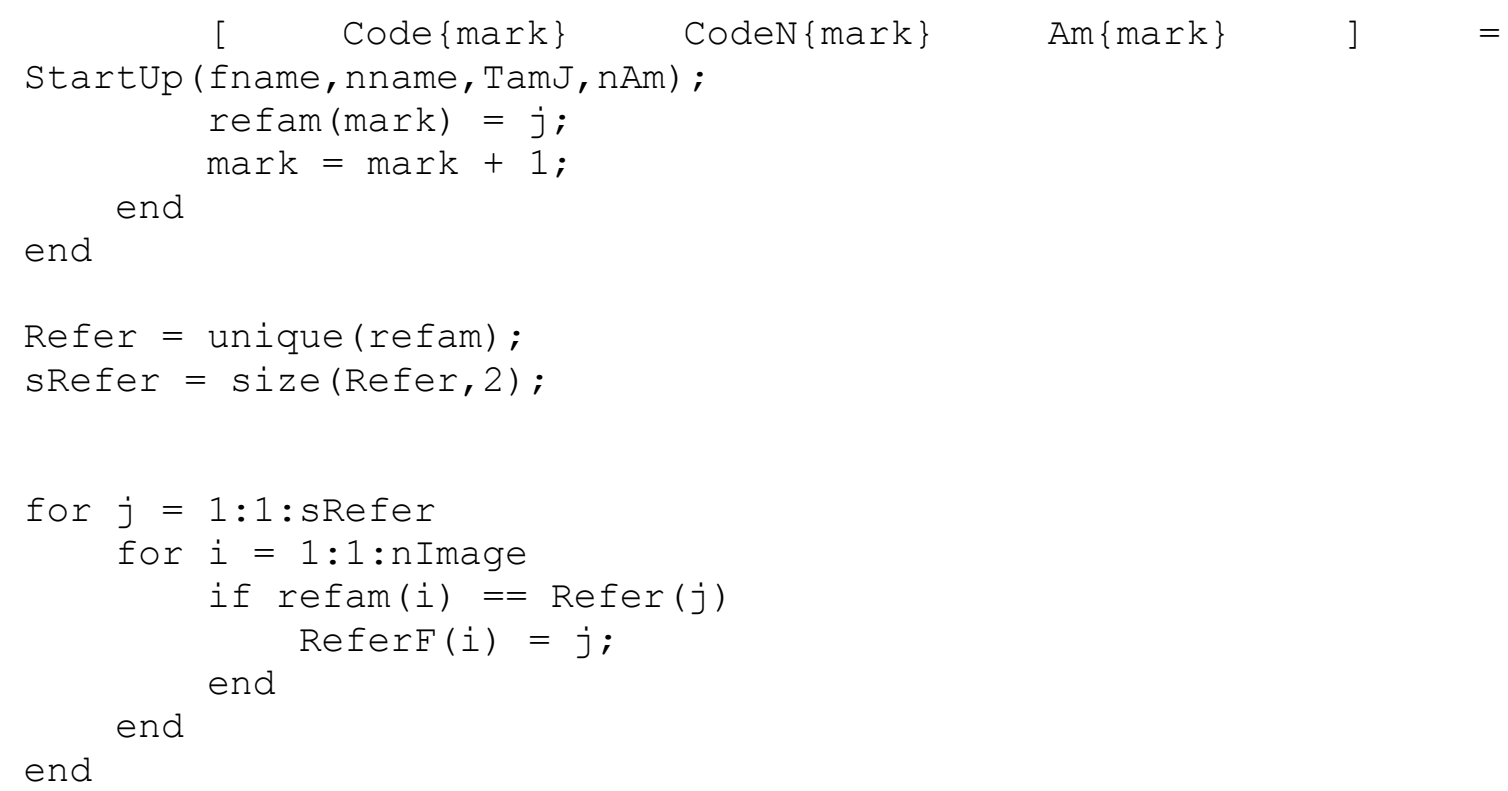

beta;

$\mathrm{MB}=\mathrm{MB}+1$

$\operatorname{BetaM}(\mathrm{MB})=$ beta;

oCriando Referências

disp('Criando o LFP das Imagens.')

for $i=1: 1:$ nImage

$\operatorname{ALFP}\{i\}=\operatorname{AmLMP}(\operatorname{Am}\{i\}, n A m$, radius, neighbor, beta) ;

end

disp ('Criando Vetores')

Amostras = ALFP $\{1\}$. Amostra;

for $i=2: 1:$ nImage

$\operatorname{Amostras}(:,(1+n A m *(i-1)):(n A m * i))$

ALFP $\{i\}$.Amostra $(:, 1: n A m)$;

end

oCálculo das Distâncias

disp('Criando a Matriz de Confusão')

ConfF $=$ zeros (sRefer, sRefer);

Conf $=$ zeros (sRefer, sRefer);

count $=0$;

for $i=1: 1: n$ Image ${ }^{*}$ Am

Ln $=\operatorname{ceil}(i / n A m) ;$

응 Conf $=$ zeros (sRefer, sRefer);

$\therefore \quad L F P$

for Pt $=1: 1: \mathrm{nAm}$

clear DC

olear m

o clear I 


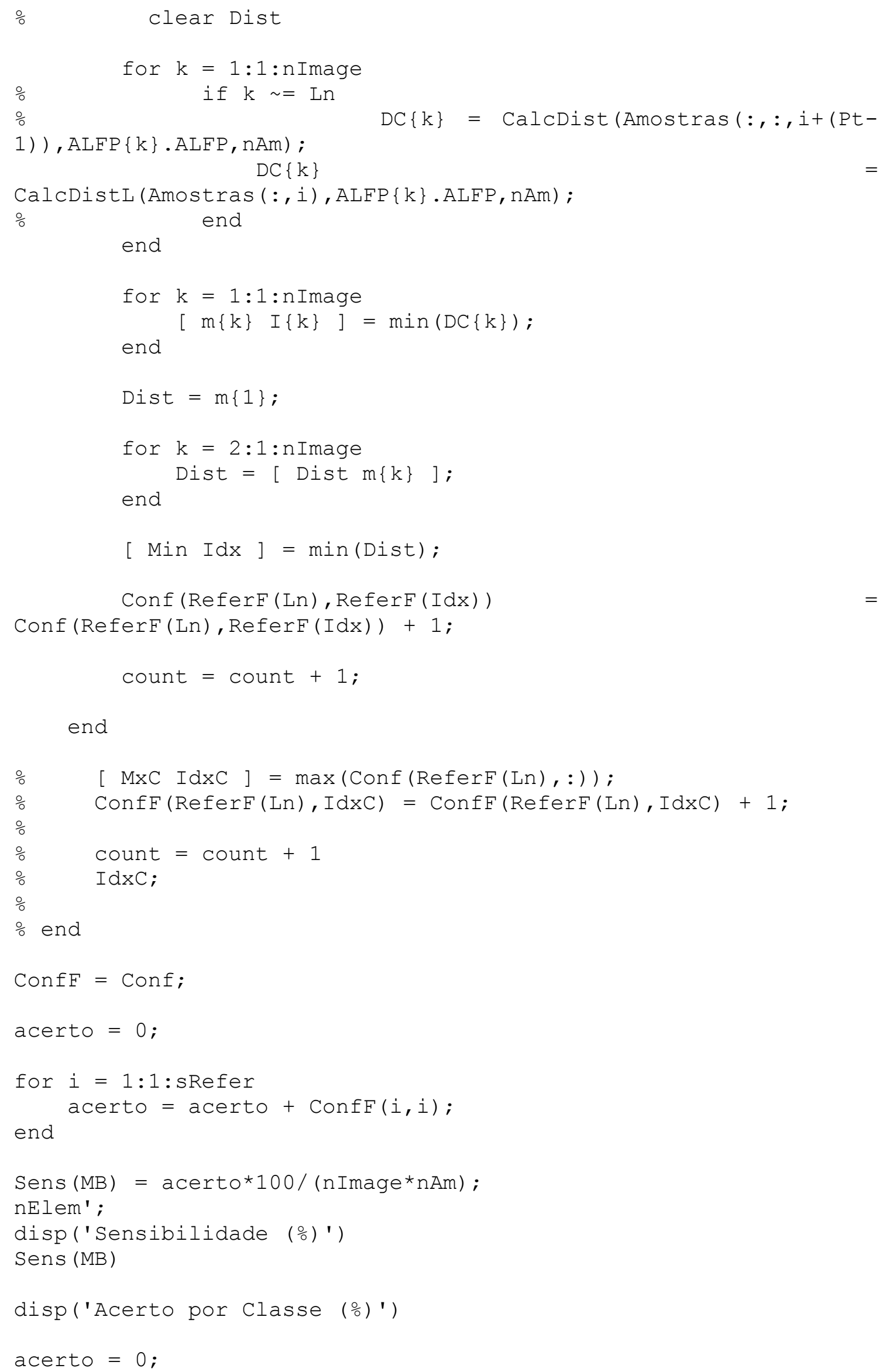


for $i=1: 1:$ sRefer acerto(i) $=\operatorname{ConfF}(i, i) / \mathrm{nElem}(i)$;

end

acerto $=$ acerto $* 100 / \mathrm{nAm} ;$

acerto'

MatrizName $=$ ['MatrizLFP']

xlswrite (MatrizName, ConfF);

MatrizName $=$ ['AcertoClasse']

xlswrite (MatrizName, acerto') ;

disp('Resultados LFP')

Rzt $=[$ BetaM' Sens'];

xlswrite('ResultadoBeta', Rzt); 


\section{APÊNDICE B - Código Fonte LBP}

○Main LBP

close all

clear all

clc

-Variáveis

Tamu $=\left[\begin{array}{ll}25 & 25\end{array}\right]$;

nAm $=50$;

$\mathrm{nFolder}=60$;

nImage $=695$;

$\operatorname{mark}=1$;

$\operatorname{marc}=1$;

oLeitura

disp ('Lendo as Imagens')

for $j=1: 1: n F o l d e r$

RefTemp $=[$ 'IrisBase/' num2str $(j)$ ];'/*.jpg'

numimg $=\operatorname{dir}(\operatorname{RefTemp})$;

nIt $=$ numel (numimg);

clear RefF

clear TRef

$\mathrm{z}=1$;

for $\mathrm{k}=1: 1: \mathrm{nIt}$

if numimg $(\mathrm{k})$. isdir $==1$

TRef $(z)=\operatorname{numimg}(k)$;

$\mathrm{z}=\mathrm{z}+1$

end

end

AuxTam = 0;

AuxTam = size (TRef);

AuxTam = AuxTam(2);

$\operatorname{RefF}=\operatorname{TRef}(3:$ AuxTam);

if (AuxTam - 2) >0

nElem (marc) = AuxTam-2;

$\operatorname{marc}=\operatorname{marc}+1$;

end

for $i=1: 1:$ AuxTam-2

fname = [ 'IrisBase/' num2str(j) '/' RefF(i).name '/('

RefF(i).name ').bmp-polar.jpg'];

nname $=[$ 'IrisBase/' num2str(j) '/' RefF(i).name '/('

Reff(i).name ').bmp-polarnoise.jpg' ];

[ Code $\{$ mark $\} \quad$ CodeN $\{$ mark $\} \quad A m\{\operatorname{mark}\} \quad]=$

StartUp (fname, nname, TamJ, nAm) ;

refam (mark) $=j$;

$\operatorname{mark}=\operatorname{mark}+1$;

end

end 


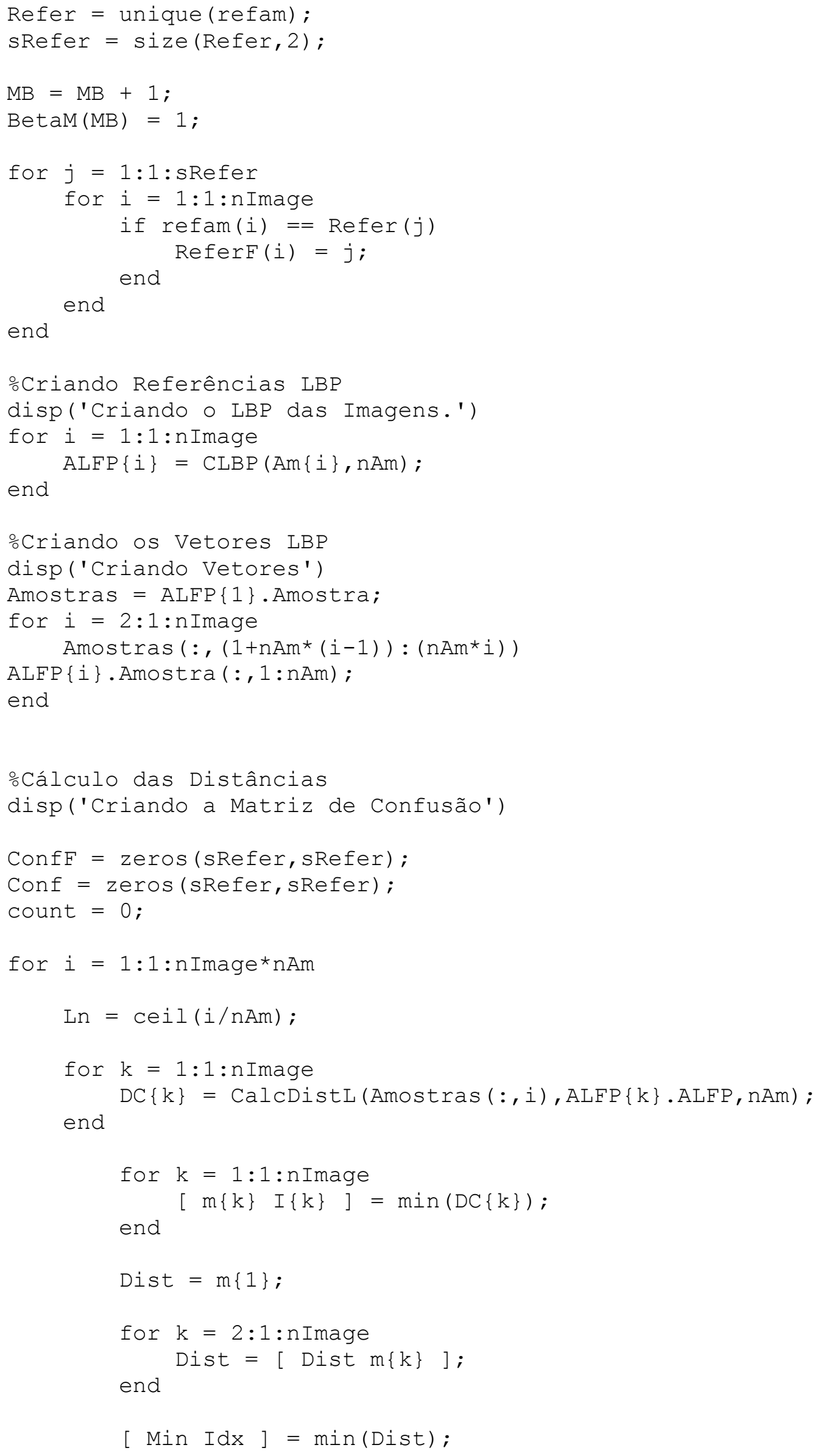


Conf (ReferF (Ln), ReferF (Idx))

Conf (Referf (Ln), Referf (Idx)) + 1;

count $=$ count +1 ;

end

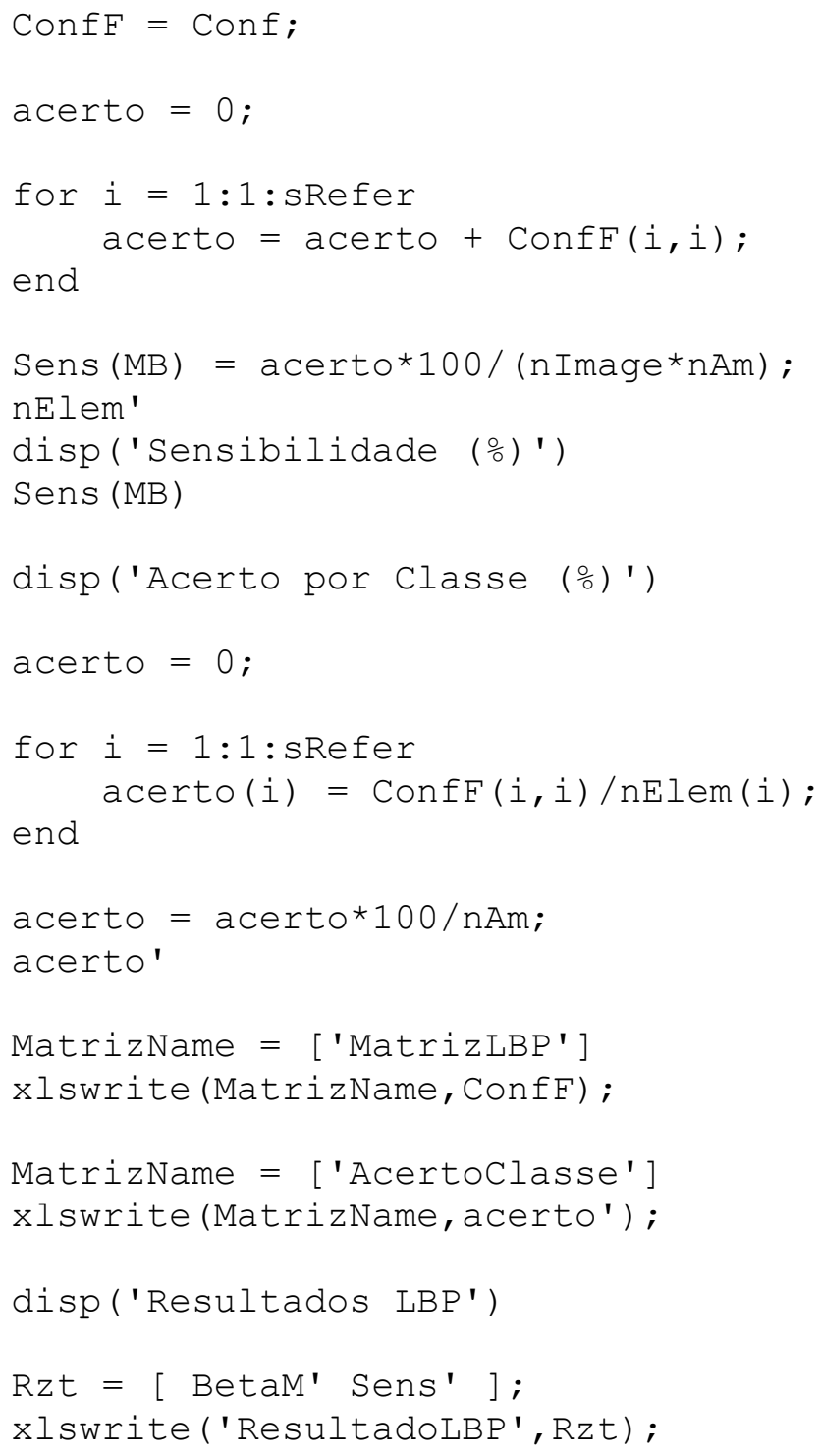




\section{APÊNDICE C - Código Fonte Função LFP}

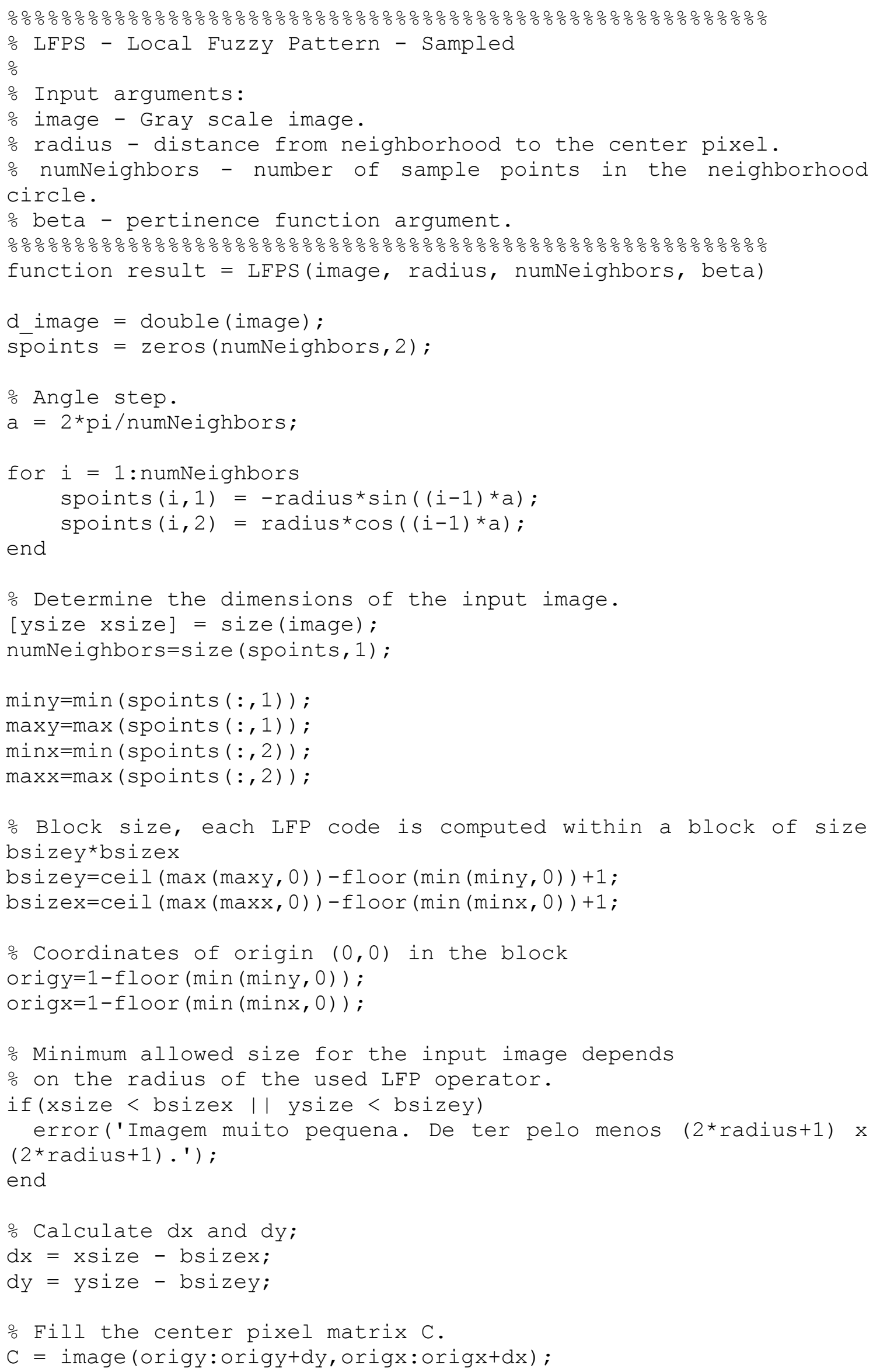


d_C $=$ double $(C)$;

o Initialize the result matrix with zeros.

pertinencesum $=\operatorname{zeros}(d y+1, d x+1)$;

oCompute the LBP code image

for $i=1$ : numNeighbors

$y=\operatorname{spoints}(i, 1)$ torigy;

$\mathrm{x}=\operatorname{spoints}(i, 2)+\operatorname{orig} \mathrm{x} ;$

o Calculate floors, ceils and rounds for the $\mathrm{x}$ and $\mathrm{y}$.

$\mathrm{f}_{\mathrm{y}}=\mathrm{floor}(\mathrm{y})$;

$\mathrm{cy}=\operatorname{ceil}(\mathrm{y})$;

$r y=\operatorname{round}(\mathrm{y})$;

$f x=f l o o r(x)$;

$\mathrm{cx}=\operatorname{ceil}(\mathrm{x}) ;$

$r x=\operatorname{round}(x)$;

\% Check if interpolation is needed.

if $(a b s(x-r x)<1 e-6)$ \&\& $(a b s(y-r y)<1 e-6)$

$\circ$ Interpolation is not needed, use original datatypes

$\mathrm{N}=$ image $(r y: r y+d y, r x: r x+d x)$; else

\% Interpolation needed, use double type images

$t_{y}=y-f_{y} ;$

$t x=x-f x ;$

\% Calculate the interpolation weights.

$\mathrm{w} 1=\left(1-t_{x}\right) *\left(1-t_{y}\right)$;

$\mathrm{w} 2=\mathrm{tx}_{\mathrm{x}} *\left(1-\mathrm{ty}_{\mathrm{y}}\right)$;

$\mathrm{w} 3=\left(1-t_{x}\right) * \quad t y ;$

$\mathrm{w} 4=\operatorname{tx} *$ ty $;$

- Compute interpolated pixel values

$\mathrm{N} \quad=\quad \mathrm{w} 1 * d_{-}$image $\left(f_{y}: f_{y}+d y, f x: f x+d x\right)+$

$\mathrm{w} 2 * d$ image $\left(\mathrm{fy}_{\mathrm{y}}: \mathrm{f}_{\mathrm{y}}+\mathrm{dy}, \mathrm{cx}: \mathrm{cx}+\mathrm{dx}\right) \overline{-} \ldots$

$w 3 * d$ image $(c y: c y+d y, f x: f x+d x)$

$\mathrm{w} 4 * \mathrm{~d}_{-}$image $(\mathrm{cy}: \mathrm{cy} \overline{+} \mathrm{dy}, \mathrm{cx}: \mathrm{cx}+\mathrm{dx})$;

end

pert $=1 . /\left(1+\exp \left(-\left(\mathrm{N}-\mathrm{d}_{-} \mathrm{C}\right) /\right.\right.$ beta $\left.)\right) ; \quad \frac{\circ}{0}$ sigmoid function pertinenceSum $=$ pertinencesum $+\max (0$, pert $)$; end

result $=$ pertinenceSum/numNeighbors; 


\section{APÊNDICE D - Código Fonte Função LBP}

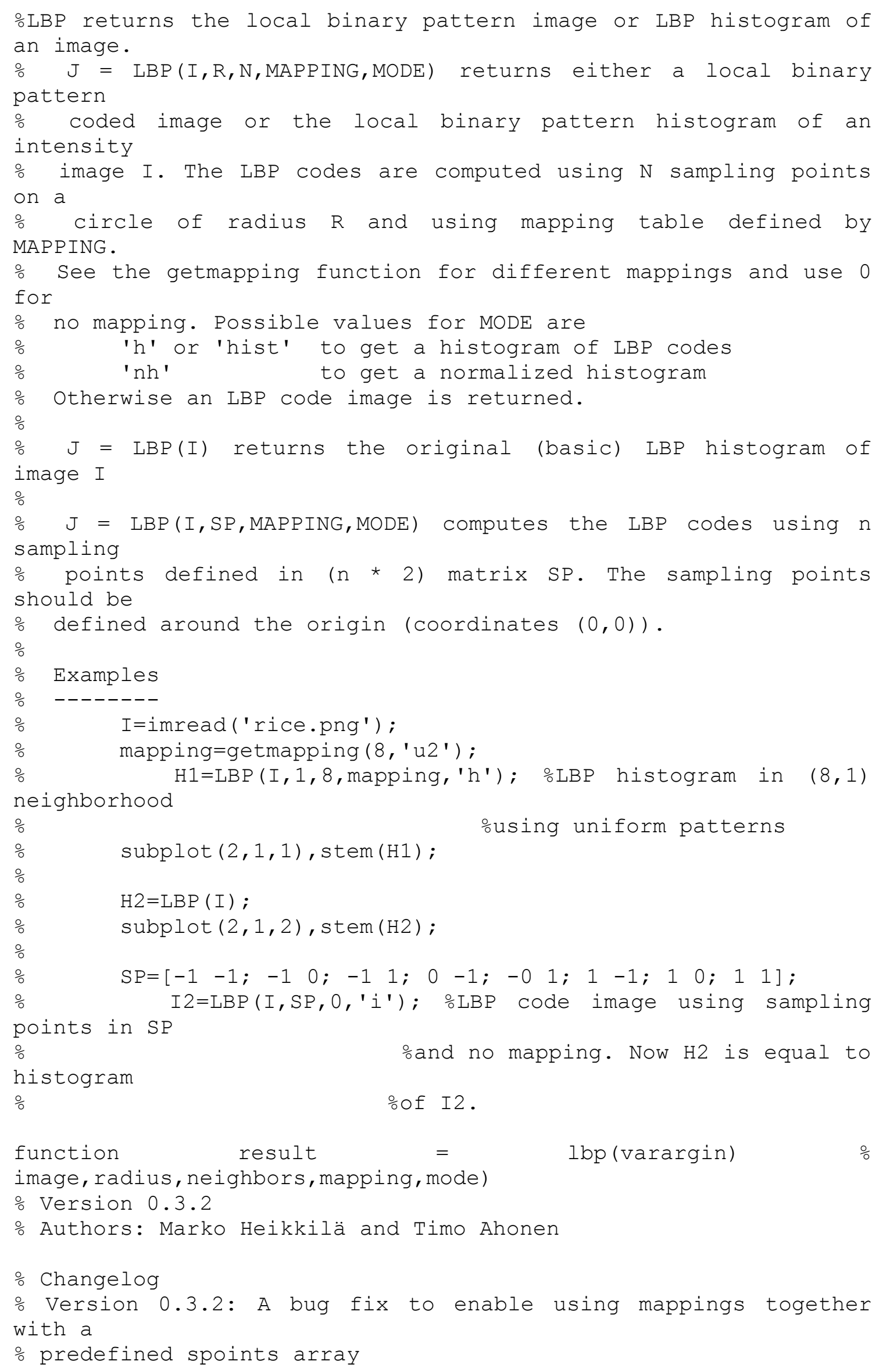


o Version 0.3.1: Changed MAPPING input to be a struct containing the mapping

o table and the number of bins to make the function run faster with high number

o of sampling points. Lauge Sorensen is acknowledged for spotting this problem.

\% Check number of input arguments.

error (nargchk $(1,5$, nargin));

image=varargin $\{1\}$;

d_image $=$ double (image) ;

if nargin==1

spoints $=[-1-1 ;-10 ;-11 ; 0-1 ;-0$ 1; $1-1 ; 10 ; 11]$;

neighbors $=8$;

mapping $=0$;

mode=' h' ;

end

if $($ nargin $==2) \quad \& \& \quad($ length (varargin $\{2\})==1$ )

error('Input arguments');

end

if (nargin $>2)$ \&\& (length (varargin $\{2\})==1$ )

radius=varargin $\{2\}$;

neighbors=varargin $\{3\}$;

spoints=zeros (neighbors, 2$)$;

을 Atep.

$\mathrm{a}=2{ }^{\star} \mathrm{pi} /$ neighbors;

for $i=1$ :neighbors

spoints $(i, 1)=-$ radius*sin $((i-1) * a)$;

end

spoints $(i, 2)=\operatorname{radius}^{*} \cos ((i-1) \star a) ;$

if (nargin $>=4$ )

mapping=varargin $\{4\}$;

if(isstruct (mapping) \&\& mapping.samples $\sim=$ neighbors) error('Incompatible mapping');

end

else

mapping $=0$;

end

if(nargin $>=5$ )

mode $=$ varargin $\{5\}$;

else

mode $=$ ' $\mathrm{h}$ ' ;

end

end 


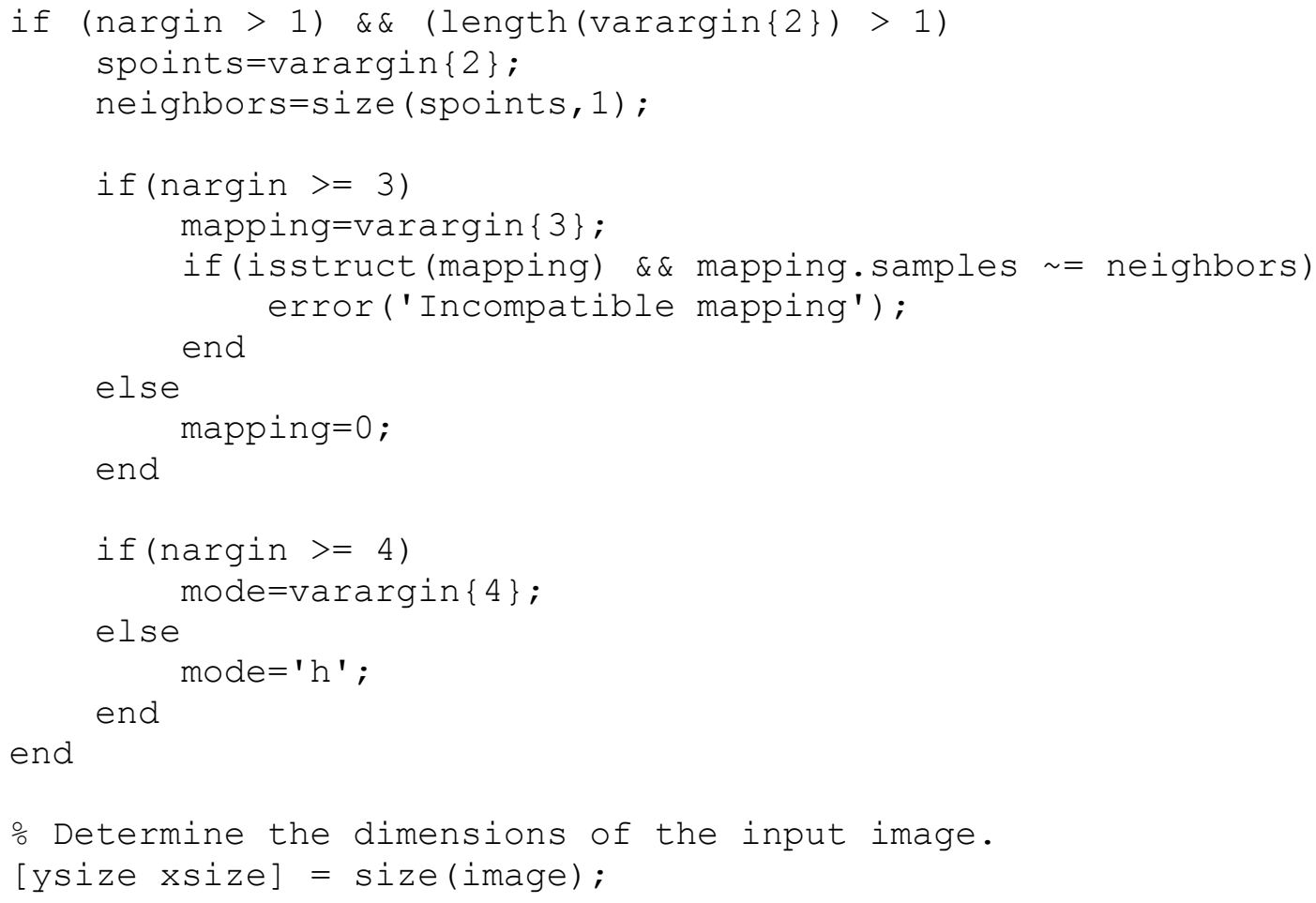


o Initialize the result matrix with zeros.

result=zeros $(d y+1, d x+1)$;

oCompute the LBP code image

for $i=1$ :neighbors

$y=\operatorname{spoints}(i, 1)$ torigy;

$x=\operatorname{spoints}(i, 2)+$ origx;

o Calculate floors, ceils and rounds for the $x$ and $y$.

$f_{y}=f l o o r(y) ; c y=\operatorname{ceil}(y) ; r y=r o u n d(y)$;

$\mathrm{fx}=\mathrm{floor}(\mathrm{x}) ; \mathrm{cx}=\operatorname{ceil}(\mathrm{x}) ; \mathrm{rx}=\operatorname{round}(\mathrm{x})$;

o Check if interpolation is needed.

if $(a b s(x-r x)<1 e-6)$ \& \& $(a b s(y-r y)<1 e-6)$

o Interpolation is not needed, use original datatypes

$\mathrm{N}=$ image $(r y: r y+d y, r x: r x+d x)$;

$\mathrm{D}=\mathrm{N}>=\mathrm{C}$;

else

\% Interpolation needed, use double type images

$t_{y}=y-f_{y} ;$

$t x=x-f x ;$

o Calculate the interpolation weights.

$\mathrm{w} 1=\left(1-t_{x}\right) *\left(1-t_{y}\right) ;$

$\mathrm{w} 2=\operatorname{tx} *\left(1-t_{y}\right) ;$

$\mathrm{w} 3=\left(1-t_{x}\right) * \quad$ ty ;

$\mathrm{w} 4=$ tx $*$ ty ;

o Compute interpolated pixel values

$\mathrm{N} \quad=\quad \mathrm{w} 1 * \mathrm{~d}$ image $\left(f_{\mathrm{y}}: \mathrm{f}_{\mathrm{y}}+\mathrm{dy}, \mathrm{fx}: \mathrm{fx}+\mathrm{dx}\right)$

$\mathrm{w} 2 * \mathrm{~d}_{\text {_image }}\left(\mathrm{fy}_{\mathrm{y}}: \mathrm{fy}_{\mathrm{y}}+\mathrm{dy}, \mathrm{cx}: \mathrm{cx}+\mathrm{dx}\right)+\ldots$ $w 3 * d$ image $(c y: c y+d y, f x: f x+d x)$

$\mathrm{w} 4 * d$ image $(c y: c y+d y, c x: c x+d x)$;

$\overline{\mathrm{D}}=\mathrm{N}>=\mathrm{d} \mathrm{C}_{\mathrm{C}}$;

end

o Update the result matrix.

$\mathrm{v}=2^{\wedge}(i-1)$;

result $=$ result $+\mathrm{v}^{\star} \mathrm{D}$;

end

-Apply mapping if it is defined

if isstruct (mapping)

bins = mapping.num;

for $i=1$ :size(result, 1$)$

for $j=1$ :size(result, 2$)$

result $(i, j)=$ mapping.table(result $(i, j)+1)$;

end

end

end

if (strcmp (mode, 'h') II strcmp (mode, 'hist')

strcmp (mode, 'nh'))

\% Return with LBP histogram if mode equals 'hist'.

result=hist (result (:) , 0: (bins-1));

if ( $\mathrm{str} \mathrm{cmp}$ (mode, 'nh'))

result=result/sum(result);

end 
else

oOtherwise return a matrix of unsigned integers

if ( (bins-1)<=intmax ('uint8')) result=uint 8 (result);

elseif ( (bins-1)<=intmax ('uint16'))

result=uint16 (result);

else

result=uint 32 (result);

end

end

end 
APÊNDICE E - Matriz de Confusão LFP

\begin{tabular}{|c|c|c|c|c|c|c|c|c|c|c|c|c|c|c|c|c|c|c|c|c|c|c|c|}
\hline & $\Omega$ & $\Omega$ & $\tilde{\omega}$ & $\stackrel{2}{\perp}$ & u & $a$ & $\mathcal{Z}$ & 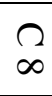 & ? & $\tilde{\sigma}$ & 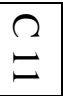 & $\hat{n}$ & $\vec{\omega}$ & $\stackrel{\Omega}{\perp}$ & $\hat{\tilde{u}}$ & $\vec{a}$ & 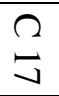 & $\stackrel{\beta}{\infty}$ & 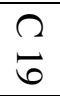 & $\begin{array}{l}\Omega \\
\tilde{O}\end{array}$ & $\mathcal{N}$ & N & $\widetilde{N}$ \\
\hline$\Omega$ & 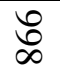 & 0 & 0 & 0 & 0 & 0 & 0 & 0 & 0 & 0 & 0 & 0 & 0 & 0 & 0 & 0 & 0 & 0 & - & 0 & 0 & 0 & 0 \\
\hline$\Omega$ & 0 & $\begin{array}{l}\infty \\
0 \\
ن\end{array}$ & 0 & - & - & - & 0 & 0 & 0 & - & 0 & 0 & 0 & 0 & 0 & 0 & 0 & - & 0 & 0 & 0 & 0 & 0 \\
\hline$\tilde{\omega}$ & 0 & 0 & $\overrightarrow{8}$ & 0 & 0 & 0 & 0 & 0 & 0 & 0 & 0 & 0 & 0 & 0 & 0 & 0 & 0 & 0 & 0 & 0 & 0 & 0 & 0 \\
\hline$\stackrel{\Omega}{\rho}$ & 0 & 0 & 0 & $\stackrel{\infty}{8}$ & 0 & 0 & 0 & 0 & 0 & 0 & 0 & 0 & 0 & 0 & 0 & 0 & 0 & 0 & 0 & 0 & 0 & 0 & 0 \\
\hline$\Omega$ & 0 & 0 & 0 & 0 & $\infty$ & 0 & 0 & - & 0 & 0 & 0 & 0 & 0 & 0 & 0 & 0 & 0 & 0 & 0 & 0 & 0 & 0 & 0 \\
\hline 2 & 0 & - & 0 & 0 & 0 & $\underset{\infty}{\infty}$ & 0 & 0 & 0 & 0 & 0 & 0 & 0 & 0 & 0 & 0 & 0 & 0 & 0 & 0 & 0 & 0 & 0 \\
\hline 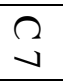 & 0 & 0 & 0 & 0 & 0 & 0 & \& & 0 & - & 0 & 0 & 0 & 0 & 0 & 0 & 0 & 0 & 0 & 0 & 0 & 0 & 0 & $N$ \\
\hline$\infty$ & 0 & 0 & 0 & 0 & 0 & 0 & 0 & $\stackrel{8}{\perp}$ & 0 & 0 & - & 0 & 0 & 0 & 0 & 0 & - & 0 & - & 0 & - & 0 & - \\
\hline 8 & 0 & 0 & 0 & 0 & 0 & 0 & 0 & 0 & $\underset{0}{\infty}$ & 0 & 0 & 0 & 0 & 0 & 0 & 0 & 0 & 0 & 0 & 0 & 0 & 0 & 0 \\
\hline$\tilde{\sigma}$ & 0 & 0 & 0 & 0 & 0 & 0 & 0 & 0 & 0 & 8 & 0 & 0 & 0 & 0 & 0 & 0 & 0 & 0 & 0 & 0 & 0 & 0 & 0 \\
\hline$\Omega$ & 0 & 0 & 0 & 0 & 0 & 0 & 0 & 0 & 0 & 0 & $\begin{array}{l}\infty \\
\infty\end{array}$ & 0 & 0 & 0 & 0 & 0 & 0 & 0 & 0 & 0 & 0 & 0 & 0 \\
\hline $\begin{array}{l}\Omega \\
N\end{array}$ & 0 & 0 & 0 & 0 & 0 & 0 & 0 & 0 & 0 & - & 0 & $\underset{\nabla}{0}$ & 0 & 0 & 0 & 0 & 0 & 0 & 0 & 0 & - & 0 & 0 \\
\hline$\stackrel{\Omega}{\omega}$ & 0 & 0 & 0 & 0 & 0 & 0 & 0 & - & 0 & 0 & 0 & 0 & $\stackrel{8}{\circ}$ & - & 0 & 0 & 0 & 0 & 0 & 0 & 0 & 0 & 0 \\
\hline$\frac{\Omega}{\not}$ & 0 & 0 & 0 & 0 & 0 & - & 0 & 0 & 0 & 0 & 0 & 0 & 0 & $\begin{array}{l}\infty \\
+ \\
t\end{array}$ & 0 & 0 & 0 & 0 & 0 & 0 & 0 & 0 & 0 \\
\hline$\frac{\Omega}{u}$ & 0 & 0 & 0 & 0 & 0 & 0 & 0 & 0 & 0 & 0 & 0 & 0 & 0 & 0 & $\begin{array}{l}\omega \\
t\end{array}$ & 0 & 0 & 0 & 0 & 0 & 0 & 0 & 0 \\
\hline $\begin{array}{l}\Omega \\
\sigma\end{array}$ & 0 & 0 & 0 & 0 & 0 & 0 & 0 & 0 & 0 & 0 & 0 & 0 & 0 & 0 & 0 & $\stackrel{u}{ \pm}$ & 0 & 0 & 0 & 0 & 0 & 0 & 0 \\
\hline $\begin{array}{l}\Omega \\
\exists\end{array}$ & 0 & 0 & 0 & 0 & 0 & 0 & 0 & 0 & 0 & 0 & 0 & 0 & 0 & 0 & 0 & 0 & $\begin{array}{l}\infty \\
t \\
t\end{array}$ & 0 & 0 & 0 & 0 & - & 0 \\
\hline $\begin{array}{c}\Omega \\
\infty\end{array}$ & 0 & 0 & 0 & 0 & 0 & 0 & 0 & 0 & 0 & 0 & 0 & 0 & 0 & 0 & 0 & 0 & 0 & 8 & 0 & 0 & 0 & 0 & 0 \\
\hline$\frac{\Omega}{6}$ & 0 & 0 & 0 & - & 0 & 0 & 0 & 0 & 0 & 0 & 0 & 0 & 0 & 0 & 0 & 0 & 0 & 0 & $\begin{array}{l}\stackrel{\perp}{4} \\
\text { un }\end{array}$ & - & 0 & 0 & 0 \\
\hline $\begin{array}{l}\Omega \\
\tilde{O}\end{array}$ & 0 & 0 & 0 & 0 & $N$ & 0 & 0 & 0 & 0 & - & 0 & 0 & 0 & 0 & 0 & 0 & 0 & 0 & 0 & 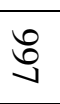 & 0 & 0 & 0 \\
\hline$\Omega$ & 0 & 0 & 0 & 0 & 0 & 0 & 0 & 0 & 0 & 0 & 0 & 0 & 0 & 0 & 0 & 0 & 0 & 0 & 0 & 0 & $\infty$ & - & 0 \\
\hline $\begin{array}{l}\Omega \\
N \\
N\end{array}$ & 0 & 0 & 0 & 0 & 0 & 0 & 0 & 0 & 0 & 0 & 0 & 0 & 0 & 0 & 0 & 0 & 0 & 0 & - & 0 & 0 & ఫౌ & - \\
\hline $\begin{array}{l}\Omega \\
N \\
\omega\end{array}$ & 0 & 0 & 0 & 0 & 0 & 0 & 0 & 0 & 0 & 0 & 0 & 0 & 0 & 0 & 0 & 0 & 0 & 0 & 0 & 0 & 0 & 0 & 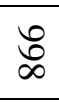 \\
\hline
\end{tabular}




\begin{tabular}{|c|c|c|c|c|c|c|c|c|c|c|c|c|c|c|c|c|c|c|c|c|c|c|c|}
\hline & $\stackrel{N}{A}$ & N & N & N & N & న్రి & $\tilde{O}$ & $\tilde{\omega}$ & $\stackrel{N}{N}$ & $\mathcal{\omega}_{\omega}$ & $\underset{\perp}{\mathcal{A}}$ & $\mathcal{u}_{u}$ & w్ & w & $\tilde{\infty}_{\infty}$ & $\widehat{్ ర ~}$ & $\frac{8}{0}$ & $\nexists$ & $\stackrel{尺}{N}$ & $\stackrel{s}{\omega}$ & $\stackrel{\curvearrowright}{+}$ & $\stackrel{尺}{\mathrm{c}}$ & $\frac{\Omega}{a}$ \\
\hline$\stackrel{\Omega}{N}$ & $\begin{array}{l}\infty \\
0\end{array}$ & 0 & 0 & 0 & 0 & 0 & 0 & 0 & 0 & - & 0 & 0 & 0 & 0 & 0 & 0 & 0 & 0 & 0 & 0 & 0 & 0 & 0 \\
\hline $\begin{array}{l}\Omega \\
\tilde{N}\end{array}$ & 0 & $\vec{\jmath}$ & 0 & 0 & 0 & 0 & 0 & 0 & 0 & 0 & 0 & 0 & 0 & 0 & 0 & 0 & 0 & 0 & 0 & 0 & 0 & 0 & 0 \\
\hline $\begin{array}{l}\Omega \\
\tilde{N}\end{array}$ & 0 & 0 & $\begin{array}{l}\infty \\
+ \\
+\end{array}$ & 0 & 0 & 0 & 0 & 0 & 0 & 0 & 0 & 0 & 0 & 0 & 0 & 0 & $N$ & 0 & 0 & 0 & 0 & 0 & 0 \\
\hline $\mathcal{N}$ & 0 & 0 & 0 & $\tilde{b}_{0}$ & 0 & 0 & 0 & 0 & 0 & 0 & 0 & 0 & 0 & 0 & 0 & 0 & 0 & 0 & 0 & 0 & 0 & 0 & 0 \\
\hline $\begin{array}{l}\Omega \\
N \\
\infty \\
\end{array}$ & 0 & 0 & 0 & 0 & : & 0 & 0 & 0 & 0 & 0 & 0 & 0 & 0 & 0 & 0 & 0 & 0 & 0 & 0 & 0 & 0 & - & 0 \\
\hline $\begin{array}{l}\Omega \\
N \\
\end{array}$ & 0 & 0 & 0 & 0 & - & 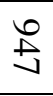 & 0 & 0 & - & 0 & 0 & 0 & 0 & 0 & 0 & 0 & 0 & 0 & 0 & 0 & 0 & 0 & 0 \\
\hline $\begin{array}{l}\tilde{\omega} \\
\tilde{\sigma}\end{array}$ & 0 & 0 & 0 & 0 & 0 & 0 & 8 & 0 & 0 & 0 & 0 & 0 & 0 & 0 & 0 & 0 & 0 & 0 & 0 & 0 & 0 & 0 & 0 \\
\hline$\tilde{\omega}$ & 0 & 0 & 0 & 0 & 0 & 0 & 0 & $\tilde{w}^{\prime}$ & 0 & 0 & 0 & 0 & 0 & 0 & 0 & 0 & 0 & 0 & 0 & 0 & 0 & 0 & 0 \\
\hline$\underset{\sim}{\sim}$ & 0 & 0 & 0 & 0 & 0 & 0 & 0 & 0 & $\frac{a}{b}$ & 0 & 0 & 0 & 0 & 0 & 0 & 0 & 0 & 0 & 0 & 0 & 0 & 0 & 0 \\
\hline$\underset{\omega}{\omega}$ & 0 & 0 & 0 & 0 & 0 & 0 & 0 & 0 & 0 & U్రి & 0 & 0 & 0 & 0 & 0 & 0 & 0 & 0 & 0 & 0 & 0 & 0 & $N$ \\
\hline$\underset{\omega}{\tilde{\perp}}$ & 0 & 0 & 0 & 0 & 0 & 0 & 0 & 0 & 0 & 0 & f̆ & 0 & 0 & 0 & 0 & 0 & 0 & 0 & 0 & 0 & 0 & 0 & 0 \\
\hline$\tilde{u}$ & 0 & 0 & 0 & 0 & 0 & 0 & 0 & 0 & 0 & 0 & 0 & 8 & 0 & 0 & 0 & 0 & 0 & 0 & 0 & 0 & 0 & 0 & 0 \\
\hline $\begin{array}{l}\tilde{w} \\
w \\
\sigma\end{array}$ & 0 & 0 & 0 & 0 & 0 & 0 & 0 & 0 & 0 & 0 & 0 & 0 & lo & 0 & 0 & 0 & 0 & 0 & 0 & 0 & 0 & 0 & 0 \\
\hline$\tilde{w}$ & 0 & 0 & 0 & 0 & 0 & 0 & 0 & 0 & 0 & 0 & 0 & 0 & 0 & $\vec{b}$ & 0 & 0 & 0 & 0 & 0 & 0 & 0 & 0 & 0 \\
\hline$\underset{\infty}{\Omega}$ & 0 & 0 & 0 & 0 & 0 & 0 & 0 & 0 & 0 & 0 & 0 & 0 & 0 & 0 & $\ddot{g}$ & 0 & 0 & 0 & 0 & 0 & 0 & 0 & 0 \\
\hline $\begin{array}{l}\tilde{\omega} \\
\omega \\
\end{array}$ & 0 & 0 & 0 & 0 & 0 & 0 & 0 & 0 & 0 & 0 & 0 & 0 & 0 & 0 & 0 & $\stackrel{ \pm}{ \pm}$ & 0 & 0 & 0 & 0 & 0 & 0 & 0 \\
\hline $\begin{array}{c}\Omega \\
0\end{array}$ & 0 & 0 & 0 & 0 & 0 & 0 & 0 & 0 & 0 & 0 & 0 & 0 & 0 & 0 & 0 & 0 & 8 & 0 & 0 & 0 & 0 & 0 & 0 \\
\hline$\stackrel{\Omega}{\nexists}$ & 0 & 0 & 0 & 0 & 0 & 0 & - & 0 & 0 & 0 & 0 & 0 & 0 & 0 & 0 & 0 & 0 & $\frac{u}{t}$ & 0 & 0 & 0 & 0 & 0 \\
\hline $\begin{array}{l}\Omega \\
\text { N } \\
\end{array}$ & 0 & 0 & 0 & 0 & 0 & 0 & 0 & 0 & 0 & 0 & 0 & 0 & 0 & 0 & 0 & 0 & 0 & 0 & 8 & 0 & 0 & 0 & 0 \\
\hline $\begin{array}{l}\Omega \\
\omega\end{array}$ & 0 & 0 & 0 & 0 & 0 & 0 & 0 & 0 & 0 & 0 & 0 & 0 & 0 & 0 & 0 & 0 & 0 & 0 & 0 & $\vec{b}$ & 0 & 0 & 0 \\
\hline $\begin{array}{l}\Omega \\
\$ \\
+\end{array}$ & 0 & 0 & 0 & 0 & 0 & 0 & 0 & 0 & 0 & 0 & 0 & 0 & 0 & 0 & 0 & 0 & 0 & 0 & 0 & 0 & ర్రి & 0 & 0 \\
\hline $\begin{array}{l}\Omega \\
\dot{u}\end{array}$ & - & 0 & 0 & 0 & 0 & 0 & 0 & 0 & 0 & 0 & 0 & 0 & 0 & 0 & 0 & 0 & 0 & 0 & 0 & 0 & 0 & $\vec{ర}$ & 0 \\
\hline $\begin{array}{l}2 \\
a \\
a\end{array}$ & 0 & 0 & 0 & 0 & 0 & 0 & 0 & 0 & 0 & 0 & 0 & 0 & 0 & 0 & 0 & 0 & 0 & 0 & 0 & 0 & 0 & 0 & lo \\
\hline
\end{tabular}




\begin{tabular}{|c|c|c|c|c|c|c|c|c|c|c|c|c|c|c|c|c|c|c|c|c|c|c|c|}
\hline & $\Omega$ & $\hat{N}$ & $\tilde{\omega}$ & $\AA$ & $\Omega$ & $\Omega$ & 3 & $\infty$ & 8 & $\stackrel{\Omega}{0}$ & $\cong$ & $\frac{\Omega}{N}$ & $\tilde{\omega}$ & $\stackrel{\Omega}{\not}$ & $\stackrel{\Omega}{u}$ & $\frac{\Omega}{a}$ & $\cong$ & $\widetilde{\Omega}$ & $\frac{\Omega}{6}$ & Nિ & $\mathcal{N}$ & N & N \\
\hline N & 0 & 0 & 0 & 0 & 0 & 0 & 0 & 0 & 0 & 0 & 0 & 0 & 0 & 0 & 0 & 0 & 0 & 0 & 0 & 0 & 0 & 0 & 0 \\
\hline N & 0 & 0 & 0 & 0 & 0 & 0 & 0 & 0 & 0 & 0 & 0 & 0 & 0 & 0 & 0 & 0 & 0 & 0 & 0 & 0 & 0 & 0 & 0 \\
\hline న్ & 0 & 0 & 0 & 0 & 0 & 0 & 0 & 0 & 0 & 0 & - & 0 & 0 & 0 & 0 & 0 & 0 & 0 & - & 0 & 0 & 0 & 0 \\
\hline N & 0 & 0 & 0 & 0 & 0 & 0 & 0 & 0 & 0 & 0 & - & 0 & 0 & 0 & 0 & 0 & 0 & 0 & 0 & 0 & 0 & 0 & 0 \\
\hline ని & 0 & 0 & 0 & 0 & 0 & 0 & 0 & 0 & 0 & 0 & 0 & 0 & 0 & 0 & 0 & 0 & 0 & 0 & 0 & 0 & 0 & 0 & 0 \\
\hline N్ర & 0 & 0 & 0 & 0 & 0 & 0 & 0 & 0 & 0 & 0 & 0 & 0 & 0 & 0 & 0 & 0 & 0 & 0 & - & 0 & 0 & 0 & 0 \\
\hline$\tilde{O}$ & 0 & 0 & 0 & 0 & 0 & 0 & 0 & 0 & 0 & 0 & - & 0 & 0 & 0 & 0 & 0 & 0 & 0 & 0 & 0 & 0 & 0 & 0 \\
\hline$\tilde{\omega}$ & 0 & 0 & 0 & 0 & 0 & 0 & 0 & 0 & 0 & 0 & 0 & 0 & 0 & 0 & 0 & 0 & 0 & 0 & 0 & 0 & 0 & 0 & 0 \\
\hline $\mathcal{N}$ & 0 & 0 & 0 & 0 & 0 & 0 & 0 & 0 & 0 & 0 & 0 & 0 & 0 & 0 & 0 & 0 & 0 & 0 & - & 0 & 0 & 0 & 0 \\
\hline w్ & 0 & 0 & 0 & 0 & 0 & 0 & 0 & 0 & 0 & 0 & 0 & 0 & 0 & 0 & 0 & 0 & 0 & 0 & 0 & 0 & 0 & 0 & 0 \\
\hline$\underset{\perp}{W}$ & 0 & 0 & 0 & 0 & 0 & 0 & 0 & 0 & 0 & 0 & 0 & 0 & 0 & 0 & 0 & 0 & 0 & 0 & 0 & 0 & 0 & 0 & 0 \\
\hline $\mathcal{w}_{u}$ & 0 & 0 & 0 & 0 & 0 & 0 & 0 & 0 & 0 & 0 & 0 & 0 & 0 & 0 & 0 & 0 & 0 & 0 & 0 & 0 & 0 & 0 & 0 \\
\hline$\tilde{\alpha}$ & 0 & 0 & 0 & 0 & 0 & 0 & 0 & 0 & 0 & 0 & 0 & 0 & 0 & 0 & 0 & 0 & 0 & 0 & 0 & 0 & 0 & 0 & 0 \\
\hline$\tilde{v}$ & 0 & 0 & 0 & 0 & 0 & 0 & 0 & 0 & 0 & 0 & - & 0 & 0 & 0 & 0 & 0 & 0 & 0 & 0 & 0 & 0 & 0 & 0 \\
\hline$\underset{\infty}{\infty}$ & 0 & 0 & 0 & 0 & 0 & 0 & 0 & 0 & 0 & 0 & 0 & 0 & 0 & 0 & 0 & 0 & 0 & 0 & 0 & 0 & 0 & 0 & 0 \\
\hline$\tilde{W}$ & 0 & 0 & 0 & 0 & 0 & 0 & 0 & - & 0 & 0 & 0 & 0 & 0 & 0 & 0 & 0 & - & 0 & 0 & 0 & 0 & - & 0 \\
\hline$\frac{8}{0}$ & 0 & 0 & 0 & 0 & 0 & 0 & 0 & 0 & 0 & 0 & 0 & 0 & 0 & 0 & 0 & 0 & 0 & 0 & 0 & 0 & 0 & 0 & 0 \\
\hline 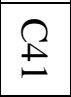 & 0 & 0 & 0 & 0 & 0 & 0 & 0 & 0 & 0 & 0 & 0 & 0 & 0 & 0 & 0 & 0 & 0 & 0 & 0 & 0 & 0 & 0 & 0 \\
\hline$\frac{B}{N}$ & 0 & 0 & 0 & 0 & 0 & 0 & 0 & 0 & 0 & 0 & 0 & 0 & 0 & 0 & 0 & 0 & 0 & 0 & 0 & 0 & 0 & 0 & 0 \\
\hline$\stackrel{尺}{E}$ & 0 & 0 & 0 & 0 & 0 & 0 & 0 & 0 & 0 & 0 & 0 & 0 & 0 & - & 0 & 0 & 0 & 0 & 0 & 0 & 0 & 0 & 0 \\
\hline$\stackrel{尺}{\perp}$ & 0 & 0 & 0 & 0 & 0 & 0 & 0 & 0 & 0 & 0 & 0 & - & 0 & 0 & 0 & 0 & 0 & 0 & 0 & 0 & 0 & 0 & 0 \\
\hline$\stackrel{8}{4}$ & 0 & 0 & 0 & 0 & 0 & 0 & 0 & 0 & 0 & 0 & 0 & 0 & 0 & 0 & 0 & 0 & 0 & 0 & 0 & 0 & 0 & 0 & 0 \\
\hline$\frac{f}{a}$ & 0 & 0 & 0 & 0 & 0 & 0 & 0 & 0 & 0 & 0 & 0 & 0 & 0 & 0 & 0 & 0 & 0 & 0 & 0 & 0 & 0 & 0 & 0 \\
\hline
\end{tabular}




\begin{tabular}{|c|c|c|c|c|c|c|c|c|c|c|c|c|c|c|c|c|c|c|c|c|c|c|c|}
\hline & $\stackrel{N}{A}$ & Nي & Nૂ & N & N & $\mathcal{N}$ & జ్రి & $\mathcal{\omega}$ & W & $\mathcal{\omega}_{\omega}$ & $\underset{\sim}{\mathcal{A}}$ & $\mathcal{W}_{u}$ & $\tilde{w}$ & $\mathcal{W}$ & $\widehat{W}_{\infty}$ & $\tilde{W}$ & 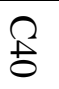 & $\nexists$ & $\frac{\Omega}{N}$ & 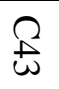 & $\stackrel{\curvearrowright}{\$}$ & $\stackrel{8}{*}$ & $\frac{\Omega}{a}$ \\
\hline$\Omega$ & 0 & 0 & 0 & 0 & 0 & 0 & 0 & 0 & 0 & - & 0 & 0 & 0 & 0 & 0 & 0 & 0 & 0 & 0 & 0 & 0 & 0 & 0 \\
\hline N & 0 & 0 & 0 & 0 & 0 & 0 & 0 & 0 & 0 & 0 & 0 & 0 & 0 & 0 & 0 & 0 & 0 & 0 & 0 & 0 & 0 & 0 & 0 \\
\hline $\mathcal{\omega}$ & 0 & 0 & - & 0 & 0 & 0 & 0 & 0 & 0 & 0 & 0 & 0 & 0 & 0 & 0 & 0 & 0 & 0 & 0 & 0 & 0 & 0 & 0 \\
\hline$\AA$ & 0 & 0 & 0 & 0 & 0 & 0 & 0 & 0 & 0 & 0 & 0 & 0 & 0 & 0 & 0 & 0 & 0 & 0 & 0 & 0 & 0 & 0 & 0 \\
\hline $\mathcal{O}_{1}$ & 0 & 0 & 0 & 0 & 0 & 0 & 0 & 0 & 0 & 0 & 0 & - & 0 & 0 & 0 & 0 & 0 & 0 & 0 & 0 & 0 & 0 & 0 \\
\hline 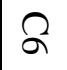 & 0 & 0 & 0 & 0 & 0 & 0 & 0 & 0 & 0 & 0 & 0 & 0 & - & 0 & 0 & 0 & 0 & 0 & 0 & 0 & 0 & 0 & 0 \\
\hline $\mathcal{S}$ & 0 & 0 & - & 0 & 0 & 0 & 0 & 0 & 0 & 0 & 0 & 0 & 0 & 0 & 0 & 0 & 0 & 0 & - & 0 & 0 & 0 & 0 \\
\hline$\infty$ & 0 & 0 & 0 & 0 & 0 & 0 & 0 & 0 & 0 & 0 & 0 & 0 & 0 & 0 & 0 & 0 & 0 & 0 & 0 & - & 0 & 0 & 0 \\
\hline 8 & 0 & 0 & 0 & 0 & 0 & 0 & 0 & 0 & 0 & 0 & 0 & 0 & 0 & 0 & 0 & 0 & 0 & 0 & 0 & 0 & 0 & 0 & 0 \\
\hline$\frac{\Omega}{0}$ & 0 & 0 & 0 & 0 & 0 & 0 & 0 & 0 & 0 & 0 & 0 & 0 & 0 & 0 & 0 & 0 & 0 & - & 0 & 0 & 0 & 0 & 0 \\
\hline$\Omega$ & 0 & 0 & 0 & 0 & 0 & 0 & 0 & 0 & - & 0 & 0 & 0 & 0 & 0 & 0 & 0 & 0 & 0 & 0 & 0 & 0 & 0 & - \\
\hline$\frac{\Omega}{N}$ & 0 & 0 & 0 & 0 & - & 0 & 0 & 0 & 0 & 0 & 0 & 0 & 0 & 0 & 0 & 0 & 0 & 0 & 0 & 0 & 0 & 0 & 0 \\
\hline$\tilde{\omega}$ & 0 & 0 & 0 & 0 & 0 & 0 & 0 & 0 & 0 & $N$ & 0 & 0 & 0 & 0 & 0 & 0 & 0 & 0 & 0 & 0 & $N$ & 0 & 0 \\
\hline$\stackrel{\Omega}{\perp}$ & 0 & 0 & 0 & 0 & 0 & 0 & 0 & 0 & 0 & 0 & 0 & 0 & 0 & 0 & 0 & 0 & 0 & 0 & 0 & 0 & 0 & 0 & 0 \\
\hline$\frac{\Omega}{u}$ & 0 & 0 & 0 & 0 & 0 & 0 & 0 & 0 & 0 & 0 & - & 0 & 0 & 0 & 0 & 0 & 0 & 0 & 0 & 0 & 0 & 0 & 0 \\
\hline 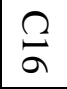 & 0 & 0 & 0 & 0 & 0 & 0 & 0 & 0 & 0 & 0 & 0 & 0 & 0 & 0 & 0 & $\omega$ & 0 & 0 & 0 & 0 & 0 & 0 & 0 \\
\hline$\Omega$ & 0 & 0 & 0 & 0 & 0 & 0 & 0 & 0 & 0 & 0 & 0 & 0 & 0 & 0 & 0 & 0 & 0 & 0 & 0 & 0 & 0 & 0 & 0 \\
\hline$\stackrel{\Omega}{\infty}$ & 0 & 0 & 0 & 0 & 0 & 0 & 0 & 0 & 0 & 0 & 0 & 0 & 0 & 0 & 0 & 0 & 0 & 0 & 0 & 0 & 0 & 0 & 0 \\
\hline$\widetilde{\sigma}$ & 0 & 0 & 0 & 0 & - & 0 & 0 & $N$ & 0 & 0 & 0 & 0 & 0 & 0 & 0 & 0 & 0 & 0 & 0 & 0 & 0 & 0 & 0 \\
\hline త్రి & 0 & 0 & 0 & 0 & 0 & 0 & 0 & 0 & 0 & 0 & 0 & 0 & 0 & 0 & 0 & 0 & 0 & 0 & 0 & 0 & 0 & 0 & 0 \\
\hline N & 0 & 0 & 0 & 0 & 0 & 0 & - & 0 & 0 & 0 & 0 & 0 & 0 & 0 & 0 & 0 & 0 & 0 & 0 & 0 & 0 & 0 & 0 \\
\hline N & 0 & 0 & 0 & 0 & 0 & 0 & 0 & 0 & 0 & 0 & 0 & 0 & 0 & 0 & 0 & 0 & 0 & 0 & 0 & 0 & 0 & 0 & 0 \\
\hline N & 0 & 0 & 0 & 0 & 0 & 0 & 0 & 0 & 0 & 0 & 0 & 0 & - & 0 & 0 & 0 & 0 & 0 & 0 & 0 & 0 & 0 & - \\
\hline
\end{tabular}




\section{APÊNDICE F - Matriz de Confusão LBP}

\begin{tabular}{|c|c|c|c|c|c|c|c|c|c|c|c|c|c|c|c|c|c|c|c|c|c|c|c|}
\hline & $\Omega$ & $\hat{N}$ & $\widehat{\omega}$ & $\AA$ & O & 2 & 3 & $\Omega$ & 2 & $\frac{\Omega}{0}$ & $\Xi$ & $\frac{\Omega}{N}$ & $\frac{\Omega}{\omega}$ & $\stackrel{\Omega}{\perp}$ & $\tilde{u}$ & $\stackrel{\Omega}{a}$ & $\Xi$ & $\frac{\Omega}{\infty}$ & $\frac{2}{6}$ & $\tilde{N}$ & $\widehat{N}$ & N & N \\
\hline 2 & 8 & _ & 0 & 0 & $c$ & 0 & 0 & & & 0 & 0 & 0 & 0 & 0 & 0 & 0 & 0 & 0 & 0 & 0 & 0 & 0 & 0 \\
\hline 3 & 0 & $\infty$ & 0 & 0 & 0 & 0 & 0 & & & 0 & 0 & 0 & - & 0 & 0 & 0 & 0 & 0 & 0 & 0 & 0 & 0 & 0 \\
\hline 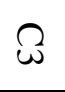 & 0 & 0 & $\overrightarrow{\mathrm{E}}$ & 0 & 0 & 0 & 0 & & 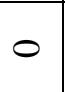 & 0 & 0 & 0 & 0 & 0 & 0 & 0 & 0 & 0 & 0 & 0 & 0 & 0 & 0 \\
\hline$f$ & 0 & 0 & 0 & 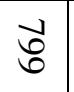 & 0 & & 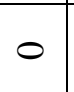 & & 0 & 0 & 0 & 0 & 0 & 0 & 0 & 0 & 0 & 0 & 0 & 0 & 0 & 0 & 0 \\
\hline$u_{12}^{2}$ & 10 & - & 0 & 0 & $\stackrel{\alpha}{0}$ & & 0 & & 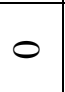 & 0 & 0 & 0 & 0 & 0 & 0 & 0 & 0 & 0 & 0 & 0 & 0 & 0 & 0 \\
\hline 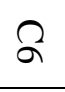 & 0 & 0 & 0 & 0 & 0 & 8 & 0 & $\mathrm{~N}$ & 0 & 0 & 0 & 0 & 0 & 0 & 0 & 0 & 0 & 0 & 0 & 0 & 0 & 0 & 0 \\
\hline$\widehat{3}$ & 0 & 0 & 0 & 0 & 0 & 0 & a & 0 & 0 & 0 & 0 & 0 & 0 & 0 & 0 & 0 & 0 & 0 & 0 & 0 & 0 & 0 & 0 \\
\hline$\infty$ & - & 0 & 0 & 0 & - & 0 & 0 & $\doteq$ & - & 0 & 0 & 0 & 0 & 0 & 0 & 0 & 0 & 0 & 0 & 0 & 0 & 0 & 0 \\
\hline 6 & 0 & 0 & 0 & 0 & 0 & 0 & 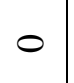 & 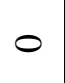 & $\infty$ & 0 & o & 0 & 0 & 0 & 0 & 0 & 0 & b & $b$ & 0 & 0 & 0 & 0 \\
\hline$\frac{2}{6}$ & 0 & 0 & 0 & 0 & 0 & 0 & 0 & 0 & 0 & : & 0 & 0 & 0 & 0 & 0 & 0 & 0 & 0 & 0 & 0 & 0 & - & 0 \\
\hline$\Omega$ & - & 0 & 0 & 0 & 0 & 0 & 0 & 0 & 0 & 0 & 占 & 0 & - & 0 & 0 & 0 & 0 & 0 & 0 & 0 & 0 & 0 & 0 \\
\hline u & 0 & 0 & 0 & 0 & 0 & 0 & 0 & 0 & - & 0 & - & $\begin{array}{l}0 \\
\infty \\
\infty\end{array}$ & 0 & 0 & 0 & 0 & 0 & 0 & 0 & 0 & 0 & 0 & 0 \\
\hline$\frac{1}{\omega}$ & 0 & 0 & $c$ & 0 & 0 & 0 & 0 & 0 & 0 & 0 & 0 & 0 & $\begin{array}{l} \\
\infty \\
\infty\end{array}$ & 0 & 0 & 0 & 0 & - & 0 & 0 & 0 & 0 & 0 \\
\hline$\frac{2}{A}$ & 0 & 0 & 0 & 0 & 0 & 0 & 0 & 0 & 0 & 0 & 0 & $N$ & 0 & $\stackrel{\infty}{\stackrel{\infty}{*}}$ & 0 & 0 & 0 & 0 & 0 & 0 & 0 & 0 & 0 \\
\hline$\frac{2}{n}$ & 0 & 0 & 0 & 0 & 0 & 0 & 0 & 0 & 0 & 0 & 0 & 0 & 0 & 0 & $\underset{t}{t}$ & 0 & 0 & 0 & 0 & 0 & 0 & 0 & 0 \\
\hline$\frac{2}{\sigma}$ & 0 & 0 & 0 & 0 & - & 0 & 0 & 0 & 0 & 0 & 0 & 0 & 0 & 0 & 0 & tu & 0 & 0 & 0 & 0 & 0 & 0 & 0 \\
\hline$\frac{\Omega}{2}$ & 0 & 0 & 0 & 0 & 0 & 0 & 0 & 0 & $N$ & 0 & 0 & 0 & 0 & 0 & 0 & 0 & $\begin{array}{l}\infty \\
\pm\end{array}$ & 0 & 0 & 0 & 0 & 0 & 0 \\
\hline$\frac{\Omega}{\infty}$ & 0 & 0 & 0 & 0 & 0 & 0 & 0 & 0 & 0 & 0 & 0 & 0 & 0 & 0 & 0 & 0 & 0 & $\begin{array}{l} \\
8\end{array}$ & 0 & 0 & 0 & 0 & 0 \\
\hline$\frac{2}{6}$ & 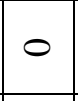 & 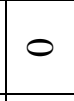 & 0 & 0 & 0 & 0 & 0 & 0 & 0 & - & 0 & 0 & 0 & 0 & 0 & 0 & 0 & 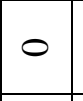 & $\begin{array}{l} \\
\\
\end{array}$ & 0 & 0 & 0 & 0 \\
\hline స్ & 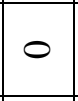 & 0 & 0 & 0 & 0 & 8 & 0 & 0 & 0 & 0 & 0 & 0 & 0 & 0 & 0 & 0 & 0 & 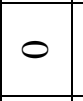 & 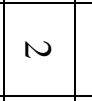 & : & 0 & - & 0 \\
\hline$\stackrel{N}{N}$ & 0 & 0 & 0 & 0 & 0 & 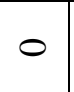 & 0 & 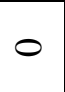 & 0 & 0 & 0 & 0 & 0 & 0 & 0 & 0 & 0 & - & 0 & 0 & $\begin{array}{l}\infty \\
0 \\
0\end{array}$ & - & 0 \\
\hline N & 0 & 0 & 0 & 0 & 0 & 0 & 0 & 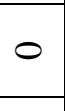 & - & 0 & 0 & 0 & 0 & - & 0 & 0 & 0 & 0 & 0 & 0 & 0 & ర్ర & 0 \\
\hline న్心 & 0 & 0 & 0 & 0 & 0 & 0 & 0 & 0 & 0 & 0 & 0 & 0 & 0 & 0 & 0 & 0 & 0 & 0 & 0 & 0 & 0 & 0 & $\bar{\varnothing}$ \\
\hline
\end{tabular}




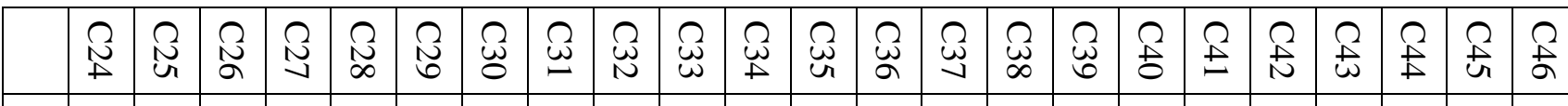

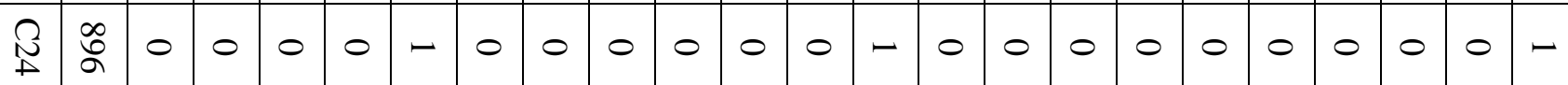

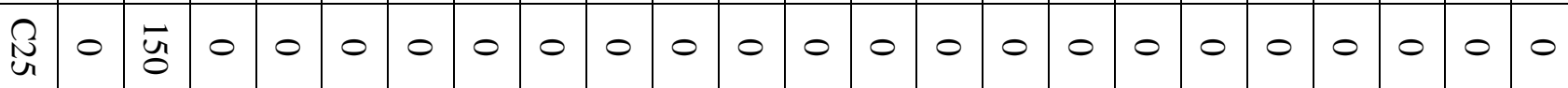
Nૂ心

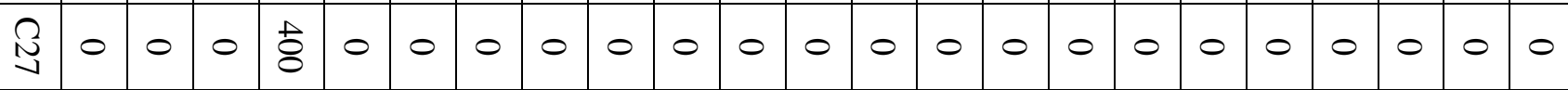

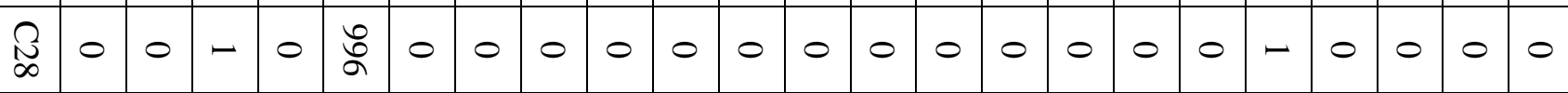

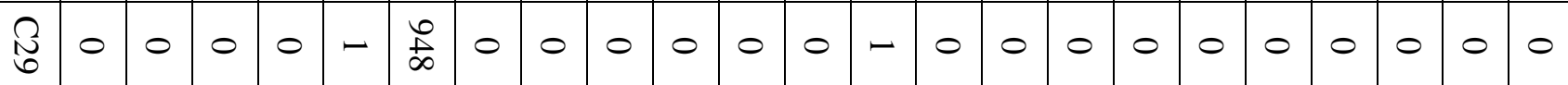

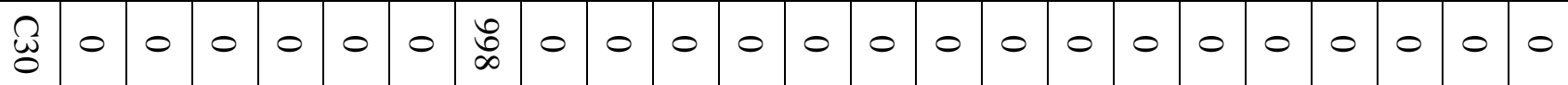

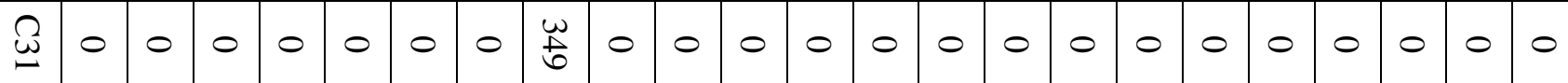
\begin{tabular}{|lllllllllllllllllllll|l|l|l|l|lll}
$\mathfrak{N}^{\prime}$ & 0 & 0 & 0 & 0 & 0 & 0 & 0 & 0 & $\hat{y}$ & 0 & 0 & 0 & 0 & 0 & 0 & 0 & 0 & 0 & 0 & 0 & 0 & 0 & 0
\end{tabular}

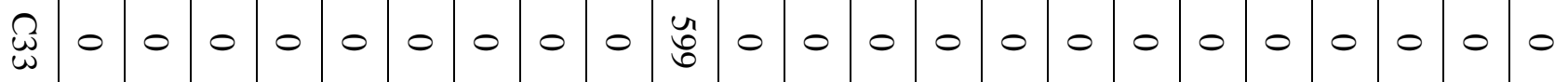

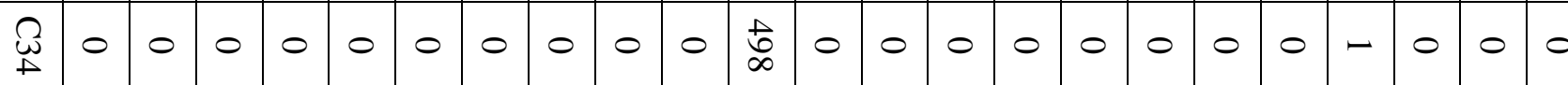
$\begin{array}{lllllllllllllllllllllllllllllll}\tilde{U}_{1} & 0 & 0 & 0 & 0 & 0 & 0 & 0 & 0 & 0 & 0 & 0 & 8 & 0 & 0 & 0 & 0 & 0 & 0 & 0 & 0 & 0 & 0 & 0\end{array}$

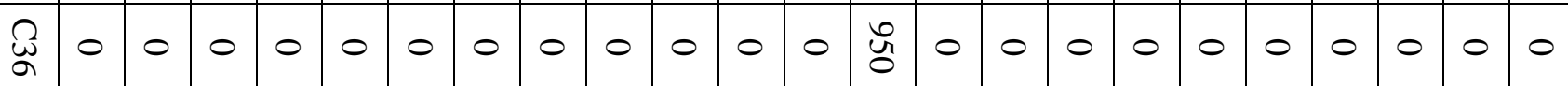

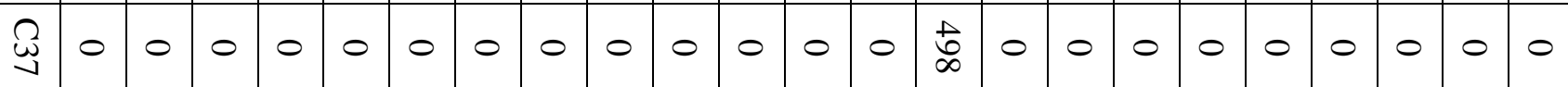
\begin{tabular}{llllllllllllllllllllllllllllllll}
$\tilde{W}_{0}$ & 0 & 0 & 0 & 0 & 0 & 0 & 0 & 0 & 0 & 0 & 0 & 0 & 0 & 0 & $\mathscr{8}$ & 0 & 0 & 0 & 0 & 0 & 0 & 0 & 0 \\
\hline
\end{tabular}

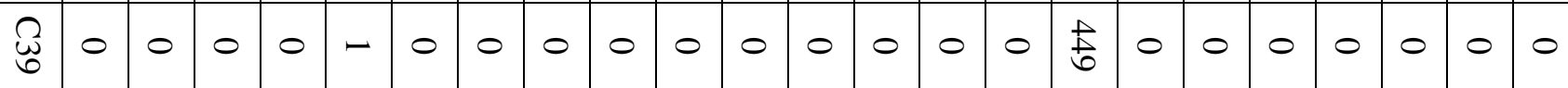
\begin{tabular}{lllllllllllllllllllll|l|l|l|l|l|l|l|}
\hline$f$ & 0 & 0 & 0 & 0 & 0 & 0 & 0 & 0 & 0 & 0 & 0 & 0 & 0 & 0 & 0 & 0 & 8 & 0 & 0 & 0 & 0 & 0 & 0
\end{tabular}

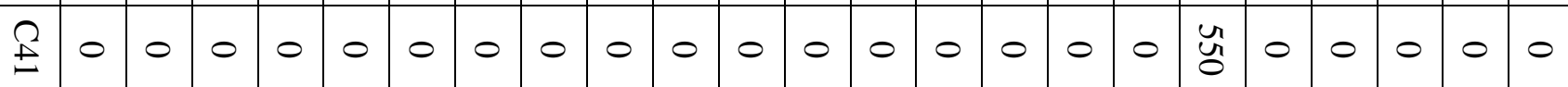

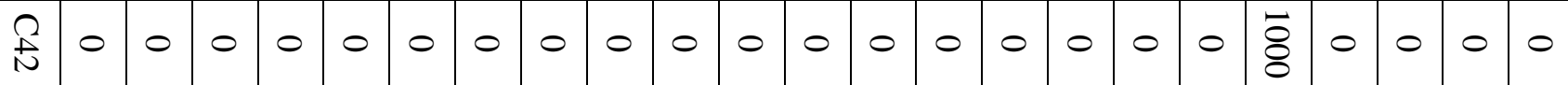

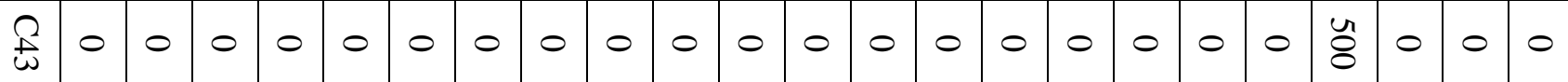

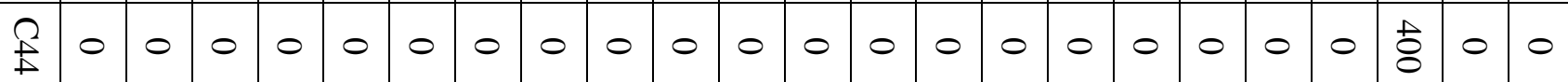
\begin{tabular}{lllllllllllllllllllllllll|l|l|l|l|l|}
\hline & 0 & 0 & 0 & 0 & 0 & 0 & 0 & 0 & 0 & 0 & 0 & 0 & 0 & 0 & 0 & 0 & 0 & 0 & 0 & 0 & 0 & 8 & 0
\end{tabular}

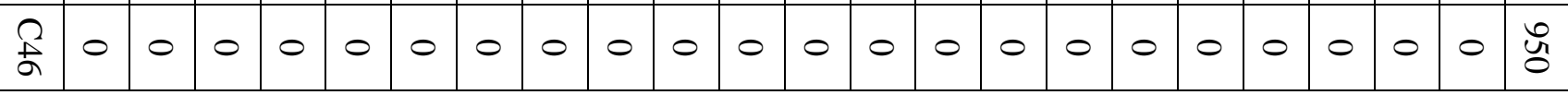




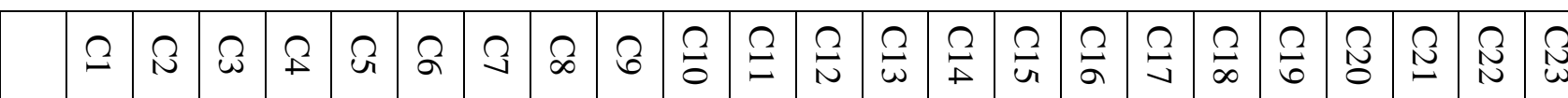
$\begin{array}{llllllllllllllllllllllllll}+ & 0 & - & 0 & 0 & 0 & 0 & 0 & 0 & 0 & 0 & 0 & 0 & 0 & 0 & 0 & 0 & 0 & 0 & 0 & 0 & 0 & 0 & 0\end{array}$ $\begin{array}{lllllllllllllllllllllllll}\mathcal{N}_{1} & 0 & 0 & 0 & 0 & 0 & 0 & 0 & 0 & 0 & 0 & 0 & 0 & 0 & 0 & 0 & 0 & 0 & 0 & 0 & 0 & 0 & 0 & 0\end{array}$ $\begin{array}{lllllllllllllllllllllllll}\mathcal{N} & 0 & 0 & 0 & 0 & - & 0 & 0 & 0 & 0 & 0 & 0 & 0 & 0 & 0 & 0 & 0 & 0 & 0 & 0 & 0 & 0 & 0 & 0\end{array}$ N $\begin{array}{lllllllllllllllllllllllll}\mathbb{N}_{\infty} & 0 & 0 & 0 & 0 & 0 & 0 & 0 & 0 & 0 & 0 & 0 & 0 & 0 & 0 & 0 & - & 0 & 0 & 0 & - & 0 & 0 & 0\end{array}$

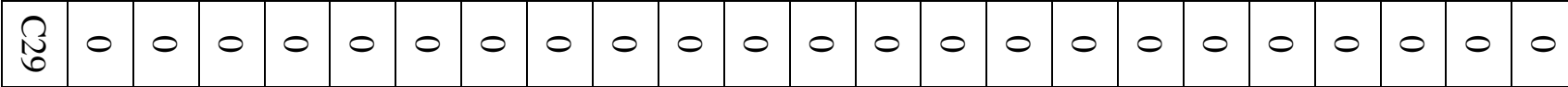
\begin{tabular}{|lllllllllllllllllllllllllll|l}
$\tilde{U}$ & 0 & 0 & 0 & 0 & 0 & 0 & 0 & 0 & - & 0 & 0 & 0 & 0 & 0 & 0 & 0 & - & 0 & 0 & 0 & 0 & 0 & 0
\end{tabular}

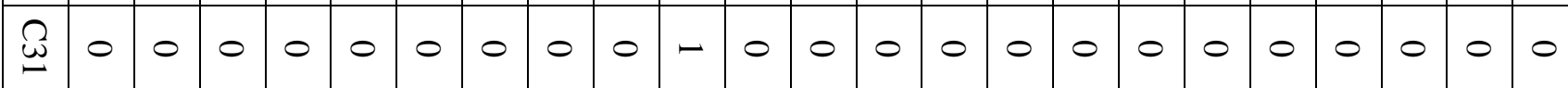

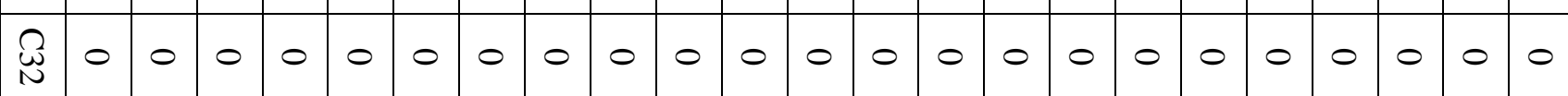
$\begin{array}{llllllllllllllllllllllll}\mathcal{\omega}^{\prime} & 0 & 0 & 0 & 0 & 0 & - & 0 & 0 & 0 & 0 & 0 & 0 & 0 & 0 & 0 & 0 & 0 & 0 & 0 & 0 & 0 & 0 & 0\end{array}$

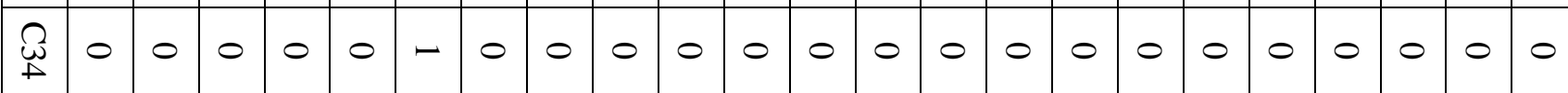
$\begin{array}{llllllllllllllllllllllll}\tilde{u} & 0 & 0 & 0 & 0 & 0 & 0 & 0 & 0 & 0 & 0 & 0 & 0 & 0 & 0 & 0 & 0 & 0 & 0 & 0 & 0 & 0 & 0 & 0\end{array}$ $\begin{array}{lllllllllllllllllllllllll}\mathcal{W}_{\omega} & 0 & 0 & 0 & 0 & 0 & 0 & 0 & 0 & 0 & 0 & 0 & 0 & 0 & 0 & 0 & 0 & 0 & 0 & 0 & 0 & 0 & 0 & 0\end{array}$ $\begin{array}{llllllllllllllllllllllllll}\mathcal{U}^{\prime} & 0 & 0 & 0 & 0 & 0 & 0 & 0 & 0 & 0 & 0 & 0 & 0 & N & 0 & 0 & 0 & 0 & 0 & 0 & 0 & 0 & 0 & 0\end{array}$ $\begin{array}{lllllllllllllllllllllllll}\bigcup_{\infty} & 0 & 0 & 0 & 0 & 0 & 0 & 0 & 0 & 0 & 0 & 0 & 0 & 0 & 0 & 0 & 0 & 0 & 0 & 0 & 0 & 0 & 0 & 0\end{array}$ $\begin{array}{lllllllllllllllllllllllll}\tilde{\omega} & 0 & 0 & 0 & 0 & 0 & 0 & 0 & 0 & 0 & 0 & 0 & 0 & 0 & 0 & 0 & 0 & 0 & 0 & 0 & 0 & 0 & 0 & 0\end{array}$ $\begin{array}{lllllllllllllllllllllllll}f & 0 & 0 & 0 & 0 & 0 & 0 & 0 & 0 & 0 & 0 & 0 & 0 & 0 & 0 & 0 & 0 & 0 & 0 & 0 & 0 & 0 & 0 & 0\end{array}$ E

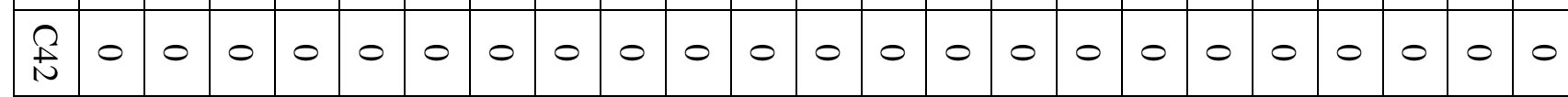
\begin{tabular}{|l|lllllllllllllllllllllllll|}
\hline $\mathcal{H}$ & 0 & 0 & 0 & 0 & 0 & 0 & 0 & 0 & 0 & 0 & 0 & 0 & 0 & 0 & 0 & 0 & 0 & 0 & 0 & 0 & 0 & 0 & 0 \\
\hline
\end{tabular} f \begin{tabular}{lllllllllllllllllllllllll}
$f$ & $f$ & 0 & 0 & 0 & 0 & 0 & 0 & 0 & 0 & 0 & 0 & 0 & 0 & 0 & 0 & 0 & 0 & 0 & 0 & 0 & 0 & 0 & 0 & 0 \\
\hline
\end{tabular}

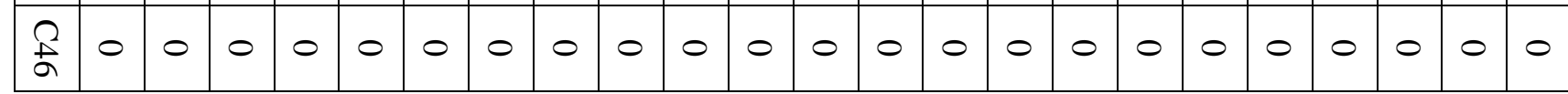




\begin{tabular}{|c|c|c|c|c|c|c|c|c|c|c|c|c|c|c|c|c|c|c|c|c|c|c|c|}
\hline & $\stackrel{N}{A}$ & N & న్ & N & N & Nิ & $\tilde{O}$ & $\tilde{\omega}$ & $\mathcal{N}$ & $\stackrel{\omega}{\omega}$ & $\underset{\perp}{A}$ & $\tilde{u}_{u}$ & $\tilde{\sigma}$ & $\tilde{U}$ & $\mathcal{W}_{\infty}$ & W్ర & $\stackrel{\S}{0}$ & 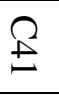 & $\stackrel{\AA}{\mathrm{N}}$ & $\stackrel{\overbrace{}}{\omega}$ & $\stackrel{尺}{f}$ & $\stackrel{\leftrightarrow}{\mathrm{H}}$ & $\frac{\Omega}{a}$ \\
\hline$\Omega$ & 0 & 0 & 0 & 0 & 0 & 0 & 0 & 0 & 0 & 0 & 0 & 0 & 0 & 0 & 0 & 0 & 0 & 0 & 0 & 0 & 0 & - & 0 \\
\hline N & 0 & 0 & 0 & 0 & 0 & 0 & 0 & 0 & 0 & 0 & 0 & 0 & 0 & 0 & 0 & 0 & 0 & 0 & 0 & 0 & 0 & 0 & 0 \\
\hline$\omega$ & 0 & 0 & 0 & 0 & 0 & 0 & 0 & 0 & 0 & 0 & 0 & 0 & 0 & 0 & - & 0 & 0 & 0 & 0 & 0 & 0 & 0 & 0 \\
\hline$\AA$ & 0 & 0 & - & 0 & 0 & 0 & 0 & 0 & 0 & 0 & 0 & 0 & 0 & 0 & 0 & 0 & 0 & 0 & 0 & 0 & 0 & 0 & 0 \\
\hline O & 0 & 0 & 0 & 0 & 0 & 0 & - & 0 & 0 & 0 & 0 & 0 & 0 & 0 & 0 & 0 & 0 & 0 & $N$ & 0 & 0 & 0 & 0 \\
\hline 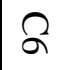 & 0 & 0 & 0 & 0 & 0 & 0 & - & 0 & 0 & 0 & 0 & 0 & 0 & 0 & 0 & 0 & 0 & 0 & 0 & 0 & 0 & 0 & 0 \\
\hline $\mathcal{3}$ & 0 & 0 & 0 & 0 & 0 & 0 & 0 & 0 & 0 & 0 & 0 & 0 & 0 & 0 & 0 & 0 & 0 & 0 & 0 & 0 & 0 & 0 & 0 \\
\hline$\infty$ & - & 0 & 0 & 0 & 0 & 0 & 0 & 0 & 0 & 0 & 0 & 0 & 0 & 0 & 0 & 0 & 0 & 0 & 0 & 0 & 0 & 0 & 0 \\
\hline 6 & 0 & 0 & 0 & 0 & 0 & 0 & $N$ & 0 & 0 & 0 & 0 & 0 & 0 & 0 & 0 & 0 & 0 & 0 & 0 & 0 & 0 & 0 & 0 \\
\hline$\frac{\Omega}{0}$ & 0 & 0 & 0 & 0 & 0 & 0 & 0 & 0 & 0 & 0 & 0 & 0 & 0 & 0 & 0 & 0 & 0 & 0 & 0 & 0 & 0 & 0 & 0 \\
\hline$\Omega$ & 0 & - & 0 & 0 & 0 & - & 0 & 0 & 0 & 0 & 0 & 0 & 0 & 0 & 0 & 0 & 0 & 0 & 0 & 0 & 0 & 0 & 0 \\
\hline$\frac{\Omega}{N}$ & 0 & 0 & 0 & 0 & 0 & 0 & 0 & 0 & 0 & 0 & 0 & 0 & 0 & 0 & 0 & 0 & 0 & 0 & 0 & 0 & 0 & 0 & 0 \\
\hline$\tilde{\omega}$ & 0 & 0 & 0 & 0 & 0 & 0 & 0 & 0 & 0 & 0 & 0 & 0 & 0 & 0 & 0 & 0 & 0 & - & 0 & 0 & 0 & 0 & 0 \\
\hline$\stackrel{\Omega}{\perp}$ & 0 & 0 & 0 & 0 & 0 & 0 & 0 & 0 & 0 & 0 & 0 & 0 & 0 & - & 0 & 0 & 0 & 0 & 0 & 0 & 0 & 0 & 0 \\
\hline$\stackrel{\Omega}{u}$ & 0 & 0 & 0 & 0 & 0 & 0 & 0 & 0 & 0 & 0 & 0 & 0 & 0 & 0 & - & 0 & 0 & 0 & 0 & 0 & 0 & 0 & 0 \\
\hline 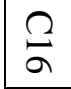 & 0 & 0 & 0 & 0 & 0 & 0 & 0 & 0 & 0 & 0 & 0 & 0 & 0 & 0 & 0 & 0 & 0 & 0 & 0 & 0 & 0 & 0 & 0 \\
\hline$\Omega$ & 0 & 0 & - & 0 & 0 & 0 & 0 & 0 & 0 & 0 & 0 & 0 & 0 & 0 & 0 & 0 & 0 & 0 & 0 & 0 & 0 & 0 & 0 \\
\hline$\stackrel{\Omega}{\infty}$ & 0 & 0 & 0 & 0 & 0 & 0 & 0 & 0 & 0 & 0 & 0 & 0 & 0 & 0 & 0 & 0 & 0 & 0 & 0 & 0 & 0 & 0 & 0 \\
\hline$\widetilde{\sigma}$ & 0 & 0 & 0 & 0 & 0 & 0 & 0 & 0 & - & 0 & 0 & - & 0 & 0 & 0 & 0 & 0 & 0 & 0 & 0 & 0 & 0 & 0 \\
\hline త్రి & 0 & 0 & 0 & 0 & 0 & 0 & 0 & 0 & 0 & 0 & 0 & 0 & - & 0 & 0 & 0 & 0 & 0 & 0 & 0 & 0 & 0 & 0 \\
\hline N & 0 & 0 & 0 & 0 & 0 & 0 & 0 & 0 & 0 & 0 & 0 & 0 & 0 & 0 & 0 & 0 & 0 & 0 & 0 & 0 & 0 & 0 & - \\
\hline N & 0 & 0 & 0 & 0 & 0 & 0 & - & 0 & 0 & 0 & 0 & 0 & 0 & 0 & 0 & 0 & 0 & 0 & 0 & 0 & 0 & 0 & 0 \\
\hline N & 0 & 0 & 0 & 0 & 0 & 0 & 0 & 0 & 0 & 0 & 0 & 0 & 0 & 0 & 0 & 0 & 0 & 0 & 0 & 0 & 0 & 0 & 0 \\
\hline
\end{tabular}

